FEDERAL RESERVE BANK OF SAN FRANCISCO

WORKING PAPER SERIES

\title{
Inflation Expectations and Risk Premia in Emerging Bond Markets: Evidence from Mexico
}

\author{
Remy Beauregard \\ University of California at Davis \\ Jens H. E. Christensen \\ Federal Reserve Bank of San Francisco \\ Eric Fischer \\ Federal Reserve Bank of New York \\ Simon Zhu \\ University of Texas at Austin
}

November 2021

Working Paper 2021-08

https://www.frbsf.org/economic-research/publications/working-papers/2021/08/

\section{Suggested citation:}

Beauregard, Remy, Jens H. E. Christensen, Eric Fischer, Simon Zhu. "Inflation

Expectations and Risk Premia in Emerging Bond Markets: Evidence from Mexico,"

Federal Reserve Bank of San Francisco Working Paper 2021-08.

https://doi.org/10.24148/wp2021-08

The views in this paper are solely the responsibility of the authors and should not be interpreted as reflecting the views of the Federal Reserve Bank of San Francisco or the Board of Governors of the Federal Reserve System. 


\title{
Inflation Expectations and Risk Premia in Emerging Bond Markets: Evidence from Mexico
}

\author{
Remy Beauregard ${ }^{\dagger}$ \\ Jens H. E. Christensen \\ Eric Fischer* \\ Simon $\mathrm{Zhu}^{\S}$
}

\begin{abstract}
To study inflation expectations and associated risk premia in emerging bond markets, this paper provides estimates for Mexico based on an arbitrage-free dynamic term structure model of nominal and real bond prices that accounts for their liquidity risk. In addition to documenting the existence of large and time-varying liquidity premia in nominal and real bond prices that are only weakly correlated, the results indicate that long-term inflation expectations in Mexico are well anchored close to the inflation target of the Bank of Mexico. Furthermore, Mexican inflation risk premia are larger and more volatile than those in Canada and the United States.
\end{abstract}

JEL Classification: D84, E31, E43, E44, E47, E52, E58, G12

Keywords: term structure modeling, liquidity risk, financial market frictions, central bank credibility

We thank seminar participants at the Bank of Mexico, the Federal Reserve Bank of New York, and the Central Bank of Chile for helpful comments and suggestions. Furthermore, we thank Bernardo Keiserman for helpful comments and suggestions. The views in this paper are solely the responsibility of the authors and should not be interpreted as reflecting the views of the Federal Reserve Bank of New York, the Federal Reserve Bank of San Francisco, or the Federal Reserve System.

${ }^{\dagger}$ University of California at Davis; e-mail: rebeauregard@ucdavis.edu.

${ }^{\ddagger}$ Corresponding author: Federal Reserve Bank of San Francisco, 101 Market Street MS 1130, San Francisco, CA 94105, USA; phone: 1-415-974-3115; e-mail: jens.christensen@sf.frb.org.

*Federal Reserve Bank of New York; e-mail: eric.fischer@ny.frb.org.

${ }^{\S}$ University of Texas at Austin; e-mail: simonwzhu@gmail.com.

This version: November 8, 2021. 


\section{Introduction}

Breakeven Inflation (BEI) - the difference between yields on comparable-maturity nominal and real debt - is a widely used indicator of inflation expectations. In particular, long-term BEI is frequently used to measure the credibility of the central bank's inflation objective. ${ }^{1}$ However, BEI is a noisy measure of expected inflation because it contains both an inflation risk premium and differential liquidity premia. As a consequence, better measures of investors' underlying inflation expectations could be obtained by subtracting both inflation risk premia and the differential liquidity premia in nominal and real yields from BEI rates.

The literature on inflation expectations and associated inflation risk premia extracted from nominal and real yields in advanced economies is burgeoning. ${ }^{2}$ However, these topics have received far less attention for emerging economies, although they arguably matter more there for policymakers and bond investors due to higher macroeconomic uncertainty, in general, and larger inflation variability, specifically. The main contribution of this paper is to fill this gap by building on recent advances in fixed-income analysis.

The challenge in accounting for the differential liquidity premia in nominal and real bond prices is to distinguish them from more fundamental factors such as inflation risk premia that would affect asset prices even in a world without any frictions to trading. To achieve this separation, we augment a flexible dynamic term structure model of nominal and real bond prices studied in Carriero et al. (2018) with separate liquidity risk factors for nominal and real bonds using the approach described in Andreasen et al. (2021, henceforth ACR). For each class of bonds, the identification of the liquidity risk factor comes from its unique loading, which mimics the idea that, over time, an increasing amount of the outstanding notional of individual securities gets locked up in buy-and-hold investors' portfolios. This increases their sensitivity to variation in the market-wide liquidity risk captured by the corresponding liquidity risk factor. By observing prices for balanced panels of nominal and real bonds, their respective liquidity risk factors can be separately identified. This separation is particularly salient in emerging bond markets as they tend to be much less deep and liquid than the well-established major international bond markets in the United States and elsewhere.

To better understand the properties and dynamics of inflation expectations and associated risk premia in emerging bond markets, we choose to focus on a country where they are likely to play a first-order role, namely Mexico. Several motivations underlie this choice. First, Mexico has a long history of high and fairly volatile inflation. ${ }^{3}$ Second and equally important

\footnotetext{
${ }^{1}$ Provided the objective is credible, it should be reflected in inflation expectations for the distant future as any current inflation shocks should be considered temporary and not affect long-run inflation expectations.

${ }^{2}$ For Canada, see Christensen et al. (2021); for the euro area, see Hördahl and Tristani (2012, 2014); for the United Kingdom, see Joyce et al. (2010) and Carriero et al. (2018); for the United States, see Christensen et al. (2010), Abrahams et al. (2016), D'Amico et al. (2018), among many others.

${ }^{3}$ For the 2010-2019 period, the year-over-year inflation in Mexico as measured by the consumer price index averaged 3.96 percent with a standard deviation of 1.02 percent. For comparison, the corresponding statistics in the United States were 1.75 percent and 0.85 percent, respectively, while the matching statistics for Canada were 1.74 percent and 0.65 percent, respectively.
} 
for our analysis, it has well-functioning markets for both standard nominal fixed-coupon government bonds, so-called bonos, and real inflation-indexed government bonds, known as udibonos. Finally, we consider Mexico and its government bond market to be representative of the wider set of large emerging bond markets; for example, it typically makes up between 10 percent and 13 percent of most emerging market bond indices.

In terms of our empirical findings, we make a number of observations. First, we find that the model delivers estimates of investors' inflation expectations that are robust to a range of different model implementations. Furthermore, we evaluate the model-implied inflation expectations using model-based projections of the outlook for long-term inflation expectations in Mexico for the following three-year period. The results suggest that bond investors' longterm inflation expectations are likely to remain close to the 3 percent inflation target of the Bank of Mexico in the foreseeable future, which we take as a sign that long-term inflation expectations are well anchored in Mexico. In addition, we compare the calendar-year ahead model-implied inflation forecasts to those reported in the monthly Consensus Forecasts and find our model to be reliable, but slightly less accurate than the survey forecasts.

Second, our results indicate that the average liquidity premia embedded in both nominal and real Mexican bond yields exhibit notable time variation. For nominal yields, our sample covers the period from January 2007 through December 2019, and their estimated liquidity premia average 45 basis points with a standard deviation of 22 basis points. For real yields, our sample contains data from May 2009 through December 2019, and their estimated liquidity premia average 58 basis points with a standard deviation of 47 basis points. Thus, the liquidity premia of Mexican inflation-indexed government bonds are larger and more variable than those of standard Mexican nominal government bonds. These results are consistent with the findings of ACR, who report that the average liquidity premium in U.S. Treasury InflationProtected Securities (TIPS) is estimated at 34 basis points for the 1997-2013 period, which is well above measures of liquidity premia in regular U.S. Treasury bonds. The difference in liquidity premium levels across the U.S. TIPS and the Mexican udibonos markets is likely to be due to the much greater relative liquidity of U.S. Treasury securities. Importantly, the nominal and real bond liquidity risk premia we estimate are practically uncorrelated in levels and their monthly changes are only mildly positively correlated. These results suggest that inflation-indexed Mexican bonds are less liquid and less desirable than nominal Mexican bonds. However, a full judgment of the tradeoff between nominal and inflation-indexed debt on the part of the Mexican government requires an estimate of the inflation risk premium, which is the excess return investors demand to hold nominal bonds. We assess this tradeoff in the final section of the paper and summarized below.

Third, the model's decomposition of the liquidity-adjusted or frictionless BEI rates indicates that investors' long-term inflation expectations have been stable at a level close to the inflation target of the Bank of Mexico with some mild fluctuations. This finding implies 
that most of the variation in the liquidity-adjusted BEI rates is driven by fluctuations in the inflation risk premium, which has trended lower since 2009. Furthermore, we compare our estimated inflation risk premium series to estimates from Canada and the United States and find them to be positively correlated and of fairly similar magnitude, although the estimated Mexican inflation risk premium is clearly larger and more volatile, as anticipated. Still, for extended periods, inflation risk in Mexico only commands a premium slightly above those seen in Canada and the United States, which is somewhat surprising. These findings support the claim that long-term inflation expectations in Mexico are well anchored, as also noted by De Pooter et al. (2014), and they underscore that the inflation target of the Bank of Mexico is viewed as being highly credible by financial market participants. ${ }^{4}$

As for the determinants of Mexican inflation risk premia, we perform regression analysis with a large battery of explanatory variables. The regressions have large explanatory power with adjusted $R^{2}$ s of 0.75 and above. Furthermore, focusing on our preferred regression specification, we note that higher CPI inflation tends to depress the inflation risk premia. This somewhat counterintuitive result comes about because the positive effects of higher CPI inflation on the real term premia dominate its positive effects on the nominal term premia and hence squeezes both BEI and the inflation risk premia. Also, a higher debt-to-GDP ratio tends to put downward pressure on the Mexican inflation risk premium as it tends to depress nominal term premia more than real term premia, resulting in lower inflation risk premia. Lastly, increases in the one-month cetes rate tend to push up Mexican inflation risk premia as it tends to depress nominal term premia less than real term premia, resulting in higher inflation risk premia. Thus, a tightening of financial conditions as reflected in higher shortterm nominal interest rates tend to coincide with higher inflation risk premia, presumably because inflation tends to be high or trending higher in those situations. Overall, we take these findings to be sensible in light of the results we obtain in supporting regressions using the model-implied nominal and real term premia as dependent variables, see online Appendix I.

In a final exercise, we use our estimation results to examine the benefit to the Mexican government of issuing udibonos instead of bonos. As noted earlier, the liquidity risk premia embedded in the prices of udibonos average higher than those of bonos. Thus, issuance of udibonos face a liquidity disadvantage based on our results. However, that can be overcome provided the inflation risk premia are sufficiently large as they represent the excess yield investors demand to assume the inflation risk of nominal bonos. Our model allows us to construct synthetic measures of the net benefit of udibonos over bonos at constant maturities, where we focus on the 5-year, 10-year, 20-year, and 30-year horizons to be consistent with the maturities of the securities actually issued in the bonos and udibonos markets. Our results show that the average net benefit of udibonos issuance during the period from May 2009 to

\footnotetext{
${ }^{4}$ The ability of the Bank of Mexico to affect asset prices, the exchange rate, and portfolio flows through its conduct of monetary policy is documented in Solís (2020).
} 
December 2019 was 6 basis points, 33 basis points, 138 basis points, and 295 basis points, respectively. Thus, issuance of 5-year and 10-year securities is fairly competitive across the two markets, while issuance of longer-term securities clearly should be steered towards the udibonos market, while 20-year and in particular 30-year bonos issuance appears to be very expensive for the Mexican government thanks to a steep upward sloping term structure of both bonos liquidity premia and general inflation risk premia. By implication, although longterm inflation expectations are anchored around the Bank of Mexico's target, investors are clearly concerned about sustained overshoots of inflation when they trade long-term bonos.

The remainder of the paper is structured as follows. Section 2 contains the data description, while Section 3 details the model, the empirical results, and some sensitivity analysis. Section 4 describes the BEI decomposition and scrutinizes the estimated inflation risk premia, while Section 5 examines the net benefit of udibonos issuance to the Mexican government. Finally, Section 6 concludes. An online appendix contains additional analysis, estimation results, and robustness exercises.

\section{Mexican Government Bond Data}

This section first describes the Mexican government bond data we use in the model estimation before we proceed to a discussion of the credit risk, bond holdings, and bid-ask spreads in the markets for these bonds.

\section{$2.1 \quad$ Bonos}

The available universe of individual Mexican government fixed-coupon bonds, known as bonos, is illustrated in Figure 1(a). Each bond is represented by a solid black line that starts at its date of issuance with a value equal to its original maturity and ends at zero on its maturity date. These bonds are all marketable non-callable bonds denominated in Mexican pesos that pay a fixed rate of interest semiannually. We note that we track the entire universe of bonos issued since January 2007. In addition, we include a set of bonos outstanding at the start of our sample period identical to those analyzed by Christensen et al. (2021, henceforth CFS). As a consequence, our sample entirely encompasses theirs. In general, the Mexican government has been issuing five-, ten-, twenty- and thirty-year bonos on a fairly regular basis during the period shown. As a result, there is a wide variety of bonds with different maturities and coupon rates in the data throughout our sample. It is this variation that provides the foundation for the econometric identification of the factors in the yield curve models we use.

The contractual characteristics of all 28 bonos securities in our sample are reported in Table 1. The number of monthly observations for each bond using three-month censoring before maturity is also reported in the table.

Figure 1(b) shows the distribution across time of the number of bonds included in the 


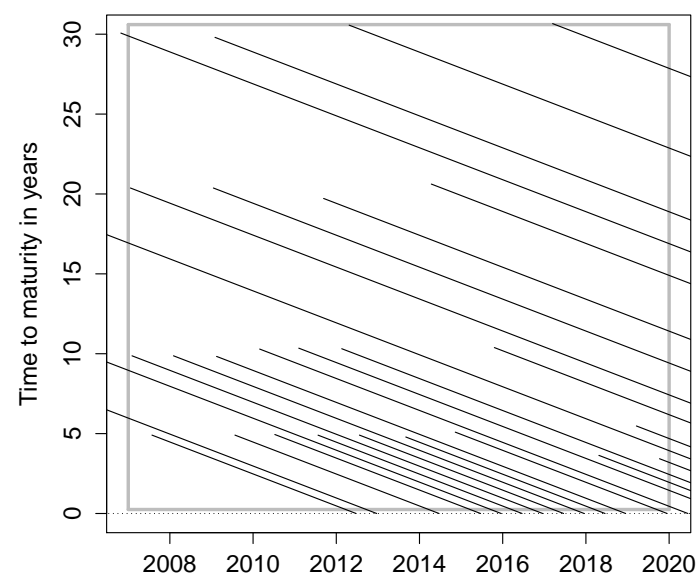

(a) Distribution of bonos

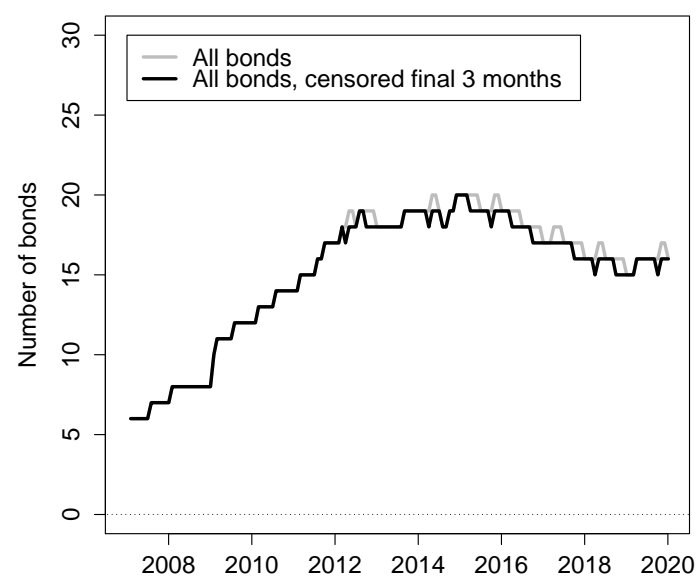

(b) Number of bonos

\section{Figure 1: Overview of the Mexican Government Bonos Data}

Panel (a) shows the maturity distribution of the Mexican government fixed-coupon bonos considered in the paper. The solid gray rectangle indicates the sample used in the empirical analysis, where the sample is restricted to start on January 31, 2007, and limited to bonos prices with more than three months to maturity after issuance. Panel (b) reports the number of outstanding bonos at a given point in time.

sample. We note a gradual increase from six bonds at the start of the sample to 16 at its end. Combined with the cross sectional dispersion in the maturity dimension observed in Figure 1(a), this implies that we have a very well-balanced panel of Mexican bonos prices.

Figure 2 shows the time series of the yields to maturity implied by the observed Mexican bonos prices downloaded from Bloomberg. First, we note that the general yield level in Mexico has been fairly stable since 2007, unlike government bond yields in advanced economies, which have declined significantly during this period, see Holston et al. (2017) and Christensen and Rudebusch (2019), among others. Second, as in U.S. Treasury yield data, there is notable variation in the shape of the yield curve. At times like in mid-2018, yields across maturities are relatively compressed. At other times, the yield curve is steep with long-term bonos trading at yields that are 300-400 basis points above those of shorter-term securities like in 2015 .

Finally, regarding the important question of a lower bound, the Bank of Mexico has never been forced to lower its conventional policy rate even close to zero, and the bond yields in the data have remained well above zero throughout the sample period. Thus, there is no need to account for any lower bounds to model these fixed-coupon bond prices, which motivates our focus on Gaussian models. 


\begin{tabular}{|l|c|c|c|c|c|}
\hline \multirow{2}{*}{ Fixed-coupon bonos } & No. & \multicolumn{2}{|c|}{ Issuance } & Number of & Total notional \\
\cline { 3 - 4 } & obs. & Date & Amount & auctions & amount \\
\hline$(1) 9 \% 12 / 20 / 2012^{\dagger}$ & 68 & $1 / 9 / 2003$ & 1,500 & 40 & 85,033 \\
$(2) 8 \% 12 / 7 / 2023^{+}$ & 156 & $10 / 30 / 2003$ & 1,000 & 46 & 256,860 \\
$(3) 8 \% 12 / 17 / 2015^{\dagger}$ & 104 & $1 / 5 / 2006$ & 3,100 & 33 & 102,797 \\
$(4) 10 \% 11 / 20 / 2036^{\times}$ & 156 & $10 / 26 / 2006$ & 2,000 & 36 & 88,945 \\
$(5) 7.5 \% 6 / 3 / 2027^{+}$ & 156 & $1 / 18 / 2007$ & 4,650 & 41 & 298,760 \\
$(6) 7.25 \% 12 / 15 / 2016^{\dagger}$ & 116 & $2 / 1 / 2007$ & 4,800 & 26 & 129,746 \\
$(7) 7.5 \% 6 / 21 / 2012^{*}$ & 56 & $7 / 26 / 2007$ & 4,500 & 30 & 100,825 \\
$(8) 7.75 \% 12 / 14 / 2017^{\dagger}$ & 116 & $1 / 31 / 2008$ & 7,650 & 25 & 85,454 \\
$(9) 8.5 \% 5 / 31 / 2029^{+}$ & 132 & $1 / 15 / 2009$ & 2,000 & 35 & 253,419 \\
$(10) 8.5 \% 11 / 18 / 2038^{\times}$ & 132 & $1 / 29 / 2009$ & 2,000 & 51 & 167,443 \\
$(11) 8.5 \% 12 / 13 / 2018^{\dagger}$ & 115 & $2 / 12 / 2009$ & 2,500 & 29 & 91,276 \\
$(12) 6.25 \% 6 / 19 / 2014^{*}$ & 56 & $7 / 23 / 2009$ & 5,000 & 15 & 75,837 \\
$(13) 8 \% 6 / 11 / 2020^{\dagger}$ & 119 & $2 / 25 / 2010$ & 25,000 & 21 & 179,356 \\
$(14) 6 \% 6 / 18 / 2015^{*}$ & 54 & $7 / 8 / 2010$ & 108,010 & 15 & 94,361 \\
$(15) 6.5 \% 6 / 10 / 2021^{\dagger}$ & 107 & $2 / 3 / 2011$ & 25,000 & 30 & 241,630 \\
$(16) 6.25 \% 6 / 16 / 2016^{*}$ & 56 & $7 / 22 / 2011$ & 25,000 & 17 & 142,425 \\
$(17) 7.75 \% 5 / 29 / 2031^{+}$ & 100 & $9 / 9 / 2011$ & 60,500 & 21 & 144,780 \\
$(18) 6.5 \% 6 / 9 / 2022^{\dagger}$ & 95 & $2 / 15 / 2012$ & 74,500 & 22 & 290,969 \\
$(19) 7.75 \% 11 / 13 / 2042^{\times}$ & 93 & $4 / 20 / 2012$ & 33,000 & 37 & 196,466 \\
$(20) 5 \% 6 / 15 / 2017^{*}$ & 56 & $7 / 19 / 2012$ & 30,000 & 11 & 114,713 \\
$(21) 4.75 \% 6 / 14 / 2018^{*}$ & 55 & $8 / 30 / 2013$ & 211,054 & 19 & 125,477 \\
$(22) 7.75 \% 11 / 23 / 2034^{+}$ & 69 & $4 / 11 / 2014$ & 15,000 & 25 & 96,462 \\
$(23) 5 \% 12 / 11 / 2019^{*}$ & 58 & $11 / 7 / 2014$ & 15,000 & 20 & 203,968 \\
$(24) 5.75 \% 3 / 5 / 2026^{\dagger}$ & 51 & $10 / 16 / 2015$ & 17,000 & 11 & 187,736 \\
$(25) 8 \% 11 / 7 / 2047^{\times}$ & 34 & $3 / 10 / 2017$ & 3,000 & 24 & 145,266 \\
$(26) 7.25 \% 12 / 9 / 2021$ & 21 & $4 / 20 / 2018$ & 25,000 & 18 & 236,936 \\
$(27) 8 \% 9 / 5 / 2024^{*}$ & 10 & $3 / 15 / 2019$ & 9,700 & 10 & 191,289 \\
$(28) 6.75 \% 3 / 9 / 2023$ & 3 & $10 / 4 / 2019$ & 10,500 & 6 & 76,689 \\
\hline
\end{tabular}

Table 1: Sample of Mexican Government Bonos

The table reports the characteristics, first issuance date and amount, the total number of auctions, and total amount issued in millions of Mexican pesos for the available universe of Mexican government fixed-coupon bonos in the sample. Also reported are the number of monthly observation dates for each bond during the sample period from January 31, 2007, to December 31, 2019. Asterisk * indicates five-year bonds, dagger $\dagger$ indicates ten-year bonds, plus + indicates twenty-year bonds, and cross $\times$ indicates thirty-year bonds.

\section{$2.2 \quad$ Udibonos}

The Mexican government also issues inflation-indexed bonds, known as udibonos. These bonds pay semiannual interest based upon a real interest rate. Unlike standard fixed-coupon marketable bonds, interest payments on udibonos are adjusted for changes in the general price level. Technically, their payoff is measured in a unit called Unidad de Inversión (UDI), which is calculated and published daily by the Bank of Mexico. UDI changes with the biweekly release of the National Consumer Price Index, abbreviated INPC in Spanish, according to 


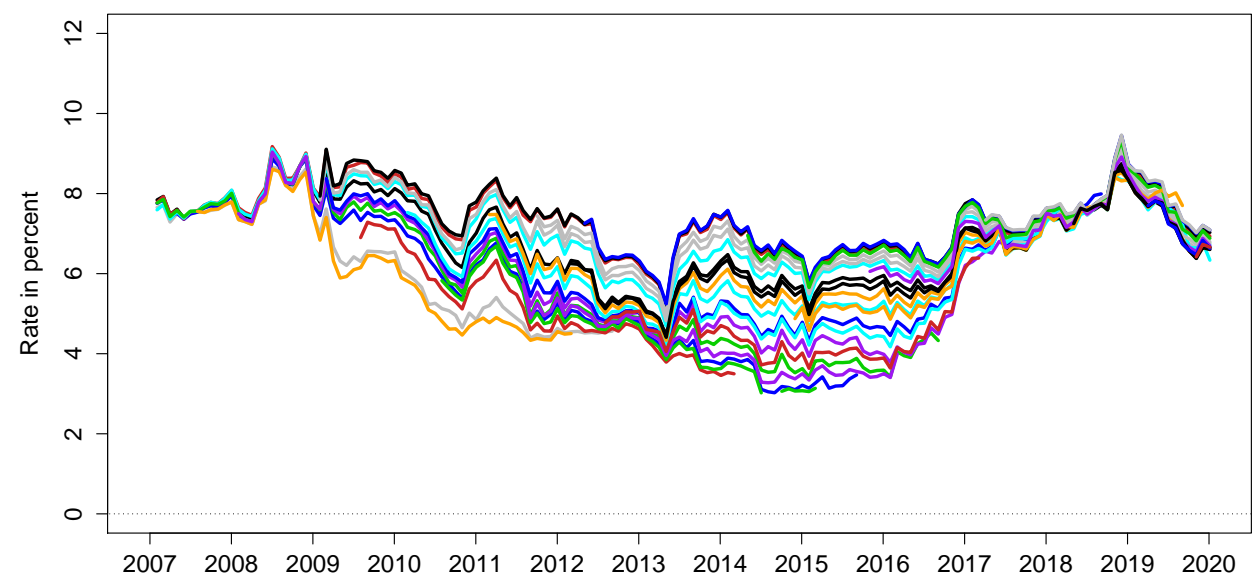

Figure 2: Yield to Maturity of Mexican Government Bonos

Illustration of the yields to maturity implied by the Mexican government fixed-coupon bonos prices downloaded from Bloomberg. The data is monthly covering the period from January 31, 2007, to December 31, 2019, and censors the last three months for each maturing bond.

the procedure determined by the Bank of Mexico as originally laid out in Mexico's Federal Official Gazette on April 4, 1995. UDI represents the accumulated inflation in Mexico since April 1, 1995, denominated in Mexican pesos, and it is the factor used to convert the real return of udibonos into the corresponding value measured in current pesos at any given point in time.

The Mexican government launched its udibonos program in 1996. However, due to the quality of the available data from Bloomberg, we are limited to starting our sample in May 2009. The available universe of udibonos and their maturity distribution across time is shown in Figure 3(a). It includes the entire universe of udibonos issued since May 2009 combined with the outstanding stock of udibonos at the start of our sample. We note that the issuance is concentrated in ten-year udibonos with occasional issuance of twenty- and thirty-year udibonos.

The contractual details of each udibonos in our sample are reported in Table 2. It also contains the number of monthly observations for each bond in our sample with the last year before maturity censored to avoid erratic variation in their prices arising from seasonality in the inflation adjustment of their payoffs.

The total number of udibonos in our sample across time is shown in Figure 3(b). As with the nominal bonos, we stress that the sample of udibonos we use is very well-balanced across maturities at all times, which underpins the econometric identification of the state variables in the term structure models we use.

Figure 4 shows the yields to maturity implied by the udibonos prices. Similar to what we 


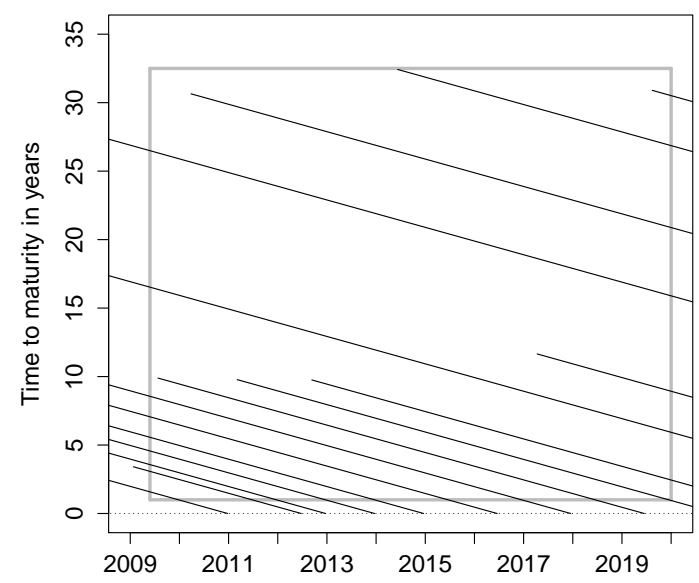

(a) Distribution of udibonos

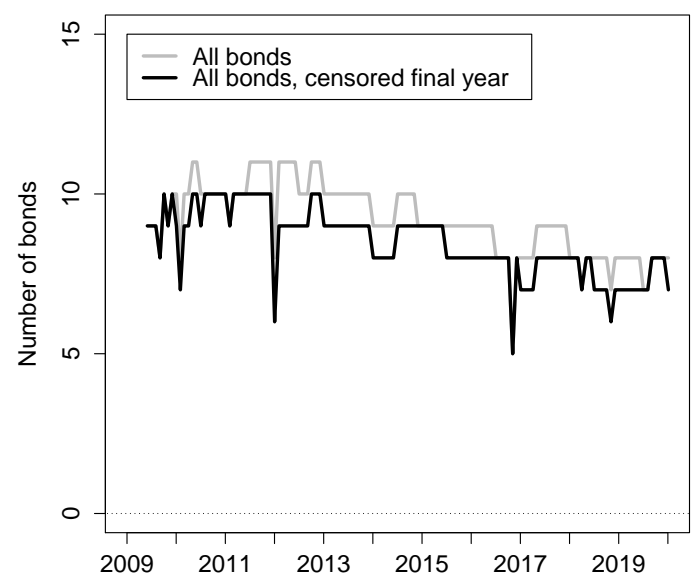

(b) Number of udibonos

Figure 3: Overview of the Mexican Government Udibonos Data

Panel (a) shows the maturity distribution of the Mexican government inflation-indexed udibonos considered in the paper. The solid gray rectangle indicates the sample used in the empirical analysis, where the sample is restricted to start on May 29, 2009, and limited to udibonos prices with more than one year to maturity after issuance. Panel (b) reports the number of outstanding bonos at a given point in time.

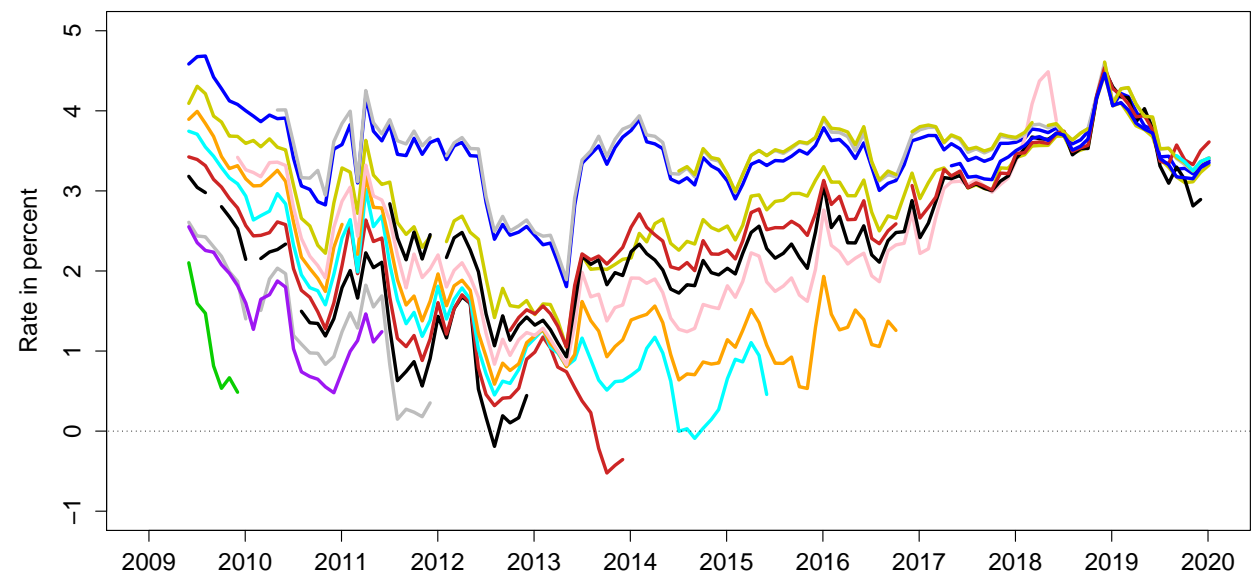

Figure 4: Yield to Maturity of Mexican Government Udibonos

Illustration of the yield to maturity implied by the Mexican government inflation-indexed udibonos prices considered in this paper, which are subject to two sample choices: (1) sample limited to the period from May 29, 2009, to December 31, 2019; (2) censoring of a bond's price when it has less than one year to maturity.

observe for the nominal bonos yields, the yields of udibonos have fluctuated around a fairly stable level during the shown period, but with some variation in the steepness of the udibonos 


\begin{tabular}{|l|c|c|c|c|c|}
\hline \multirow{2}{*}{ Indexed udibonos } & \multirow{2}{*}{$\begin{array}{c}\text { No. } \\
\text { obs. }\end{array}$} & \multicolumn{2}{|c|}{ Issuance } & Number of & Total notional \\
\cline { 3 - 4 } & auctions & amount \\
\hline (1) $5.5 \% 12 / 20 / 2012 \dagger$ & 116 & $1 / 2 / 2003$ & 300 & 23 & 8,950 \\
(2) $3.5 \% 12 / 19 / 2013 \dagger$ & 116 & $1 / 15 / 2004$ & 500 & 24 & 10,230 \\
(3) $4.5 \% 12 / 18 / 2014 \dagger$ & 116 & $1 / 13 / 2005$ & 500 & 35 & 22,501 \\
(4) $4.5 \% 12 / 4 / 2025^{+}$ & 116 & $1 / 5 / 2006$ & 1,700 & 65 & 42,793 \\
(5) $4.5 \% 11 / 22 / 2035^{\times}$ & 116 & $1 / 5 / 2006$ & 21,533 & 63 & 25,266 \\
(6) $5 \% 6 / 16 / 2016 \dagger$ & 116 & $7 / 27 / 2006$ & 600 & 41 & 30,467 \\
(7) $3.25 \% 12 / 23 / 2010$ & 35 & $10 / 4 / 2007$ & 300 & 22 & 7,519 \\
(8) $3.5 \% 12 / 14 / 2017 \dagger$ & 116 & $1 / 10 / 2008$ & 550 & 41 & 14,571 \\
(9) $3.25 \% 6 / 21 / 2012$ & 38 & $1 / 22 / 2009$ & 450 & 27 & 7,211 \\
(10) $4 \% 6 / 13 / 2019 \dagger$ & 116 & $7 / 23 / 2009$ & 450 & 43 & 29,674 \\
(11) $4 \% 11 / 15 / 2040^{\times}$ & 116 & $3 / 25 / 2010$ & 3,500 & 55 & 46,632 \\
(12) $2.5 \% 12 / 10 / 2020 \dagger$ & 106 & $3 / 3 / 2011$ & 550 & 32 & 26,475 \\
(13) $2 \% 6 / 9 / 2022 \dagger$ & 88 & $9 / 7 / 2012$ & 12,118 & 39 & 47,054 \\
(14) $4 \% 11 / 8 / 2046^{\times}$ & 67 & $6 / 6 / 2014$ & 3,000 & 58 & 42,598 \\
(15) $4 \% 11 / 30 / 2028 \dagger$ & 33 & $4 / 7 / 2017$ & 3,000 & 32 & 36,633 \\
(16) $4 \% 11 / 3 / 2050^{\times}$ & 5 & $8 / 9 / 2019$ & 600 & 8 & 9,216 \\
\hline
\end{tabular}

Table 2: Sample of Mexican Government Udibonos

The table reports the characteristics, first issuance date and amount, the total number of auctions, and total amount issued in millions of Mexican pesos for the available sample of Mexican government inflation-indexed udibonos. Also reported are the number of monthly observation dates for each bond during the sample period from May 29, 2009, to December 31, 2019. Dagger $\dagger$ indicates ten-year bonds, plus + indicates twenty-year bonds, and cross $\times$ indicates thirty-year bonds.

yield curve. Our model exploits this variation to deliver estimates of their liquidity premia, as explained in Section 3. Also, the greater dispersion in the udibonos yields across maturities in the early part of the sample is a tangible sign that bond-specific premia in this market are likely to play a particularly large role during this period.

\subsection{The Credit Risk of Mexican Government Bonds}

To gauge whether there are any material credit risk issues to consider in modeling Mexican government bond prices, we use rates on credit default swap (CDS) contracts. They reflect the annual rate investors are willing to pay to buy protection against default-related losses on these bonds over a fixed period of time stipulated in the contract. Such contracts have been used to price the credit risk of many countries, including Mexico, since the early 2000s.

In Figure 5, we plot the series for the one- and five-year Mexican CDS rate since 2007 with solid gray and black lines, respectively. Also shown with a solid red line is the spread between these two CDS rates. We note that the five-year CDS rate has fluctuated in a fairly narrow range between 100 and 200 basis points, except for a brief period during the global financial crisis when Mexican CDS rates temporarily spiked above 300 basis points. This is a level of credit risk on par with most investment-grade firms in the United States, and 


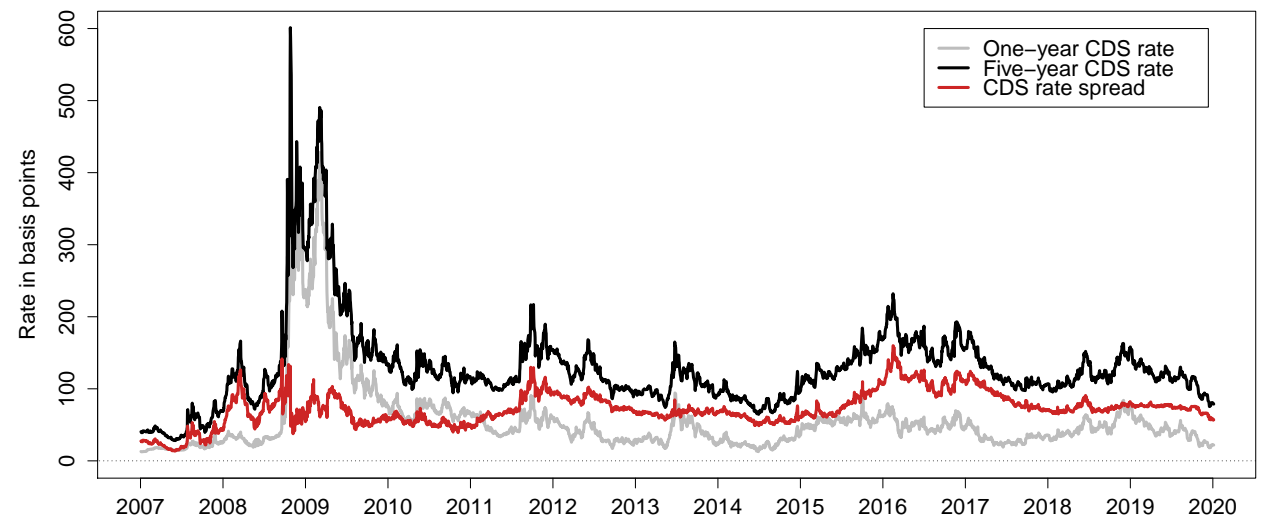

Figure 5: Mexican CDS Rates

its variation is mostly very gradual. This suggests that credit risk-related components are unlikely to be the driver of the results we present later on. To further support this view, we note that our measure of the Mexican government debt relative to GDP never goes above 52 percent, which is not a high value by international standards. Furthermore, the slope of the CDS rate curve measured as the difference between the five-year and one-year CDS rates is always positive, is fairly stable, fluctuates in a narrow range, and is mostly uncorrelated (11\%) with the one-year CDS rate. Thus, the steepness of the CDS rate curve for Mexican government debt has little connection to the near-term level of the priced credit risk of the Mexican government. We take this as a sign that the bulk of the variation in Mexican CDS rates reflect investor sentiment and risk aversion rather than actual credit risk. ${ }^{5}$ Overall, we take this evidence to imply that credit risk is not likely to materially affect our results and are comfortable not accounting for credit risk premia in our analysis.

More importantly, on a practical note, there are no differences in the credit risk of bonos and udibonos in the sense that they will receive the same treatment in case the Mexican government stops servicing its debt. Thus, using arguments similar to those made by Fleckenstein et al. (2014) for U.S. Treasuries and TIPS, there is no reason to believe that there are any differentials in the pricing of bonos and udibonos tied to credit risk. By implication, our measures and decompositions of Mexican BEI are unaffected by variation in the credit risk premia of Mexican government debt.

\subsection{Domestic and Foreign Mexican Government Bond Holdings}

In addition to the bond price data described above, our regression analysis later on utilizes data on domestic and foreign holdings of Mexican government debt securities that the Bank

\footnotetext{
${ }^{5}$ This is a phenomenon also seen in the pricing of corporate bonds and frequently referred to as the credit spread puzzle; see Christensen (2008) and references therein.
} 


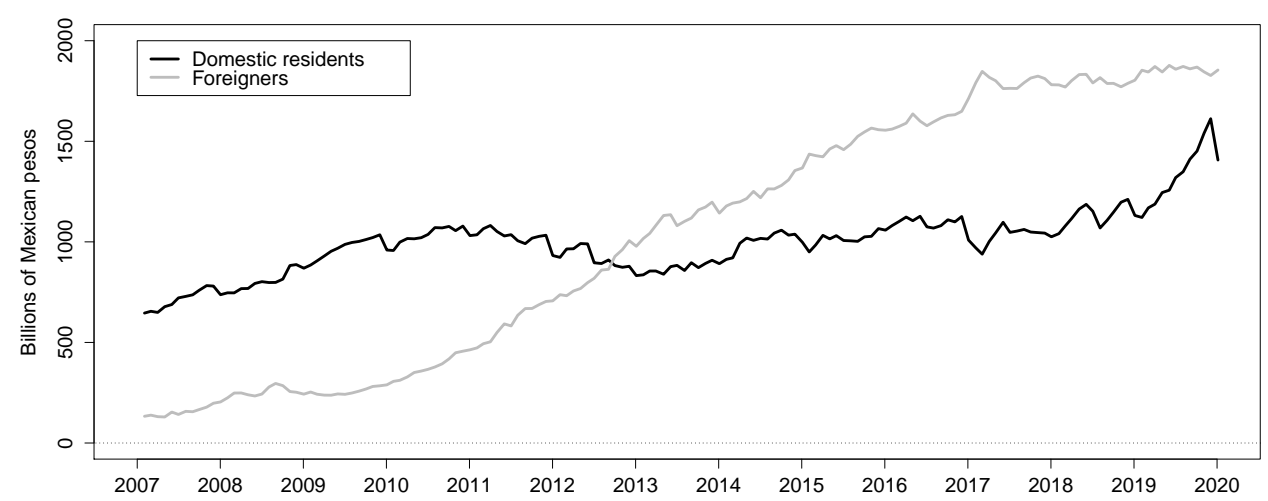

(a) Bonos

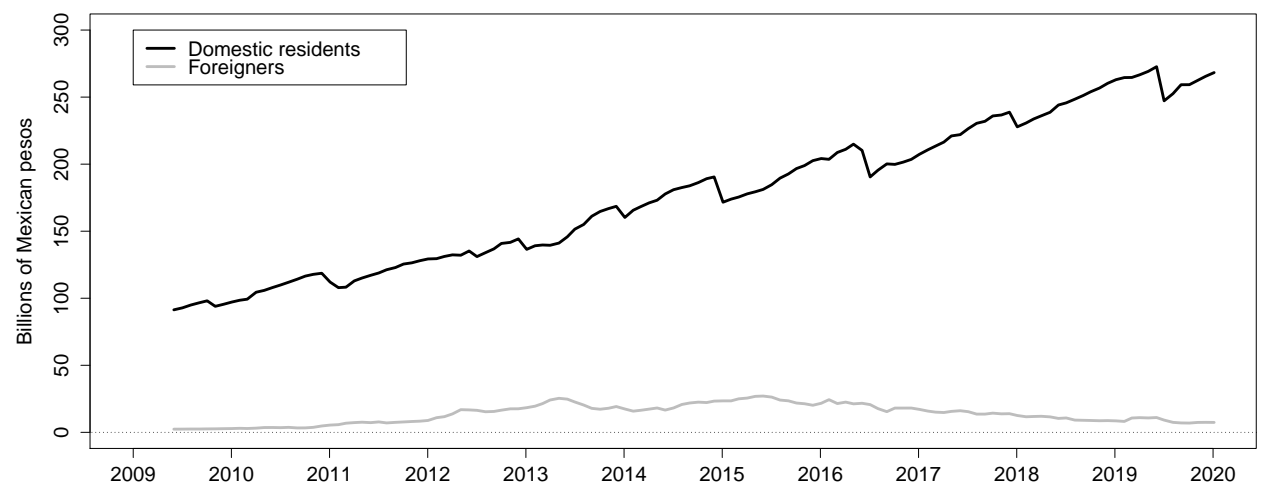

(b) Udibonos

Figure 6: Holdings of Mexican Bonos and Udibonos

of Mexico requires financial intermediaries to report as a way to track market activity in the Mexican sovereign bond markets. These data have been collected since 1978 and are available at a daily frequency up to the present. A key strength of the data set is that it covers any change in Mexican government debt holdings by either domestic or foreign investors. For each transaction, the reporting forms also identify the type of Mexican government security. Therefore, we are able to exploit the data reported for holdings of both bonos and udibonos. Although the data are available at a daily frequency, we use only the observations at the end of each month to align them with our bond price data.

Figure 6(a) shows the monthly level of bonos holdings by domestic residents and foreigners over the period from January 2007 through December 2019. We note that foreigners overtook domestic residents in total holdings by late 2012 and have continued to increase their share quite notably such that they now exceed those of domestic residents by a wide margin. In contrast, for the udibonos holdings shown in Figure 6(b) for the period from May 2009 through December 2019, we note that only a very small share of this market is held by foreigners. 


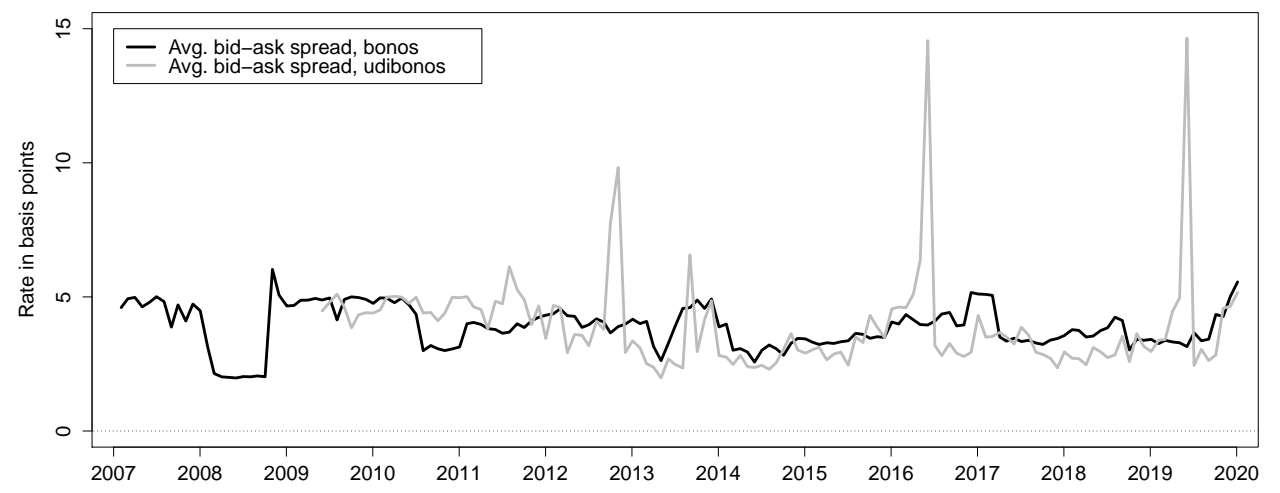

Figure 7: Bid-Ask Spreads of Mexican Bonos and Udibonos

We note that the difference in the foreign participation across the two markets could lead to significant differences in their trading dynamics and perceived liquidity risks.

To provide a sense of the relative size of the market for udibonos, we note that, as of December 31, 2019, the total outstanding amount of bonos was 3,261 billion pesos, or about USD160 billion, while the total amount of udibonos outstanding was 276 billion pesos, or about USD14 billion. ${ }^{6}$ Hence, udibonos represent about 8.5 percent of the government's long-term debt denominated in Mexican pesos. Finally, we add that the total outstanding domestic debt of the Mexican federal government was 7,586 billion pesos, or almost USD380 billion, while its gross long-term foreign debt is reported as USD102 billion as of September $30,2019 .{ }^{7}$ Thus, the vast majority of the government's debt is issued in local currency, which underscores the importance of its domestic government bond markets analyzed here.

\subsection{Bid-Ask Spreads of Mexican Government Bonds}

In this section, to shed light on the trading frictions in the markets for bonos and udibonos, we compare the average bid-ask spread of the udibonos in our sample to the average bid-ask spread of the bonos in our sample. These series are four-week moving averages and shown in Figure 7. Note that the two series tend to be close to each other. Thus, most of the time, there is no discernible difference in this measure of current liquidity across the two markets. Still, there are occasional large spikes in the average bid-ask spread of udibonos, which are driven by erratic pricing of individual udibonos as they approach maturity. This phenomenon is much less pronounced in the bonos market and further mitigated by the much larger number of bonos in our sample.

\footnotetext{
${ }^{6}$ See data from the Bank of Mexico at: https://www.banxico.org.mx/SieInternet/consultarDirectorioInternetAction.do? sector $=7 \&$ accion $=$ consultarDirectorioCuadros\&locale $=\mathrm{en}$

${ }^{7}$ See CEIC data at: https://www.ceicdata.com/en/mexico/gross-external-debt/gross-external-debt-federalgovernment-long-term
} 
The key takeaway from this evidence is twofold. First, with a level of bid-ask spreads around 5 basis points, the trading of these securities is indeed associated with some amount of liquidity risk. Second, the occasional large spikes in the bid-ask spreads of udibonos would be another sign that the liquidity risk of these securities is somewhat greater than that of bonos.

Motivated by the evidence in this section, our model assumes that both nominal and real bond prices contain liquidity premia that investors demand to assume their liquidity risk. In online Appendix A, we build further support for that assumption following the work of D'Amico et al. (2018). The purpose of the remainder of the paper is to quantify the relative importance of these bond risk premia in the pricing of bonos and udibonos and what adjustments for them may imply about bond investors' underlying inflation expectations and associated inflation risk premia.

\section{Model Estimation and Results}

In this section, we first describe the dynamic term structure model of nominal and real yields that we use to account for the liquidity bias in their pricing. We then detail how BEI is decomposed within the model before we proceed to a description of the model estimation and its econometric identification. We end the section with a brief overview of the main estimation results, including the estimated bonos and udibonos liquidity premia.

\subsection{An Arbitrage-Free Model of Nominal and Real Yields with Liquidity Risk}

In order to precisely measure nominal and real liquidity premia, we need an accurate model of the instantaneous nominal and real rate, $r_{t}^{N}$ and $r_{t}^{R}$. With that goal in mind we choose to focus on the tractable affine dynamic term structure model of nominal and real yields briefly summarized below. We emphasize that, even though the model is not formulated using the canonical form of affine term structure models introduced by Dai and Singleton (2000), it can be viewed as a restricted version of the corresponding canonical Gaussian model.

To begin, let $X_{t}=\left(L_{t}^{N}, S_{t}^{N}, C_{t}^{N}, X_{t}^{N}, L_{t}^{R}, S_{t}^{R}, X_{t}^{R}\right)$ denote the state vector of our sevenfactor model, which we refer to as the $G^{X^{N}, X^{R}}(7)$ model extending the terminology of ACR. Here, $\left(L_{t}^{N}, S_{t}^{N}, C_{t}^{N}\right)$ represent level, slope, and curvature factors in the nominal yield curve, ${ }^{8}$ while $\left(L_{t}^{R}, S_{t}^{R}\right)$ represent separate level and slope factors in the real yield curve. ${ }^{9}$ Finally, $\left(X_{t}^{N}, X_{t}^{R}\right)$ represent the added nominal and real liquidity risk factors. Our joint model of

\footnotetext{
${ }^{8}$ To motivate this choice, we note that Espada et al. (2008) show that the first three principal components in their sample of Mexican government bond yields have a level, slope, and curvature pattern in the style of Nelson and Siegel (1987) and account for more than 99 percent of the yield variation.

${ }^{9}$ Chernov and Mueller (2012) provide evidence of a hidden factor in the nominal yield curve that is observable from real yields and inflation expectations. Our model accommodates this stylized fact via the $\left(L_{t}^{R}, S_{t}^{R}\right)$ factors.
} 
nominal and real yields is a liquidity-augmented extension of the five-factor model used by Carriero et al. (2018) to analyze nominal and real U.K. gilt yields.

The instantaneous nominal and real risk-free rates are defined as

$$
\begin{aligned}
& r_{t}^{N}=L_{t}^{N}+S_{t}^{N}, \\
& r_{t}^{R}=L_{t}^{R}+S_{t}^{R} .
\end{aligned}
$$

The risk-neutral $\mathbb{Q}$-dynamics of the state variables used for pricing are given by

$$
\left(\begin{array}{c}
d L_{t}^{N} \\
d S_{t}^{N} \\
d C_{t}^{N} \\
d X_{t}^{N} \\
d L_{t}^{R} \\
d S_{t}^{R} \\
d X_{t}^{R}
\end{array}\right)=\left(\begin{array}{ccccccc}
0 & 0 & 0 & 0 & 0 & 0 & 0 \\
0 & \lambda^{N} & -\lambda^{N} & 0 & 0 & 0 & 0 \\
0 & 0 & \lambda^{N} & 0 & 0 & 0 & 0 \\
0 & 0 & 0 & \kappa_{N}^{Q} & 0 & 0 & 0 \\
0 & 0 & 0 & 0 & 0 & 0 & 0 \\
0 & 0 & 0 & 0 & 0 & \lambda^{R} & 0 \\
0 & 0 & 0 & 0 & 0 & 0 & \kappa_{R}^{Q}
\end{array}\right)\left[\left(\begin{array}{c}
0 \\
0 \\
0 \\
\theta_{N}^{Q} \\
0 \\
0 \\
\theta_{R}^{Q}
\end{array}\right)-\left(\begin{array}{c}
L_{t}^{N} \\
S_{t}^{N} \\
C_{t}^{N} \\
X_{t}^{N} \\
L_{t}^{R} \\
S_{t}^{R} \\
X_{t}^{R}
\end{array}\right)\right] d t+\Sigma\left(\begin{array}{c}
d W_{t}^{L^{N}, \mathbb{Q}} \\
d W_{t}^{S^{N}, \mathbb{Q}} \\
d W_{t}^{C^{N}, \mathbb{Q}} \\
d W_{t}^{X^{N}, \mathbb{Q}} \\
d W_{t}^{L^{R}, \mathbb{Q}} \\
d W_{t}^{S^{R}, \mathbb{Q}} \\
d W_{t}^{X^{R}, \mathbb{Q}}
\end{array}\right),
$$

where $\Sigma$ is assumed to be a diagonal matrix as per Christensen et al. (2011).

Due to the liquidity risk in the markets for nominal and real bonds, their yields are sensitive to liquidity pressures. As a consequence, the pricing of nominal and real bonds is not performed with the frictionless short rates in equations (1) and (2), but rather with discount functions that account for the liquidity risk as in ACR:

$$
\begin{aligned}
& \bar{r}_{t}^{N, i}=r_{t}^{N}+\beta^{N, i}\left(1-e^{-\delta^{N, i}\left(t-t_{0}^{i}\right)}\right) X_{t}^{N}=L_{t}^{N}+S_{t}^{N}+\beta^{N, i}\left(1-e^{-\delta^{N, i}\left(t-t_{0}^{i}\right)}\right) X_{t}^{N} \\
& \bar{r}_{t}^{R, j}=r_{t}^{R}+\beta^{R, j}\left(1-e^{-\delta^{R, j}\left(t-t_{0}^{j}\right)}\right) X_{t}^{R}=L_{t}^{R}+S_{t}^{R}+\beta^{R, j}\left(1-e^{-\delta^{R, j}\left(t-t_{0}^{j}\right)}\right) X_{t}^{R}
\end{aligned}
$$

where $t_{0}^{i}$ and $t_{0}^{j}$ denote the dates of issuance of the specific nominal and real bonds, respectively, and $\beta^{N, i}$ and $\beta^{R, j}$ are their sensitivities to the variation in their respective liquidity risk factors. Furthermore, the decay parameters $\delta^{N, i}$ and $\delta^{R, j}$ are assumed to vary across securities.

Christensen and Rudebusch (2019) show that the net present value of one unit of currency paid by nominal bond $i$ at time $t+\tau^{i}$ has the following exponential-affine form

$$
\begin{aligned}
P_{t}^{N}\left(t_{0}^{i}, \tau^{i}\right) & =E^{\mathbb{Q}}\left[e^{-\int_{t}^{t+\tau^{i}} \bar{r}^{N, i}\left(s, t_{0}^{i}\right) d s}\right] \\
& =\exp \left(B_{1}^{N}\left(\tau^{i}\right) L_{t}^{N}+B_{2}^{N}\left(\tau^{i}\right) S_{t}^{N}+B_{3}^{N}\left(\tau^{i}\right) C_{t}^{N}+B_{4}^{N}\left(t, t_{0}^{i}, \tau^{i}\right) X_{t}^{N}+A\left(t, t_{0}^{i}, \tau^{i}\right)\right)
\end{aligned}
$$

By similar arguments, the net present value of one unit of the consumption basket paid 
by real bond $j$ at time $t+\tau^{j}$ has the following exponential-affine form

$$
\begin{aligned}
P_{t}^{R}\left(t_{0}^{j}, \tau^{j}\right) & =E^{\mathbb{Q}}\left[e^{-\int_{t}^{t+\tau^{j}} \bar{r}^{R, j}\left(s, t_{0}^{j}\right) d s}\right] \\
& =\exp \left(B_{1}^{R}\left(\tau^{j}\right) L_{t}^{R}+B_{2}^{R}\left(\tau^{j}\right) S_{t}^{R}+B_{3}^{R}\left(t, t_{0}^{j}, \tau^{j}\right) X_{t}^{R}+A\left(t, t_{0}^{j}, \tau^{j}\right)\right)
\end{aligned}
$$

Now, consider the whole value of the nominal bond $i$ issued at time $t_{0}^{i}$ with maturity at $t+\tau^{i}$ that pays an annual coupon $C^{i}$ semiannually. Its price is given by ${ }^{10}$

$$
\begin{aligned}
\bar{P}_{t}^{N, i}\left(t_{0}^{i}, \tau^{i}, C^{i}\right)= & C^{i}\left(t_{1}-t\right) E^{\mathbb{Q}}\left[e^{-\int_{t}^{t_{1}} \bar{r}^{N, i}\left(s, t_{0}^{i}\right) d s}\right]+\sum_{k=2}^{n} \frac{C^{i}}{2} E^{\mathbb{Q}}\left[e^{-\int_{t}^{t_{k}} \bar{r}^{N, i}\left(s, t_{0}^{i}\right) d s}\right] \\
& +E^{\mathbb{Q}}\left[e^{-\int_{t}^{t+\tau^{i}} \bar{r}^{N, i}\left(s, t_{0}^{i}\right) d s}\right] .
\end{aligned}
$$

Next, consider the whole value of the real bond $j$ issued at time $t_{0}^{j}$ with maturity at $t+\tau^{j}$ that pays an annual coupon $C^{j}$ semiannually. Its clean price is given by ${ }^{11}$

$$
\begin{aligned}
\bar{P}_{t}^{R, j}\left(t_{0}^{j}, \tau^{j}, C^{j}\right)= & C^{j}\left(t_{1}-t\right) E^{\mathbb{Q}}\left[e^{-\int_{t}^{t_{1}} \bar{r}^{R, j}\left(s, t_{0}^{j}\right) d s}\right]+\sum_{k=2}^{n} \frac{C^{j}}{2} E^{\mathbb{Q}}\left[e^{-\int_{t}^{t_{k}} \bar{r}^{R, j}\left(s, t_{0}^{j}\right) d s}\right] \\
& +E^{\mathbb{Q}}\left[e^{-\int_{t}^{t+\tau^{j}} \bar{r}^{R, j}\left(s, t_{0}^{j}\right) d s}\right] .
\end{aligned}
$$

The only minor omission in the bond price formula above is that we do not account for the lag in the inflation indexation of the real bond payoff, but the potential error should be modest in most cases; see Grishchenko and Huang (2013) and D'Amico et al. (2018) for evidence in the case of the U.S. TIPS market.

To complete the model description, we need to specify the risk premia that connect the factor dynamics under the $\mathbb{Q}$-measure to the dynamics under the objective $\mathbb{P}$-measure, where we use the essentially affine risk premium specification introduced in Duffee (2002). In the Gaussian framework, this specification implies that the risk premia $\Gamma_{t}$ depend on the state variables; that is,

$$
\Gamma_{t}=\gamma^{0}+\gamma^{1} X_{t}
$$

where $\gamma^{0} \in \mathbf{R}^{7}$ and $\gamma^{1} \in \mathbf{R}^{7 \times 7}$ contain unrestricted parameters. Thus, the resulting unrestricted $G^{X^{N}, X^{R}}(7)$ model has $\mathbb{P}$-dynamics given by

$$
d X_{t}=K^{\mathbb{P}}\left(\theta^{\mathbb{P}}-X_{t}\right)+\Sigma d W_{t}^{\mathbb{P}}
$$

where $K^{\mathbb{P}}$ is an unrestricted $7 \times 7$ mean-reversion matrix, $\theta^{\mathbb{P}}$ is a $7 \times 1$ vector of mean levels, and $\Sigma$ is a $7 \times 7$ lower triangular volatility matrix. This is the transition equation in the

\footnotetext{
${ }^{10}$ This is the clean price that does not account for any accrued interest and maps to our observed bond prices.

${ }^{11}$ Unlike U.S. TIPS, Mexican udibonos have no embedded deflation protection option, which makes their pricing straightforward.
} 
extended Kalman filter estimation of this model.

\subsection{Decomposing BEI}

Christensen et al. (2010) show that the price of a nominal zero-coupon bond with maturity in $\tau$ years can be written as

$$
P_{t}^{N}(\tau)=P_{t}^{R}(\tau) \times E_{t}^{\mathbb{P}}\left[\frac{\Pi_{t}}{\Pi_{t+\tau}}\right] \times\left(1+\frac{\operatorname{cov}_{t}^{\mathbb{P}}\left[\frac{M_{t+\tau}^{R}}{M_{t}^{R}}, \frac{\Pi_{t}}{\Pi_{t+\tau}}\right]}{E_{t}^{\mathbb{P}}\left[\frac{M_{t+\tau}^{R}}{M_{t}^{R}}\right] \times E_{t}^{\mathbb{P}}\left[\frac{\Pi_{t}}{\Pi_{t+\tau}}\right]}\right),
$$

where $P_{t}^{R}(\tau)$ is the price of a real zero-coupon bond that pays one consumption unit in $\tau$ years, $M_{t}^{R}$ is the real stochastic discount factor, and $\Pi_{t}$ is the price level.

By taking logs, this can be converted into

$$
y_{t}^{N}(\tau)=y_{t}^{R}(\tau)+\pi_{t}^{e}(\tau)+\phi_{t}(\tau)
$$

where $y_{t}^{N}(\tau)$ and $y_{t}^{R}(\tau)$ are nominal and real frictionless zero-coupon yields as described in the previous section, while the market-implied average rate of inflation expected at time $t$ for the period from $t$ to $t+\tau$ is

$$
\pi_{t}^{e}(\tau)=-\frac{1}{\tau} \ln E_{t}^{\mathbb{P}}\left[\frac{\Pi_{t}}{\Pi_{t+\tau}}\right]=-\frac{1}{\tau} \ln E_{t}^{\mathbb{P}}\left[e^{-\int_{t}^{t+\tau}\left(r_{s}^{N}-r_{s}^{R}\right) d s}\right]
$$

and the associated inflation risk premium for the same time period is

$$
\phi_{t}(\tau)=-\frac{1}{\tau} \ln \left(1+\frac{\operatorname{cov}_{t}^{\mathbb{P}}\left[\frac{M_{t+\tau}^{R}}{M_{t}^{R}}, \frac{\Pi_{t}}{\Pi_{t+\tau}}\right]}{E_{t}^{\mathbb{P}}\left[\frac{M_{t+\tau}^{R}}{M_{t}^{R}}\right] \times E_{t}^{\mathbb{P}}\left[\frac{\Pi_{t}}{\Pi_{t+\tau}}\right]}\right) .
$$

This last equation demonstrates that the inflation risk premium can be positive or negative. It is positive if and only if

$$
\operatorname{cov}_{t}^{\mathbb{P}}\left[\frac{M_{t+\tau}^{R}}{M_{t}^{R}}, \frac{\Pi_{t}}{\Pi_{t+\tau}}\right]<0
$$

That is, the riskiness of nominal bonds relative to real bonds depends on the covariance between the real stochastic discount factor and inflation and is ultimately determined by investor preferences, as in, for example, Rudebusch and Swanson (2012).

Now, the BEI rate is defined as

$$
B E I_{t}(\tau) \equiv y_{t}^{N}(\tau)-y_{t}^{R}(\tau)=\pi_{t}^{e}(\tau)+\phi_{t}(\tau)
$$

that is, the difference between nominal and real yields of the same maturity. Note that it can 
be decomposed into the sum of expected inflation and the inflation risk premium.

\subsection{Model Estimation and Econometric Identification}

Due to the nonlinearity of the bond pricing formulas, the models cannot be estimated with the standard Kalman filter. Instead, we use the extended Kalman filter as in Kim and Singleton (2012); see Christensen and Rudebusch (2019) for details. To make the fitted errors comparable across bonds of various maturities, we follow ACR and scale each bond price by its duration. Thus, the measurement equation for the nominal bond prices takes the following form:

$$
\frac{\bar{P}_{t}^{N}\left(\tau^{i}\right)}{D_{t}^{N}\left(\tau^{i}\right)}=\frac{\widehat{P}_{t}^{N}\left(\tau^{i}\right)}{D_{t}^{N}\left(\tau^{i}\right)}+\varepsilon_{t}^{N, i},
$$

where $\widehat{P}_{t}^{N}\left(\tau^{i}\right)$ is the model-implied price of nominal bond $i$ and $D_{t}^{N}\left(\tau^{i}\right)$ is its duration, which is fixed and calculated before estimation. Similarly, the measurement equation for the real bond prices takes the following form:

$$
\frac{\bar{P}_{t}^{R}\left(t_{0}^{j}, \tau^{j}\right)}{D_{t}^{R}\left(\tau^{j}\right)}=\frac{\widehat{P}_{t}^{R}\left(t_{0}^{j}, \tau^{j}\right)}{D_{t}^{R}\left(\tau^{j}\right)}+\varepsilon_{t}^{R, j},
$$

where $\widehat{P}_{t}^{R}\left(\tau^{j}\right)$ is the model-implied price of real bond $j$ and $D_{t}^{R}\left(\tau^{j}\right)$ is its duration, which is again fixed and calculated before estimation. See Andreasen et al. (2019) for evidence supporting this formulation of the measurement equations.

Since the liquidity factors are latent factors that we do not observe, their levels are not identified without additional restrictions. As a consequence, when we include the nominal liquidity factor $X_{t}^{N}$, we let the first thirty-year bonos issued after the start of our sample window have a unit loading on the liquidity factor, that is, bonos number (10) in our sample issued on January 29, 2009, with maturity on November 18, 2038, and a coupon rate of 8.5 percent has $\beta^{N, i}=1$. When we include the real liquidity factor $X_{t}^{R}$, we let the first thirtyyear udibonos in our sample have a unit loading on this factor, that is, udibonos number (5) issued on January 5, 2006, with maturity on November 22, 2035, and a coupon rate of 4.5 percent has $\beta^{R, j}=1$.

Furthermore, we note that the liquidity decay parameters, $\delta^{N, i}$ and $\delta^{R, j}$, can be hard to identify if their values are too large or too small. As a consequence, we impose the restriction that they fall within the range from 0.0001 to 10 , which is without practical consequences based on the evidence presented in CFS. Also, for numerical stability during the model optimization, we impose the restrictions that the liquidity sensitivity parameters, $\beta^{N, i}$ and $\beta^{R, j}$, fall within the range from 0 to 250 , which turns out not to be a binding constraint at the optimum.

In addition, we assume that all nominal bond price measurement equations have i.i.d. fitted errors with zero mean and standard deviation $\sigma_{\varepsilon}^{N}$. Similarly, all real bond price measure- 
ment equations have fitted errors that are assumed to be i.i.d. with zero mean and standard deviation $\sigma_{\varepsilon}^{R}$.

We also incorporate long-term forecasts of inflation from the Consensus Forecasts survey for Latin America in our model estimation. These include monthly data on inflation forecasts for the following full calendar and semiannual data on five-year, ten-year, and so-called 5yr5yr inflation forecasts, which represent long-term inflation forecasts covering a five-year period starting five years ahead. ${ }^{12}$ As demonstrated by Kim and Orphanides (2012), the inclusion of long-term survey forecasts can help the model better capture the appropriate persistence of the factors under the objective $\mathbb{P}$-dynamics, which can otherwise suffer from significant finite-sample bias. ${ }^{13}$

The measurement equation for the survey expectations incorporating these long-term forecasts takes the form

$$
\pi_{t}^{C F}(\tau)=\pi_{t}^{e}(\tau)+\varepsilon_{t}^{C F}
$$

where $\pi_{t}^{e}(\tau)$ is the model-implied $\tau$-year expected inflation calculated using equation (5), which is affine in the state variables, while the measurement error is $\varepsilon_{t}^{C F} \sim \mathcal{N} \mathcal{I D}\left(0,\left(\sigma_{\varepsilon}^{C F}\right)^{2}\right)$ and identical for all survey forecasts independent of their horizon as we consider all survey inflation forecasts to be equally informative. As for the value $\sigma_{\varepsilon}^{C F}$, we follow D'Amico et al. (2018) and fix it at 75 basis points in order to not overly influence the estimation results by including the survey forecasts. Alternatively, this approach can be interpreted as treating the survey forecasts as relatively noisy measures of bond investors' inflation expectations. We perform a comprehensive sensitivity analysis to assess the impact of this assumption on our results in online Appendix B, while we examine the effect on our estimation results of excluding the survey information from the model in online Appendix C.

Finally, we assume that the state variables are stationary and therefore start the Kalman filter at the unconditional mean and covariance matrix. This assumption is supported by the analysis in Chiquiar et al. (2010), who find that Mexican inflation seems to have become stationary at some point in the early 2000s, while De Pooter et al. (2014) document that measures of long-term inflation expectations from both surveys and the Mexican government bond market have remained anchored close to the 3 percent inflation target of the Bank of Mexico at least since 2003. Assuming real rates and bond risk premia are stationary, ${ }^{14}$ this evidence would imply that Mexican government bond yields should be stationary as well, as also suggested by visual inspection of the individual yield series depicted in Figures 2 and 4 .

\footnotetext{
${ }^{12}$ Similar to Christensen et al. (2010) and Abrahams et al. (2016), we do not include inflation data in the model estimation. This omission is expected to, at most, have a small impact on our results due to the relatively long maturities of most of our real yield observations, see D'Amico et al. (2018) for evidence.

${ }^{13}$ Also, see Bauer et al. (2012).

${ }^{14}$ We note that these might be strong assumptions. In the United States, there is evidence of a persistent downward trend in real yields the past two decades; see Christensen and Rudebusch (2019).
} 


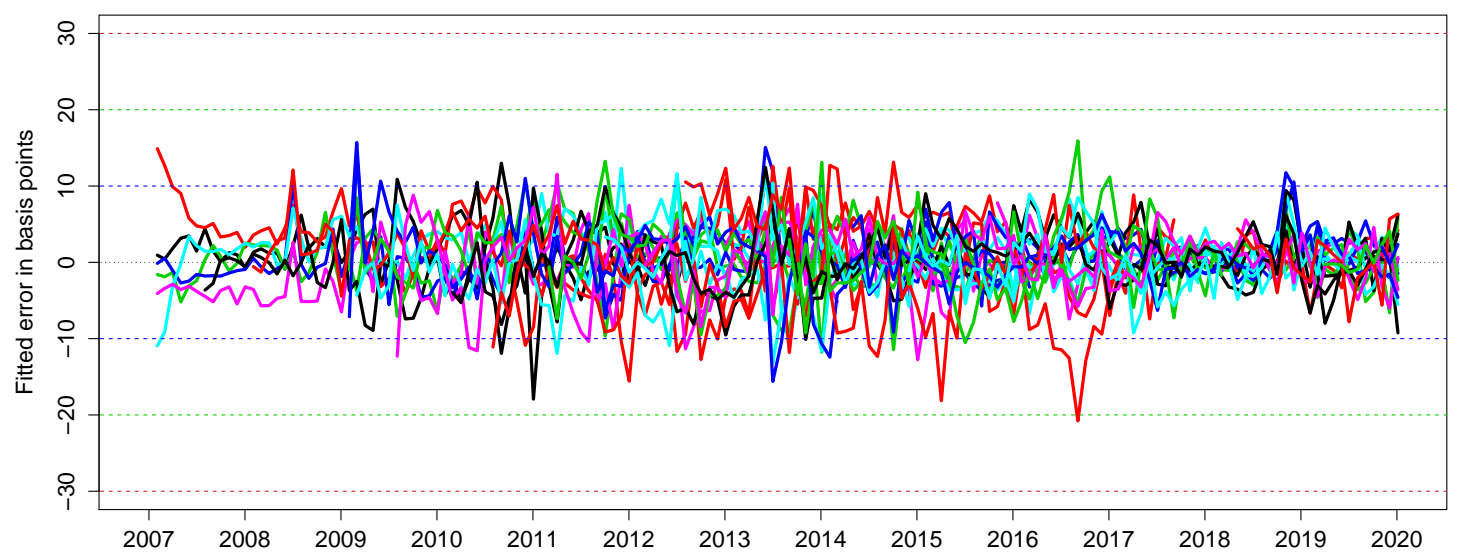

(a) Bonos

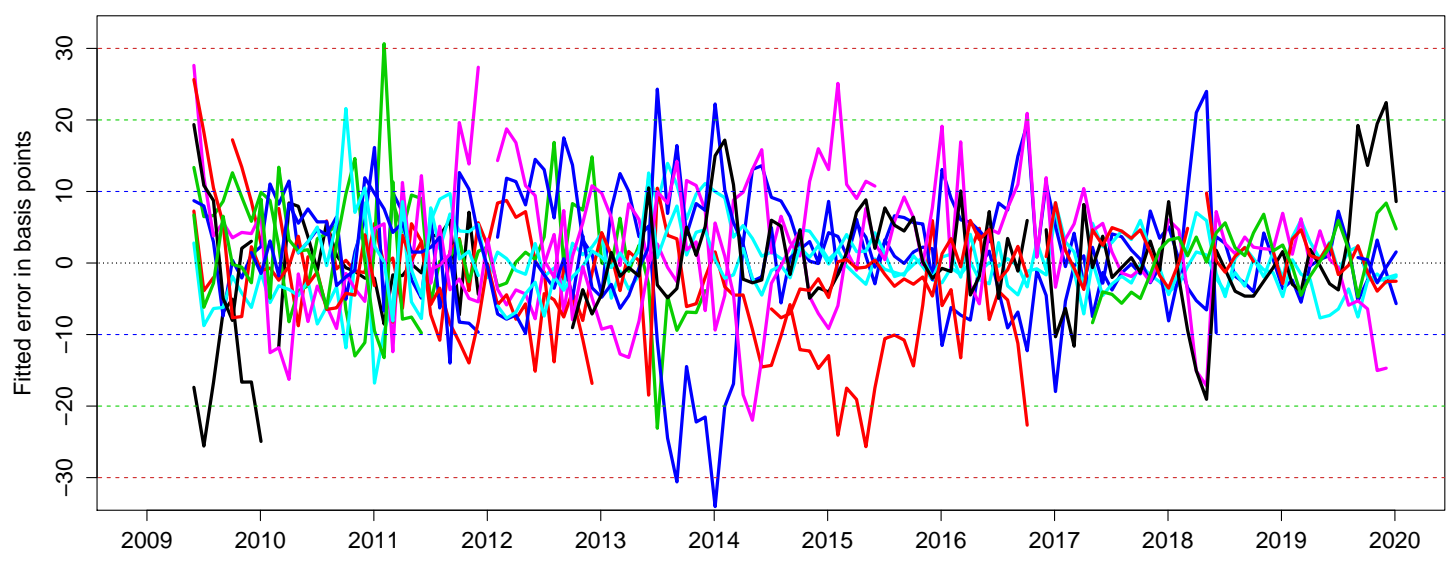

(b) Udibonos

Figure 8: Fitted Errors of Mexican Bonos and Udibonos

\subsection{Results}

In this section, we briefly summarize the main estimation results, while additional details are provided in the online appendix.

To examine the model fit, pricing errors are computed based on the implied yield on each coupon bond to make these errors comparable across securities. That is, for the price on the $i$ th coupon bond $P_{t}^{i}\left(\tau, C^{i}\right)$, we find the value of $y_{t}^{i, c}$ that solves

$$
P_{t}^{i}\left(\tau^{i}, C^{i}\right)=C^{i}\left(t_{1}-t\right) \exp \left\{-y_{t}^{i, c}\left(t_{1}-t\right)\right\}+\sum_{j=2}^{N} \frac{C^{i}}{2} \exp \left\{-y_{t}^{i, c}\left(t_{j}-t\right)\right\}+\exp \left\{-y_{t}^{i, c}\left(t_{N}-t\right)\right\}
$$

For the model-implied estimate of this bond price, denoted $\hat{P}_{t}^{i}\left(\tau, C^{i}\right)$, we find the correspond- 


\begin{tabular}{|c|ccccccc||c||c|c|}
\hline$K^{\mathbb{P}}$ & $K_{\cdot, 1}^{\mathbb{P}}$ & $K_{\cdot, 2}^{\mathbb{P}}$ & $K_{\cdot, 3}^{\mathbb{P}}$ & $K_{\cdot, 4}^{\mathbb{P}}$ & $K_{\cdot, 5}^{\mathbb{P}}$ & $K_{\cdot, 6}^{\mathbb{P}}$ & $K_{\cdot, 7}^{\mathbb{P}}$ & $\theta^{\mathbb{P}}$ & & $\Sigma$ \\
\hline$K_{1, \cdot}^{\mathbb{P}}$ & 6.9560 & 2.7982 & 2.1586 & 0.3059 & -9.7772 & -2.4220 & -1.4248 & 0.0972 & $\sigma_{11}$ & 0.0122 \\
& $(0.8123)$ & $(0.5286)$ & $(0.4366)$ & $(0.4174)$ & $(1.0588)$ & $(0.6007)$ & $(0.4853)$ & $(0.0116)$ & & $(0.0007)$ \\
$K_{2, .}^{\mathbb{P}}$ & 8.4870 & 2.9584 & 2.8008 & 0.1147 & -12.6808 & -2.2464 & -1.4215 & 0.0002 & $\sigma_{22}$ & 0.0190 \\
& $(0.8821)$ & $(0.7063)$ & $(0.6204)$ & $(0.5479)$ & $(1.0602)$ & $(0.7886)$ & $(0.5567)$ & $(0.0513)$ & & $(0.0033)$ \\
$K_{3, \cdot}^{\mathbb{P}}$ & -2.3125 & 1.3126 & -0.7021 & 0.6852 & 5.6474 & -1.0532 & -0.3518 & -0.0602 & $\sigma_{33}$ & 0.0231 \\
& $(0.9992)$ & $(0.7324)$ & $(0.5927)$ & $(0.5097)$ & $(1.0746)$ & $(0.8228)$ & $(0.4993)$ & $(0.0667)$ & & $(0.0045)$ \\
$K_{4, \cdot}^{\mathbb{P}}$ & 0.9485 & 3.3353 & -1.9118 & 2.2257 & 4.1875 & -3.4992 & -1.3987 & -0.0960 & $\sigma_{44}$ & 0.0380 \\
& $(1.0773)$ & $(1.0066)$ & $(0.8722)$ & $(0.8240)$ & $(1.1457)$ & $(0.9198)$ & $(0.8075)$ & $(0.1393)$ & & $(0.0114)$ \\
$K_{5, .}^{\mathbb{P}}$ & -3.3225 & -0.9875 & -1.7822 & 0.2846 & 6.2586 & 0.7330 & 0.5021 & 0.0268 & $\sigma_{55}$ & 0.0087 \\
& $(0.6863)$ & $(0.4330)$ & $(0.3567)$ & $(0.2696)$ & $(0.9810)$ & $(0.4836)$ & $(0.3095)$ & $(0.0114)$ & & $(0.0010)$ \\
$K_{6, .}^{\mathbb{P}}$ & -6.5535 & -4.4362 & -1.5587 & -0.6326 & 11.7622 & 5.0237 & 2.8129 & -0.1153 & $\sigma_{66}$ & 0.0190 \\
& $(0.9947)$ & $(0.8594)$ & $(0.7820)$ & $(0.5362)$ & $(1.0825)$ & $(0.8701)$ & $(0.6844)$ & $(0.1706)$ & & $(0.0040)$ \\
$K_{7, .}^{\mathbb{P}}$ & 3.9628 & 0.1022 & 2.8328 & -0.7241 & -7.4677 & 0.3344 & 0.0826 & 0.2248 & $\sigma_{77}$ & 0.0157 \\
& $(0.9394)$ & $(0.7066)$ & $(0.6006)$ & $(0.4890)$ & $(1.0459)$ & $(0.7944)$ & $(0.5010)$ & $(0.3311)$ & & $(0.0071)$ \\
\hline
\end{tabular}

Table 3: Estimated Dynamic Parameters of the $G^{X^{N}, X^{R}}(7)$ Model

The table shows the estimated parameters of the $K^{\mathbb{P}}$ matrix, $\theta^{\mathbb{P}}$ vector, and diagonal $\Sigma$ matrix for the $G^{X^{N}, X^{R}}(7)$. The estimated value of $\lambda^{N}$ is $0.2683(0.0124)$, while $\lambda^{R}=0.4767(0.0397), \kappa_{N}^{\mathbb{Q}}=2.1663$ (0.3632), $\theta_{N}^{\mathbb{Q}}=0.0105(0.0015), \kappa_{R}^{\mathbb{Q}}=0.3910(0.0848)$, and $\theta_{R}^{\mathbb{Q}}=0.0152(0.0029)$. The maximum $\log$ likelihood value is $19,743.84$. The numbers in parentheses are the estimated parameter standard deviations.

ing implied yield $\hat{y}_{t}^{i, c}$ and report the pricing error as $y_{t}^{i, c}-\hat{y}_{t}^{i, c}$.

Figure 8 shows the fitted error series for each bond price calculated this way. The top panel shows the results for the 28 bonos in our sample, while the bottom panel shows the results for the 16 udibonos in the sample. For the nominal bonos the root mean-squared error (RMSE) for all bonds combined is 4.18 basis points, while the corresponding statistics for the real udibonos is 7.51 basis points. Thus, the $G^{X^{N}, X^{R}}(7)$ model provides a very good fit to both sets of bond prices.

Finally, as for the monthly data on inflation forecasts for the following full calendar and semiannual data on five-year, ten-year, and so-called 5yr5yr inflation forecasts, the mean errors are 5.14 basis points, -7.54 basis points, -0.42 basis points, and 6.71 basis points, respectively, while the corresponding RMSEs are 45.72 basis points, 26.32 basis points, 28.50 basis points, and 34.24 basis points, respectively, which are all well below the 75 basis points assumed in the model estimation. Thus, the model is also able to simultaneously deliver an accurate fit to the full term structure of available survey inflation forecasts.

The estimated dynamic parameters in the $G^{X^{N}, X^{R}}(7)$ model are reported in Table 3. We note that the estimated mean and volatility parameters for the four nominal factors $\left(L_{t}^{N}, S_{t}^{N}, C_{t}^{N}, X_{t}^{N}\right)$ are very similar to those reported by CFS for their shorter and smaller sample of 21 bonos price series. Thus, the nominal side of our joint model of bonos and udibonos prices fits the bonos data in much the same way as their nominal model. 


\subsection{The Estimated Bonos and Udibonos Liquidity Premia}

We now use the estimated $G^{X^{N}, X^{R}}(7)$ model to extract the liquidity premium in the bonos and udibonos prices. To compute these premia we first use the estimated parameters and the filtered states $\left\{X_{t \mid t}\right\}_{t=1}^{T}$ to calculate the fitted bond prices $\left\{\hat{P}_{t}^{i}\right\}_{t=1}^{T}$ for all outstanding securities in our sample. These bond prices are then converted into yields to maturity $\left\{\hat{y}_{t}^{c, i}\right\}_{t=1}^{T}$ by solving the fixed-point problem

$$
\begin{aligned}
\hat{P}_{t}^{i}= & C\left(t_{1}-t\right) \exp \left\{-\left(t_{1}-t\right) \hat{y}_{t}^{c, i}\right\}+\sum_{k=2}^{n} \frac{C}{2} \exp \left\{-\left(t_{k}-t\right) \hat{y}_{t}^{c, i}\right\} \\
& +\exp \left\{-(T-t) \hat{y}_{t}^{c, i}\right\},
\end{aligned}
$$

for $i=1,2, \ldots, n$, meaning that $\left\{\hat{y}_{t}^{c, i}\right\}_{t=1}^{T}$ is approximately the rate of return on the $i$ th bond if held until maturity (see Sack and Elsasser 2004). To obtain the corresponding yields without correcting for liquidity risk, a new set of model-implied bond prices are computed from the estimated $G^{X^{N}, X^{R}}(7)$ model but using only its frictionless part, i.e., using the constraints that $X_{t \mid t}^{N}=0$ for all $t$ as well as $\sigma_{44}=0$ and $\theta_{N}^{Q}=0$ for the nominal bonos, and $X_{t \mid t}^{R}=0$ for all $t$ as well as $\sigma_{77}=0$ and $\theta_{R}^{Q}=0$ for the real udibonos. These prices are denoted $\left\{\tilde{P}_{t}^{i}\right\}_{t=1}^{T}$ and converted into yields to maturity $\tilde{y}_{t}^{c, i}$ using (7). They represent estimates of the prices that would prevail in a world without any financial frictions. The liquidity premium for the $i$ th bond is then defined as

$$
\Psi_{t}^{i} \equiv \hat{y}_{t}^{c, i}-\tilde{y}_{t}^{c, i}
$$

This can be calculated for bonos and udibonos separately.

Figure 9 shows the average bonos and udibonos liquidity premium series, denoted $\bar{\Psi}_{t}^{N}$ and $\bar{\Psi}_{t}^{R}$, across the outstanding set of each type of bond at each point in time. For comparison, we estimate a standard $G^{X^{N}}(4)$ model ${ }^{15}$ of bonos prices alone and a standard $G^{X^{R}}(3)$ model ${ }^{16}$ of udibonos prices alone, both with unrestricted mean-reversion matrix $K^{\mathbb{P}}$ and diagonal $\Sigma$. We note that the $G^{X^{N}}, X^{R}(7)$ model of bonos and udibonos prices jointly generates liquidity premium series that are very close to those one would get from a stand-alone analysis of each yield sample in isolation.

The bonos average liquidity premium series averages 45.10 basis points with a standard deviation of 21.81 basis points, while the average udibonos liquidity premium averages 58.17 basis points with a standard deviation of 46.54 basis points. Furthermore, their correlation in levels for the overlapping period is -2 percent, while it is 16 percent in first differences. Thus, the liquidity risk in the two markets is practically uncorrelated.

To assess the robustness of the estimated liquidity premia, we first compare the bonos

\footnotetext{
${ }^{15}$ This is identical to the AFNS-L model of bonos prices used in CFS.

${ }^{16}$ This is a three-factor model of udibonos prices with two frictionless factors representing level and slope components in addition to the liquidity risk factor $X_{t}^{R}$.
} 


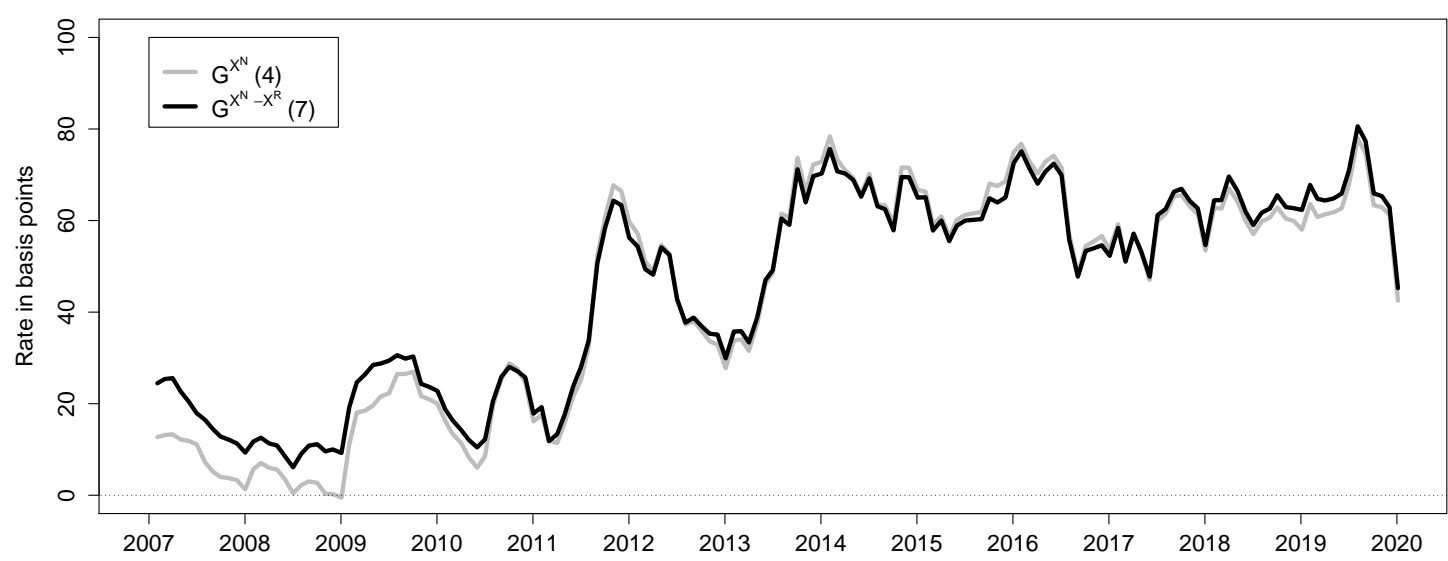

(a) Bonos

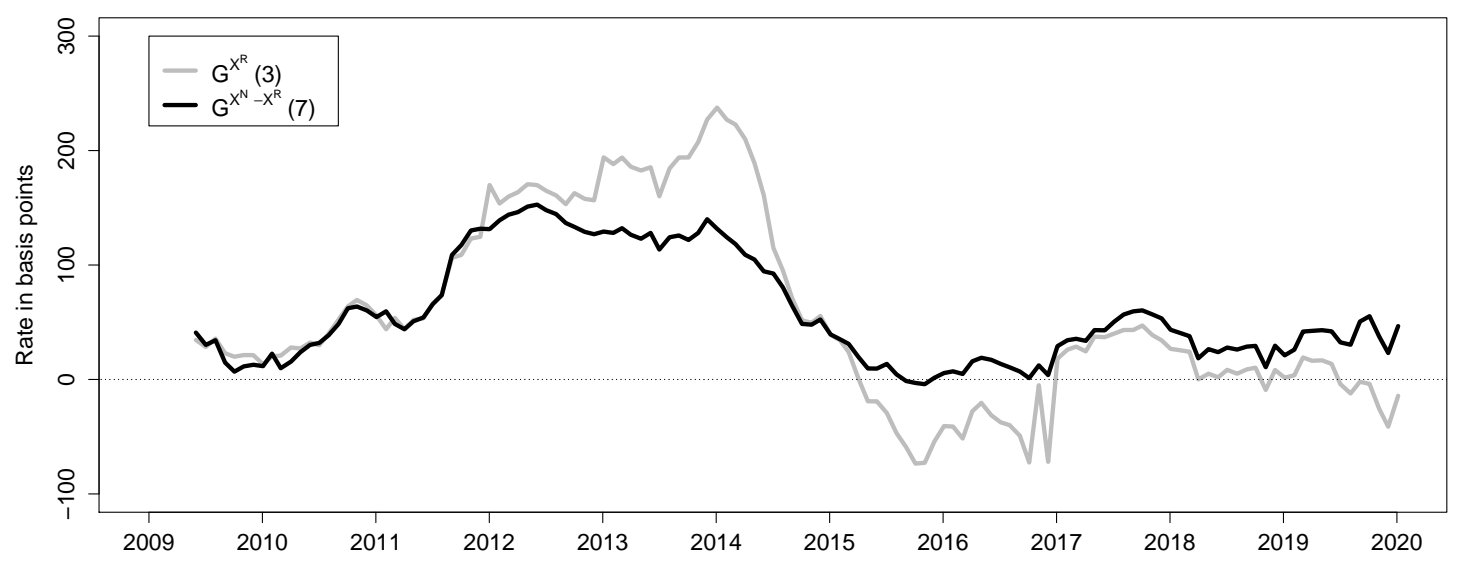

(b) Udibonos

Figure 9: Average Estimated Liquidity Premia of Mexican Bonos and Udibonos Illustration of the average estimated liquidity premium of Mexican bonos and udibonos for each observation date implied by the $G^{X^{N}, X^{R}}(7)$ model and compared to corresponding standard $G^{X^{N}}(4)$ and $G^{X^{R}}(3)$ models of nominal and real yields, respectively. The liquidity premiums are measured as the estimated yield difference between the fitted yield to maturity of individual bonds and the corresponding frictionless yield to maturity with the liquidity risk factor turned off. The bonos data cover the period from January 31, 2007, to December 30, 2019, while the udibonos data cover the period from May 31, 2009, to December 30, 2019.

liquidity premium series to the estimates reported in CFS and repeat their regression analysis, all reported in the online Appendix D. We then examine the sensitivity of the bonos and udibonos liquidity premium series to the assumed factor structure and find them to be robust as described in online Appendix E. Finally, we repeat the regression analysis of CFS using our udibonos liquidity premium series and obtain qualitatively similar results, see online Appendix F. Overall, we take this evidence to suggest that our estimated liquidity premium 
series are robustly estimated and not overly sensitive to any particular model assumption.

\section{Empirical BEI Decomposition}

In this section, we explore the properties of the BEI decomposition implied by the $G^{X^{N}, X^{R}}(7)$ model with a particular emphasis on both the model-implied expected inflation and the associated inflation risk premium that investors in bonos demand to assume their inflation risk. First, we examine the BEI decomposition and the outlook for long-term inflation expectations in Mexico before we turn to an analysis of the inflation risk premia and their determinants, including an international comparison.

\subsection{BEI Decomposition}

In this section, we examine the BEI decompostion implied by the estimated $G^{X^{N}, X^{R}}(7)$ model. To be consistent with the existing literature, we focus on a horizon long enough into the future that most transitory shocks to the economy can be expected to have vanished. At the same time, the horizon must be practically relevant and covered by the available maturities in the underlying bond data. Balancing these considerations, we limit our analysis to the five-year forward BEI rate that starts five years ahead, denoted 5yr5yr BEI.

The result of decomposing 5yr5yr BEI as described in Section 3.2 is shown in Figure 10. The solid gray line shows the fitted 5yr5yr BEI obtained by estimating a standard threefactor arbitrage-free Nelson-Siegel (AFNS) model to nominal bonos and real udibonos prices separately. This can be compared to the estimated 5yr5yr frictionless BEI implied by the $G^{X^{N}, X^{R}}(7)$ model and shown with a solid black line in the figure. The difference between these two measures of 5yr5yr BEI represents the net liquidity premium or distortion of the observed BEI series due to bond-specific liquidity risk premia in both bonos and udibonos prices. The fact that the 5yr5yr frictionless BEI is almost entirely above the 5yr5yr fitted BEI implies that the distortions due to liquidity risk are systematically larger in the real yields compared to those in the nominal yields at the 5yr5yr horizon.

Due to its theoretical consistency, the $G^{X^{N}, X^{R}}(7)$ model allows us to break down the $5 y r 5 y r$ frictionless BEI into an expected inflation component, shown with a solid red line in Figure 10, and the residual inflation risk premium, shown with a solid green line. Also shown in the figure with a solid black horizontal line is the 3 percent inflation target of the Bank of Mexico formally adopted in 2002. For comparison, the figure also shows the $5 y$ 5yr expected CPI inflation in Mexico reported semiannually in the Consensus Forecasts surveys. Although these survey inflation forecasts are included in the model estimation, the model-implied expected inflation does deviate quite notably from them for extended periods thanks to the assumed standard deviation of 75 basis points for the associated measurement

errors. Still, the closeness of the model's expected inflation to all the considered survey 


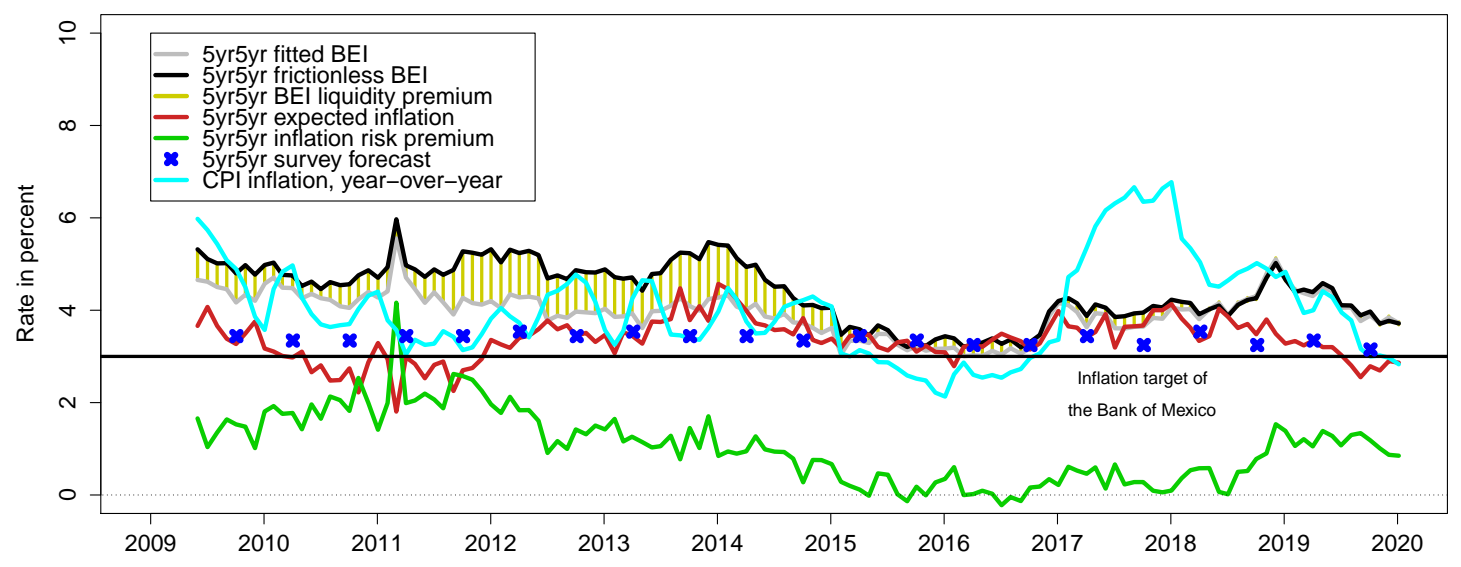

Figure 10: Decomposition of 5yr5yr BEI

Illustration of the fitted 5yr5yr BEI obtained by fitting an AFNS model to Mexican bonos and udibonos prices separately and its decomposition based on the $G^{X^{N}, X^{R}}(7)$ model estimated with an unrestricted specification of $K^{\mathbb{P}}$ and a diagonal specification of $\Sigma$ into: (1) the estimated frictionless BEI, (2) expected inflation, and (3) the residual inflation risk premium. The difference between the fitted and frictionless 5yr5yr BEI is highlighted in yellow and represents the net liquidity premium of the observed 5yr5yr BEI. The shown data cover the period from May 31, 2009, to December 30, 2019.

forecasts reported earlier underscores its ability to appropriately capture the term structure of inflation expectations among investors in the Mexican bonos and udibonos market. Finally, Figure 10 also shows the year-over-year change in the Mexican CPI with a solid cyan line to provide a measure of the actual inflation outcomes during this ten-year period.

Note that annual CPI inflation has averaged 4.02 percent during the shown period, somewhat above the Bank of Mexico's target, but mostly within the acceptable \pm 1 percentage point tolerance band around the target. As a consequence, it seems reasonable that both the survey inflation forecasts and the model-implied expected inflation are generally somewhat above the announced inflation target. However, given that the Bank of Mexico implements monetary policy with a \pm 1 percentage point tolerance band around its 3 percent target, both the survey inflation forecasts and the model-implied inflation expectations can be viewed as anchored at a level consistent with the central bank's inflation target. Furthermore, the 5yr5yr expected inflation from the model is positively correlated with the year-over-year change in the CPI, as one could expect, but only weakly so with a correlation of 40 percent.

\subsubsection{Outlook for Long-Term Inflation Expectations}

To assess the outlook for long-term inflation expectations based on the $G^{X^{N}, X^{R}}(7)$ model, we follow the approach of Christensen et al. (2015) and simulate 10,000 factor paths over a three-year horizon, conditioned on the shapes of the nominal and real yield curves and 


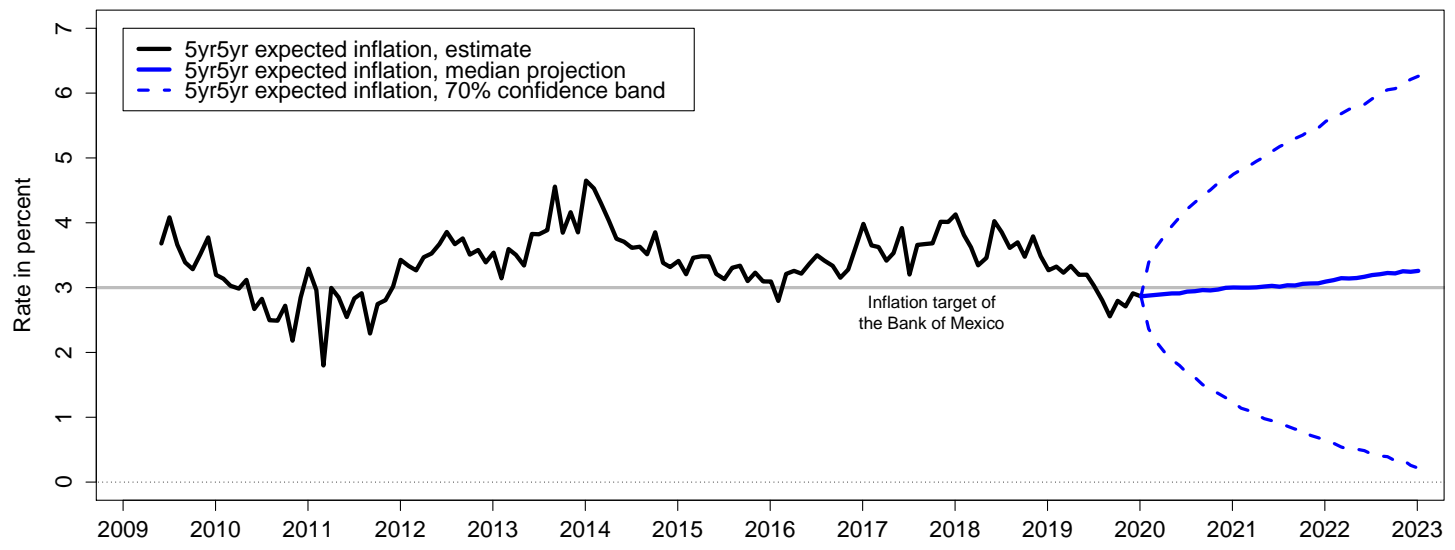

Figure 11: Three-Year Projections of 5yr5yr Expected Inflation

investors' embedded forward-looking expectations as of the end of December 2019 (that is, using estimated state variables and factor dynamics as of December 30, 2019). The simulated factor paths are then converted into forecasts of 5yr5yr expected inflation. Figure 11 shows the median projection and the 15th and 85th percentile values for the simulated 5yr5yr expected inflation over the three-year forecast horizon. ${ }^{17}$

The model projections indicate that the long-term inflation expectations are likely to gradually trend higher from their December 2019 estimate of 2.87 percent. Thus, long-term inflation expectations in Mexico appear to be well anchored at a level close to the inflation target of the Bank of Mexico, although it is important to stress the sizable uncertainty surrounding estimates of long-term inflation expectations as reflected in the very wide $70 \%$ confidence band. Given that De Pooter et al. (2014) concluded that long-term inflation expectations in Mexico were well anchored near the central bank's official target during their sample period, which ended in 2013, we feel that the evidence presented here is qualitatively similar to theirs and hence lends itself to the same conclusion, namely that long-term inflation expectations in Mexico indeed appear to be well anchored near the central bank's official target. Finally, we add that the notable uncertainty about the long-term inflation expectations justifies the sizable variation in the long-term inflation risk premia, which we analyze in greater detail in Section 4.2.

\subsubsection{Performance Comparison with Consensus Forecasts}

In this section, we explore whether the desirable properties of the $G^{X^{N}, X^{R}}(7)$ model-implied long-term inflation expectations documented so far allow it to also generate realistic shorter

\footnotetext{
${ }^{17}$ Note that the lines do not represent paths from a single simulation run over the forecast horizon; instead, they delineate the distribution of all simulation outcomes at a given point in time.
} 


\begin{tabular}{lccc}
\hline \hline Model & Mean & RMSE & MAE \\
\hline Consensus Forecasts & 19.23 & 118.98 & 75.67 \\
$G^{X^{N}, X^{R}}(7)$ model & 24.25 & 128.70 & 85.15 \\
\hline \hline
\end{tabular}

\section{Table 4: Summary Statistics of CPI Inflation Forecast Errors}

This table reports the mean forecasting errors (Mean), the root mean squared forecasting errors (RMSE), and the mean absolute forecasting errors (MAE). The $G^{X^{N}, X^{R}}(7)$ model forecasts are computed from the full sample estimation results. The forecast errors are reported as the true value minus the model-implied prediction, and all numbers are reported in annual basis points.

term inflation dynamics.

We structure the forecast exercise to match the monthly Consensus Forecasts survey. At the start of each month, the professional forecasters are asked about their expectations for the change in the CPI for the coming calendar year in addition to their expectations about the change for the current calendar year. To have a series of pure forecasts not distorted by incoming information on realized inflation outcomes, we focus on the monthly survey forecasts of CPI inflation over the coming calendar year. We then use the estimated $G^{X^{N}, X^{R}}(7)$ model to generate the matching model-implied CPI inflation forecasts. This has the advantage that the model-implied forecasts reflect information available at the end of each month and therefore lag the official survey dates by between one and two weeks. Thus, this exercise is by design conservative, although we stress the model forecasts are based on the full-sample estimates unlike the survey forecasts, which are real-time forecasts by construction. Finally, to align the exercise with the available observed udibonos prices, we start it in May 2009 and end it in November 2019, a total of 127 forecasts.

The summary statistics of the 127 monthly forecast errors from this exercise are reported in Table 4. Note that the $G^{X^{N}, X^{R}}(7)$ model produces slightly higher forecast errors as measured by the mean error, the root mean squared error, and the mean absolute error. Given the flexible structure of the $G^{X^{N}, X^{R}}(7)$ model and its high number of parameters and state variables, this is an encouraging outcome.

In comparing the forecast series, Figure 12 shows that the survey forecasts are very stable, even at the short calendar-year-ahead horizon examined here, another sign that inflation expectations in Mexico are well anchored. In contrast, the $G^{X^{N}, X^{R}}(7)$ model-implied forecasts exhibit a greater level of variation that is closer to that reflected in the subsequent CPI inflation realizations also shown in Figure 12 with solid black lines.

Overall, these observations lead us to conclude that the $G^{X^{N}, X^{R}}(7)$ model is able to generate realistic inflation dynamics with properties that match those of the actual CPI series, even though we stress that no inflation data is included in the model estimation. 


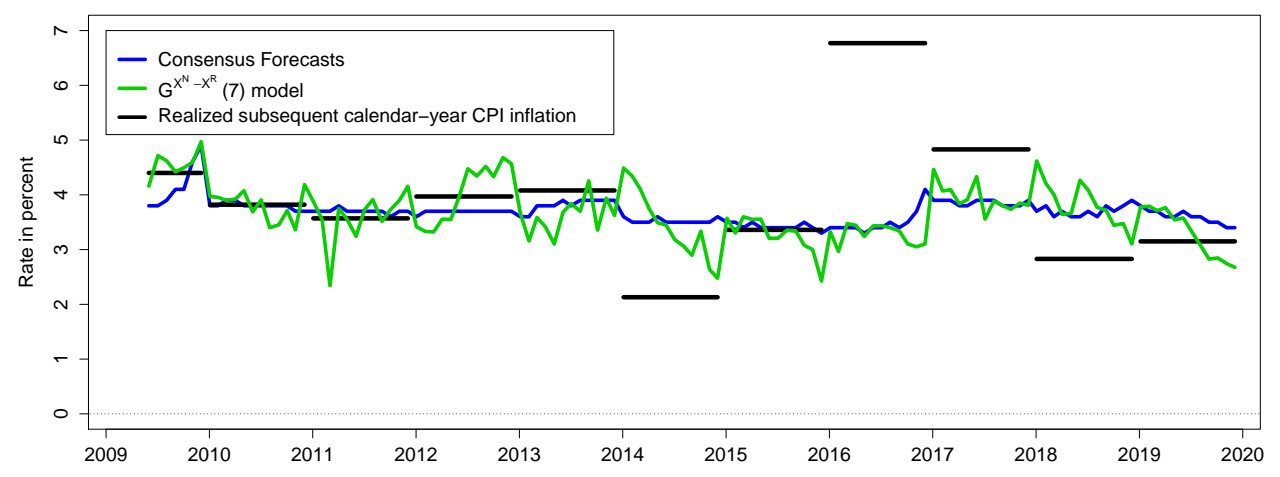

Figure 12: CPI Inflation Forecasts and Realizations

\subsubsection{Comparison with Existing BEI Decompositions}

In this section, we compare the results of the $G^{X^{N}}, X^{R}(7)$ model-implied BEI decomposition to that of an existing model of Mexican nominal and real government bond yields described in Aguilar-Argaez et al. (2016, henceforth AER). ${ }^{18}$ This AER model is a three-factor affine model that uses seven nominal bond yields with maturities ranging from one month to tenyear years in combination with the ten-year real yield and the year-over-year change in the CPI to produce estimates of both investors' inflation expectations and the premium they demand to be exposed to inflation risk. A key limitation of the AER model is that it makes no adjustments for the liquidity risk in either nominal or real yields. Furthermore, it is very parsimonious relying only on three factors for the joint modeling of the two yield curves and the included inflation series.

Figure 13 compares the estimated 5yr5yr expected inflation from the two models. We note that the long-term inflation expectations implied by the AER model are very stable. Blake et al. (2015) report long-term nominal short rate expectations for the Mexican bonos market that are similarly stable. We interpret this as evidence that these models suffer from finite-sample bias in the estimated factor dynamics, as discussed in Bauer et al. (2012). This means that the state variables are expected to revert back to steady state much faster than actually anticipated by investors. In contrast, for the $G^{X^{N}, X^{R}}(7)$ model, this problem is significantly mitigated by including medium- and long-term inflation forecasts from surveys in the information set used for the model estimation, as recommended by Kim and Orphanides (2012). As a result, the $G^{X^{N}, X^{R}}(7)$ model-implied long-term inflation expectations exhibit cyclical variation, which is positively correlated with the cyclical variation in the realized year-over-year inflation, as also noted in Section 4.1.

\footnotetext{
${ }^{18}$ The updated data from this analysis is taken from: https://www.banxico.org.mx/publicaciones-yprensa/informes-trimestrales/\%7B67E312ED-E93D-EA9C-2A3F-8C20FEE6C215\%7D.pdf. This also determines the January 2010 start date for the comparison.
} 


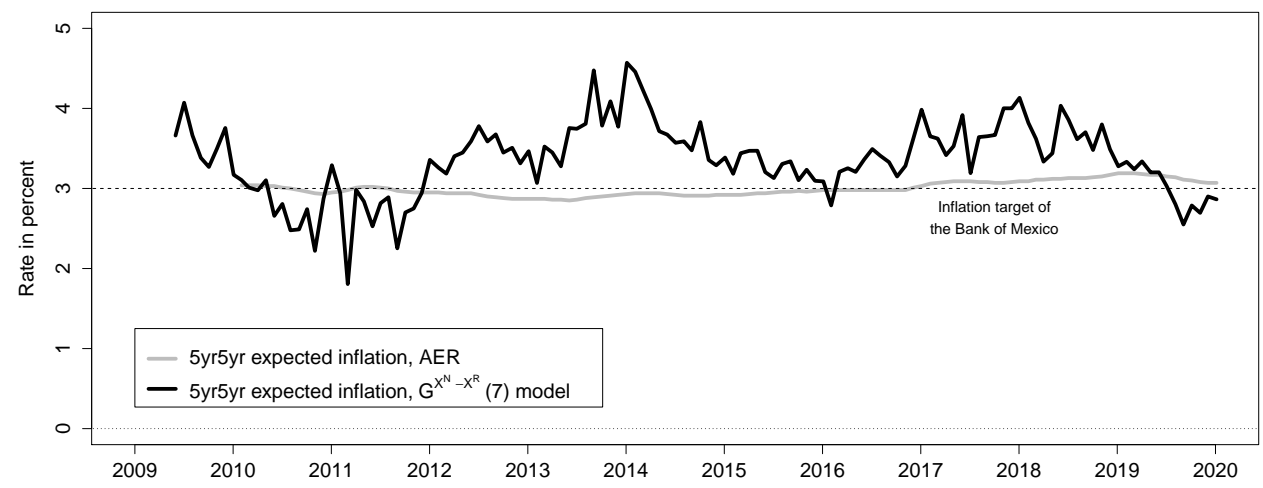

Figure 13: Comparison of Market-Based 5yr5yr Expected Inflation

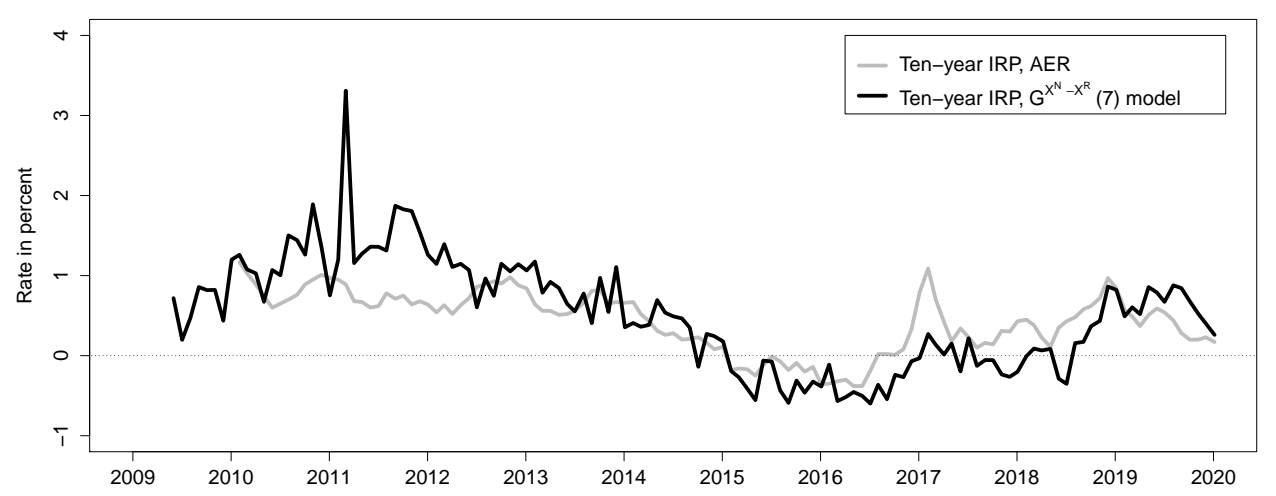

Figure 14: Comparison of Ten-Year Inflation Risk Premium

Figure 14 compares the estimated ten-year inflation risk premium from the two models. The two series align very closely with each other and have a correlation of 76 percent for the overlapping period. This closeness gives us extra confidence in the $G^{X^{N}, X^{R}}(7)$ model's estimated inflation risk premia that we examine next.

\subsection{Analysis of Inflation Risk Premia}

In this section, we first explore what determines the size of, and variation in, Mexican inflation risk premia using regression analysis. This is followed by an international comparison to Canadian and U.S. inflation risk premia. 


\subsubsection{Determinants of Inflation Risk Premia}

While the long-term inflation expectations in Mexico are largely determined by the inflation target of the Bank of Mexico, it is less clear what factors would matter for the size of Mexican long-term inflation risk premia. To explain the variation of the 5yr5yr Mexican inflation risk premium series, we therefore run a battery of standard regressions with it as the dependent variable and a wide set of explanatory variables that are thought to play a role for inflation risk premia as explained in the following.

To begin, we are interested in the role of factors that are believed to matter for bonos and udibonos market liquidity specifically or bond market liquidity more broadly as they could matter for the estimated inflation risk premia, even though we have explicitly accounted for bonos and udibonos liquidity premia in the model estimation. Building on the findings of CFS, we include the foreign-held share of the bonos market as a key explanatory variable. Second, we use the average bid-ask spread in the bonos market shown in Figure 7. Third, we add the average bonos age and the one-month realized volatility of the ten-year bonos yield as additional proxies for bond liquidity following the work of Houweling et al. (2005). Inspired by the analysis of $\mathrm{Hu}$ et al. (2013), we also include a noise measure of bonos prices to control for variation in the amount of arbitrage capital available in this market. Combining these five explanatory variables tied to bonos market liquidity and functioning produces the results reported in regression (1) in Table 5. We note a high adjusted $R^{2}$ of 0.49 . The foreign share has a significant negative coefficient. This implies that an increased presence of foreigners in the bonos market is associated with lower inflation risk premia in addition to its positive effects on bonos liquidity premia documented in CFS.

Next, we repeat the above regression exercise, but now focus on the corresponding explanatory variables derived from the udibonos market, i.e., we include the foreign-held share of the udibonos market, the average bid-ask spread of the udibonos in our sample (also shown in Figure 7), the average age of the udibonos in our sample, the one-month realized volatility of daily changes in the fitted ten-year udibonos yield, and the noise measure constructed from fitted errors of our sample of daily udibonos prices. These five explanatory variables tied to the udibonos market produce the results in regression (2) in Table 5. They generate a slightly

higher adjusted $R^{2}$ of 0.50 , but we again have the foreign share as an important variable with the same sign of its regression coefficient as before.

In a third step, we combine all ten explanatory variables tied to bonos and udibonos market functioning and liquidity. This produces the results reported for regression (3) in Table 5 . This yields a slightly higher adjusted $R^{2}$ of 0.60 . However, no single variable stands out as notably more important than any of the others. As a consequence, we choose not to consider any of these variables further.

After having explored the role of liquidity factors, we examine the effects of factors reflecting risk sentiment domestically and globally on the inflation risk premia. This set of variables 


\begin{tabular}{|c|c|c|c|c|c|c|}
\hline Explanatory variables & (1) & $(2)$ & $(3)$ & (4) & $(5)$ & (6) \\
\hline Foreign share of bonos & $\begin{array}{c}-3.69^{* *} \\
(1.01)\end{array}$ & & $\begin{array}{l}-0.63 \\
(2.02)\end{array}$ & & & $\begin{array}{c}0.51 \\
(1.70)\end{array}$ \\
\hline Bonos bid-as-spread & $\begin{array}{r}-12.48 \\
(9.23)\end{array}$ & & $\begin{array}{c}-19.89^{*} \\
(8.58)\end{array}$ & & & $\begin{array}{l}-5.97 \\
(5.56)\end{array}$ \\
\hline Avg. bonos age & $\begin{array}{l}-5.66 \\
(8.88)\end{array}$ & & $\begin{array}{c}-65.34^{* *} \\
(21.70)\end{array}$ & & & $\begin{array}{c}3.95 \\
(13.37)\end{array}$ \\
\hline One-month bonos yield vol. & $\begin{array}{l}1.28 \\
(0.81)\end{array}$ & & $\begin{array}{c}0.32 \\
(0.85)\end{array}$ & & & $\begin{array}{l}-0.09 \\
(0.61)\end{array}$ \\
\hline Bonos noise measure & $\begin{array}{l}-1.15 \\
(3.90)\end{array}$ & & $\begin{array}{l}-6.13 \\
(3.39)\end{array}$ & & & $\begin{array}{l}-4.30 \\
(2.58)\end{array}$ \\
\hline Foreign share of udibonos & & $\begin{array}{c}-8.04^{* *} \\
(2.39)\end{array}$ & $\begin{array}{l}-9.15^{*} \\
(3.97)\end{array}$ & & & $\begin{array}{c}-9.11^{* *} \\
(2.96)\end{array}$ \\
\hline Udibonos bid-ask spread & & $\begin{array}{c}2.38 \\
(3.64)\end{array}$ & $\begin{array}{c}0.03 \\
(2.64)\end{array}$ & & & $\begin{array}{c}0.21 \\
(1.22)\end{array}$ \\
\hline Avg. udibonos age & & $\begin{array}{c}-26.34^{* *} \\
(6.50)\end{array}$ & $\begin{array}{l}43.88^{*} \\
(20.71)\end{array}$ & & & $\begin{array}{c}13.69 \\
(12.92)\end{array}$ \\
\hline One-month udibonos yield vol. & & $\begin{array}{c}1.52 \\
(0.93)\end{array}$ & $\begin{array}{c}1.20 \\
(1.09)\end{array}$ & & & $\begin{array}{c}0.91 \\
(0.90)\end{array}$ \\
\hline Udibonos noise measure & & $\begin{array}{c}2.69 \\
(2.03)\end{array}$ & $\begin{array}{c}3.11 \\
(2.31)\end{array}$ & & & $\begin{array}{c}2.77 \\
(2.36)\end{array}$ \\
\hline VIX & & & & $\begin{array}{l}9.18^{* *} \\
(1.45)\end{array}$ & & $\begin{array}{c}0.74 \\
(1.00)\end{array}$ \\
\hline OTR premium & & & & $\begin{array}{l}-1.89 \\
(1.24)\end{array}$ & & $\begin{array}{l}-1.75 \\
(1.37)\end{array}$ \\
\hline EMBI & & & & $\begin{array}{c}-0.61^{* *} \\
(0.15)\end{array}$ & & $\begin{array}{c}0.03 \\
(0.16)\end{array}$ \\
\hline TED spread & & & & $\begin{array}{l}-0.82 \\
(0.89)\end{array}$ & & $\begin{array}{l}-0.11 \\
(0.41)\end{array}$ \\
\hline CDS rate & & & & $\begin{array}{c}0.07 \\
(0.30)\end{array}$ & & $\begin{array}{l}-0.06 \\
(0.26)\end{array}$ \\
\hline 10yr US Treasury yield & & & & $\begin{array}{c}18.73 \\
(15.78)\end{array}$ & & $\begin{array}{c}-2.76 \\
(10.33)\end{array}$ \\
\hline Peso/USD exchange rate & & & & & $\begin{array}{l}-4.63 \\
(7.72)\end{array}$ & $\begin{array}{c}0.95 \\
(10.29)\end{array}$ \\
\hline WTI & & & & & $\begin{array}{c}0.15 \\
(0.35)\end{array}$ & $\begin{array}{l}-0.03 \\
(0.46)\end{array}$ \\
\hline CPI Inflation & & & & & $\begin{array}{c}-23.65^{* *} \\
(3.90)\end{array}$ & $\begin{array}{l}-12.07 \\
(6.22)\end{array}$ \\
\hline Debt-to-GDP ratio & & & & & $\begin{array}{c}-11.56^{* *} \\
(2.48)\end{array}$ & $\begin{array}{c}-16.20^{* *} \\
(5.99)\end{array}$ \\
\hline MSCI one-month return & & & & & $\begin{array}{l}-0.55 \\
(0.54)\end{array}$ & $\begin{array}{c}0.07 \\
(0.56)\end{array}$ \\
\hline One-month cetes rate & & & & & $\begin{array}{c}28.87^{* *} \\
(5.57)\end{array}$ & $\begin{array}{c}2.57 \\
(11.73)\end{array}$ \\
\hline Intercept & $\begin{array}{c}263.36^{* *} \\
(52.56)\end{array}$ & $\begin{array}{c}349.53^{* *} \\
(53.14)\end{array}$ & $\begin{array}{c}341.23^{* *} \\
(59.55)\end{array}$ & $\begin{array}{c}138.00^{*} \\
(58.14)\end{array}$ & $\begin{array}{c}616.26^{* *} \\
(69.89)\end{array}$ & $\begin{array}{l}785.14^{* *} \\
(171.83)\end{array}$ \\
\hline Adjusted $R^{2}$ & 0.49 & 0.50 & 0.60 & 0.50 & 0.76 & 0.79 \\
\hline
\end{tabular}

Table 5: Regression Results for the 5yr5yr Inflation Risk Premium

The table reports the results of regressions with the estimated 5yr5yr inflation risk premium as the dependent variable and 22 explanatory variables. Standard errors computed by the Newey-West estimator (with three lags) are reported in parentheses. Asterisks $*$ and $* *$ indicate significance at the 5 percent and 1 percent levels, respectively. 
includes the VIX, which represents near-term uncertainty about the general stock market as reflected in options on the Standard \& Poor's 500 stock price index and is widely used as a gauge of investor fear and risk aversion. The set also contains the yield difference between seasoned (off-the-run) U.S. Treasury securities and the most recently issued (on-the-run) U.S. Treasury security of the same ten-year maturity mentioned earlier. This on-the-run (OTR) premium is a frequently used measure of financial frictions in the U.S. Treasury market. To control for factors that affect emerging market sovereign bonds more broadly, we include the J.P. Morgan Emerging Market Bond Index (EMBI). The fourth variable is the U.S. TED spread, which is calculated as the difference between the three-month U.S. LIBOR and the three-month U.S. T-bill interest rate. This spread represents a measure of the perceived general credit risk in global financial markets. As an additional indicator of credit risk and credit risk sentiment, we use the five-year credit default swap (CDS) rate for Mexico shown in Figure 5. The final variable in the set is the ten-year U.S. Treasury yield from the Federal Reserve's H.15 database, which is included to control for reach-for-yield effects in advanced economies. This may be particularly relevant for our sample during the period between December 2008 and December 2015 when U.S. short-term interest rates were constrained by the zero lower bound.

The results of the regression with these six explanatory variables is reported in regression (4) in Table 5. First, we note a relatively modest adjusted $R^{2}$ of 0.50 . It is really only the VIX and the EMBI, which are significant in this regression but are insignificant in the full regression (6) with all 22 explanatory variables. The other four variables appear insignificant and flip sign across the two regressions. As a consequence, we again choose not to consider any of these variables further.

In the final exercise, we assess the role played by standard macro variables for Mexican inflation risk premia. In this set of variables, we first include the Mexican peso-U.S. dollar exchange rate. As an open emerging market economy, inflation dynamics in Mexico and the premium investors attach to the associated risk is likely to be sensitive to exchange rate developments. The second variable is the West Texas Intermediate (WTI) Cushing crude oil price. Because Mexico is a major oil producing country, the revenue and bond issuance of the Mexican government are affected by changes in oil prices, and so is Mexican inflation itself. Thus, this variable could matter for Mexican inflation risk premia. To capture inflation risk in a more direct way, we include the year-over-year change in the Mexican consumer price index (CPI). Given our focus on longer-term inflation risk as reflected in the 5yr5yr inflation risk premium, the outlook for public finances and any lingering risk of inflating away an outsized debt burden could matter as well. To capture such effects, we include the public debt-to-GDP ratio as measured by the OECD. Furthermore, we include the monthly return of the MSCI Mexican stock index as a measure of the general economic developments in 
the Mexican economy of importance to investors. ${ }^{19}$ Finally, we include the one-month cetes rate. $^{20}$ In addition to capturing the stance of monetary policy, this rate serves as a proxy for the opportunity cost of holding money and the associated liquidity convenience premia of bonos, as explained in Nagel (2016).

The results of the regression with these six standard macroeconomic explanatory variables is reported in regression (5) in Table 5. They produce a notable adjusted $R^{2}$ of 0.76 . Among the six variables, the year-over-year change in the CPI, the public debt-to-GDP ratio, and the one-month cetes rate stand out as significant, while the others are mostly insignificant or have switching signs of their coefficients relative to the full regression (6). As a consequence, we consider the three former variables to be representative for this group of macroeconomic variables. More importantly, and maybe somewhat unexpectedly, two of these variables have negative coefficients while the one-month cetes rate has a positive coefficient. That is, higher inflation and public debt ratios appear to be associated with lower inflation risk premia. We speculate that this finding might come about through a "credibility-of-monetary-policy" channel in which current high inflation or public debt are both expected to be met with a tightening of monetary policy. This reduces the risk of elevated inflation in the longer run, which is what our 5yr5yr inflation risk premium series measures.

To evaluate the relative importance of the three representative variables identified from the initial round of regression exercises, namely the year-over-year change in the CPI, the public debt-to-GDP ratio, and the one-month cetes rate, we run a second set of regressions with these three variables individually and combined. This allows us to identify a final preferred regression model for our Mexican 5yr5yr inflation risk premium series.

The results are reported in Table 6. Regression (4) with all three representative variables combined delivers an adjusted $R^{2}$ of 0.76 . This is higher than that produced by any of the groups of variables we explored in the initial round of regressions. Hence, this supports our selection of representative variables. These results also underscore that our three representative variables are responsible for the vast bulk of the significant explanatory power. Furthermore, all three variables are clearly statistically significant at the $1 \%$ level. As a consequence, we consider regression (4) to be our preferred explanatory regression model for the Mexican 5 yr5yr inflation risk premium series.

As for the involved magnitudes, we note that a one percentage point increase in the Mexican CPI inflation rate lowers the 5yr5yr inflation risk premium by about a quarter of a percentage point, while a one percentage point increase in the Mexican public debt-to-GDP ratio reduces it by slightly more than 0.1 percent. Finally, a one percentage point increase in the one-month cetes rate increases the 5yr5ry inflation risk premium by a quarter percentage point. Thus, all three variables have economically meaningful impacts on the inflation risk

\footnotetext{
${ }^{19}$ The MSCI index is a free-float weighted equity index designed to measure the performance of the large and mid cap segments of the Mexican stock market. The index is reported in U.S. dollars.

${ }^{20}$ Cetes are short-term instruments issued by the Mexican government similar to U.S. Treasury bills.
} 


\begin{tabular}{lcccc}
\hline \hline Explanatory variables & $(1)$ & $(2)$ & $(3)$ & $(4)$ \\
\hline CPI Inflation & -2.42 & & & $-23.25^{* *}$ \\
& $(12.84)$ & & $(3.94)$ \\
Debt-to-GDP ratio & & $-10.02^{* *}$ & & $-13.65^{* *}$ \\
& & $(1.23)$ & & $(0.91)$ \\
One-month cetes rate & & & -3.75 & $25.91^{* *}$ \\
& & & $(5.78)$ & $(3.15)$ \\
Intercept & $113.96^{*}$ & $535.62^{* *}$ & $122.66^{* *}$ & $658.30^{* *}$ \\
& $(57.09)$ & $(52.48)$ & $(34.94)$ & $(41.70)$ \\
Adjusted $R^{2}$ & -0.01 & 0.59 & -0.00 & 0.76 \\
\hline \hline
\end{tabular}

Table 6: Preferred Regression Results for the 5yr5yr Inflation Risk Premium

The table reports the results of regressions with the estimated 5yr5yr inflation risk premium as the dependent variable and the three representative explanatory variables identified in the initial round of regressions. Standard errors computed by the Newey-West estimator (with three lags) are reported in parentheses. Asterisks * and ${ }^{* *}$ indicate significance at the 5 percent and 1 percent levels, respectively.

premium series.

The preferred regression (4) also allows us to consolidate the result that, indeed, both the year-over-year change in the CPI and the public debt-to-GDP ratio have negative coefficients. Thus, counter to intuition, long-term inflation risk premia in Mexico appear to decline when either inflation or the public debt ratio increase. As explained earlier, we speculate that this result may reflect the credibility of the monetary policy strategy of the Bank of Mexico. We leave it for future research to explore to what extent these results apply more broadly to other open emerging market economies with inflation-targeting monetary policy regimes or whether they are unique to Mexico and maybe reflect its very close ties to the U.S. economy in general and U.S. financial markets in particular.

\subsubsection{International Comparison of Inflation Risk Premia}

To go beyond the regression analysis above, we compare the estimated 5yr5yr inflation risk premium for Mexico with matching estimates from Canadian and U.S. nominal and real yields. ${ }^{21}$ Figure 15 shows all three series for the available overlapping sample period.

The Canadian and U.S. inflation risk premia are highly positively correlated (85\%). The Mexican inflation risk premium series is also positively correlated with each, 62 percent and 62 percent, respectively. Thus, both in terms of size and time variation, Mexican inflation risk premia share similarities with those observed in Canadian and U.S. bond markets. However, as expected, Mexican inflation risk premia are more volatile with a standard deviation of 76.21 basis points compared with 23.94 basis points and 34.91 basis points for the Canadian

\footnotetext{
${ }^{21}$ The Canadian estimate is taken from Christensen et al. (2021), while the U.S. estimate comes from an update of the model described in ACR using all available TIPS.
} 


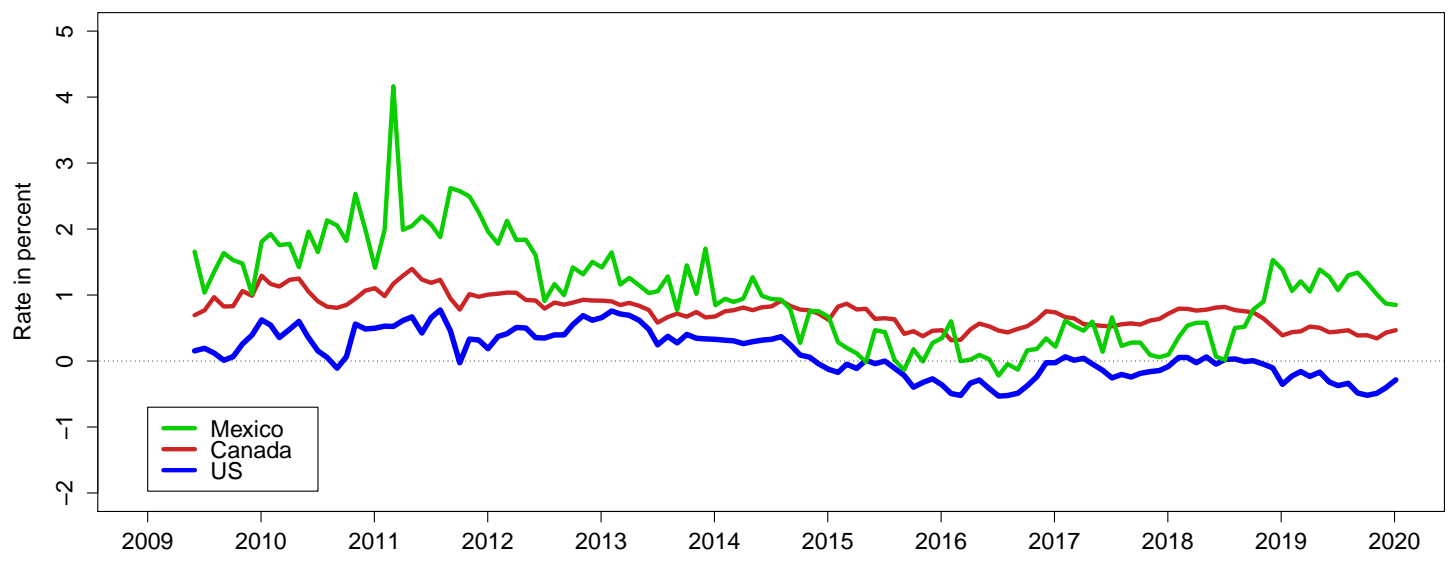

Figure 15: International Panel of 5yr5yr Inflation Risk Premia

Illustration of the estimated 5yr5yr inflation risk premium series from Mexican, Canadian, and U.S. nominal and real bond prices as described in the text. The shown data cover the period from May 31, 2009, to December 30, 2019.

and U.S. series, respectively.

The mostly positive and small inflation risk premia in Canada and the United States are consistent with the findings from simple macro-finance representative agent models; see Hördahl and Tristani (2012). For the United States, D'Amico et al. (2018) also report empirical estimates of inflation risk premia, which are mostly positive and relatively small. In turn, to observe larger and more volatile inflation risk premia in an emerging market economy such as Mexico, would seem like a reasonable result given the higher and more volatile CPI inflation in Mexico compared with Canada and the United States.

\section{Cost-Benefit Analysis of Inflation-Indexed Debt}

In this section, we demonstrate an important policy application of our estimation results. Given estimates of the liquidity penalties of both nominal bonos and udibonos along with estimates of Mexican inflation risk premia, we can assess the relative costs and benefits between issuing bonos and udibonos to the Mexican government.

Given that the Mexican government issues bonds with fairly fixed maturities (5-year, 10year, 20-year, 30-year), we need to measure both liquidity and inflation risk premia at those fixed constant maturities. To that end, we first estimate a standard three-factor arbitrage-free Nelson-Siegel (AFNS) model using the nominal bonos and real udibonos prices separately. This allows us to calculate fitted nominal and real zero-coupon yields for all relevant maturities. Given that these models are fitted to the observed bond prices directly, the resulting yields embed the liquidity premia of the nominal and real bonds. 


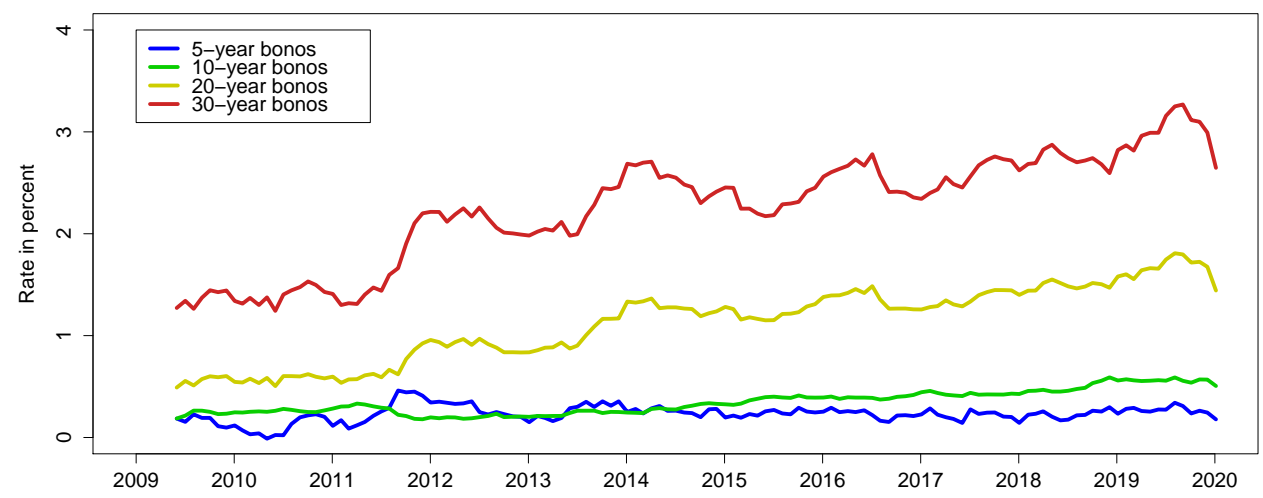

(a) Bonos liquidity premia

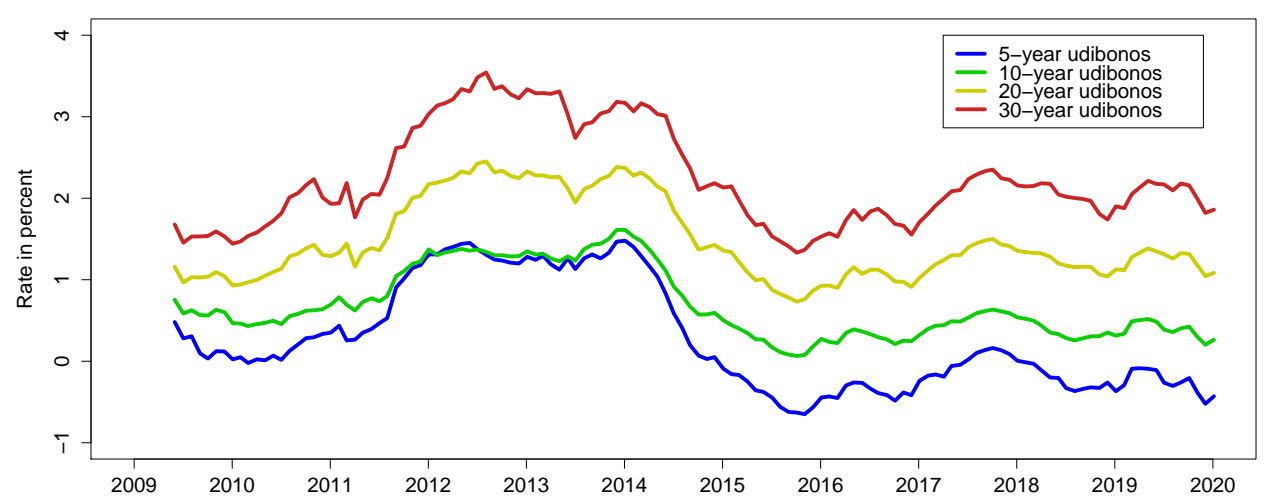

(b) Udibonos liquidity premia

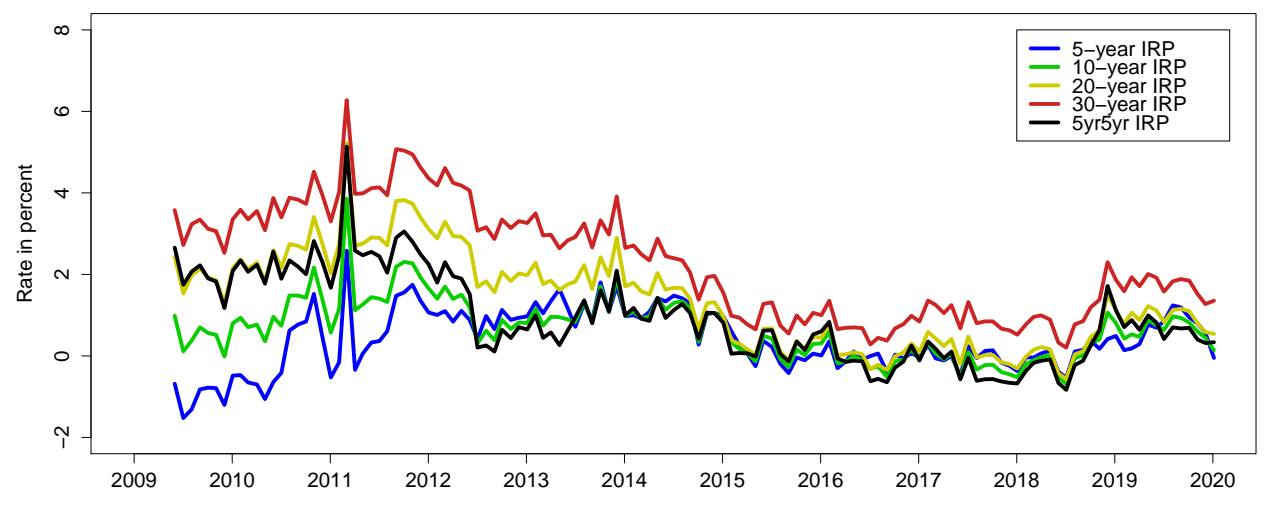

(c) Inflation risk premia

Figure 16: Term Structure of Bond Risk Premia

In the second step, we use the estimated frictionless factor dynamics within the $G^{X^{N}, X^{R}}(7)$ model to calculate the corresponding frictionless nominal and real zero-coupon yields that do 


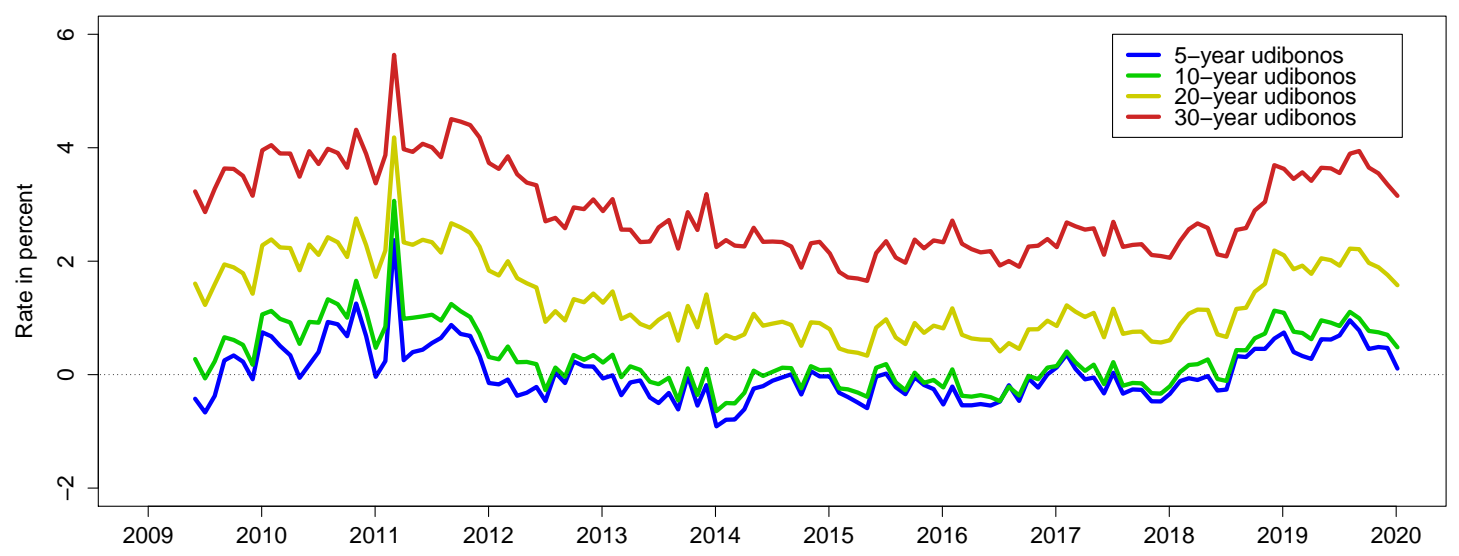

Figure 17: Term Structure of Net Benefit of Udibonos Issuance

not contain any liquidity risk premia. The difference between the fitted and frictionless nominal zero-coupon yields then becomes an alternative synthetic estimate of the bonos liquidity premia at constant maturities. These are shown in Figure 16(a) for four maturities: 5-year, 10-year, 20-year, 30-year. Repeating this for the real yields produces the synthetic estimates of udibonos liquidity premia at the same four maturities shown in Figure 16(b).

In the final step, we use the frictionless nominal and real zero-coupon yields implied by the $G^{X^{N}, X^{R}}(7)$ model to construct the corresponding frictionless BEI at the same four fixed maturities and deduct the associated model-implied expected inflation to obtain the corresponding four inflation risk premium series shown in Figure 16(c)

Note the pronounced upward sloping term structure for all three types of risk premia. This underscores the importance of combining the full term structure of bond prices for both bonos and udibonos with a full joint term structure model of both nominal and real yields.

Now, for each fixed maturity, adding the inflation risk premium and the bonos liquidity premium before deducting the udibonos liquidity premium produces a measure of the net benefit of issuing udibonos over bonos to the Mexican government. The resulting four net benefit series at the 5-year, 10-year, 20-year, and 30-year maturities are shown in Figure 17.

The average net benefit of udibonos at the 5-, 10-, 20-, and 30-year maturity is estimated at $0.06 \%, 0.33 \%, 1.38 \%$, and $2.95 \%$, respectively. Thus, while bonos issuance can be considered to be competitive, at least periodically, in the liquid 5- to 10-year maturity range, our results are really unfavorable regarding issuance of 20- and 30-year bonos. Based on our estimates it is recommendable that the Mexican government tilt its issuance of such long-term bonds towards the udibonos market. This result is a combination of elevated liquidity premia for long-term bonos compared to the liquid 5- to 10-year segment and high inflation risk premia for those same long-term bonos. 
To provide evidence that the magnitudes of the estimated bonos liquidity premium differences are real, we look at the results of initial bonos auctions. For example in 2012, the Mexican government issued new 5-, 10-, and 30-year bonos within a five-month period between February and July with coupon rates of $5 \%, 6.5 \%$, and $7.75 \%$, respectively. Thus, the 30 -year bonos pays $2.75 \%$ more in interest annually than the 5 -year bonos, even though it is clear from Figure 2 that the shape and level of the bonos yield curve changed little during this period and cannot account for this large difference in coupon rates.

To summarize, without other strategic benefits from long-term nominal debt, a strict actuarial cost-benefit analysis would recommend a halt to its issuance. Alternatively, the government can introduce regulatory rules for financial institutions and institutional investors such as pension funds and life insurance companies with some form of beneficial treatment of holdings of long-term government debt to provide an incentive to gain exposure to this part of the bonos and udibonos market.

\section{Conclusion}

In this paper, we introduce a flexible joint model of nominal and real yields that accounts for liquidity risk premia in both nominal and real bond prices. We estimate the model on a representative sample of nominal and real bond prices from Mexico. This allows us to be the first to provide estimates of the liquidity-adjusted frictionless BEI in a major open emerging market economy, along with its decomposition into investors' underlying inflation expectations and associated inflation risk premia.

Our results indicate that long-term inflation expectations in Mexico appear to have remained well anchored during our sample period at a level close to the 3 percent inflation target of the Bank of Mexico. Furthermore, inflation risk premia in Mexico are larger and more volatile than matching estimates from Canada and the United States.

A comprehensive analysis of the determinants of long-term inflation risk premia in Mexico identifies three variables of particular importance, namely the ten-year U.S. Treasury yield, the year-over-year change in the Mexican CPI, and the public debt-to-GDP ratio. While the ten-year U.S. Treasury yield has the expected positive effect, interestingly, the other two variables have negative coefficients meaning that increases in inflation and public debt tend to depress long-term inflation risk premia in Mexico. We speculate that this result may reflect the credibility of the Bank of Mexico's monetary policy, and we leave it for future research to explore whether this holds for other open emerging market economies with inflation-targeting central banks.

With estimates of bonos and udibonos liquidity premia and general inflation risk premia in hand, we are also able to assess the net benefit of udibonos issuance to the Mexican government. Here, our results show a clear advantage of udibonos over comparable bonos in the relevant 5-year to 30-year maturity range that is particularly pronounced for long- 
term udibonos. Thus, barring other strategic motives behind issuance of long-term bonos, our results suggest that a tilt towards greater issuance of long-term udibonos would be cost effective to the Mexican government.

Finally, we feel compelled to stress that our model framework can be applied to other emerging market economies with established nominal and real bond markets such as Brazil, Chile, and Colombia, among many others. However, we also leave those applications for future research. 


\section{References}

Abrahams, Michael, Tobias Adrian, Richard K. Crump, Emanuel Moench, and Rui Yu, 2016, "Decomposing Real and Nominal Yield Curves," Journal of Monetary Economics, Vol. $84,182-200$.

Adrian, Tobias, Richard K. Crump, and Emanuel Moench, 2013, "Pricing the Term Structure with Linear Regressions," Journal of Financial Economics, Vol. 110, 110-138.

Aguilar-Argaez, Ana, María Diego-Fernández, Rocío Elizondo, and Jessica Roldán-Peña, 2016, "Descomposición de la Compensación por Inflación y Inflacionario en México," Bank of Mexico Working Papers No. 2016-22.

Andreasen, Martin M., Jens H. E. Christensen, and Simon Riddell, 2021, "The TIPS Liquidity Premium," forthcoming Review of Finance.

Andreasen, Martin M., Jens H. E. Christensen, and Glenn D. Rudebusch, 2019, "Term Structure Analysis with Big Data: One-Step Estimation Using Bond Prices," Journal of Econometrics, Vol. 212, 26-46.

Bauer, Michael D., Glenn D. Rudebusch, and Jing (Cynthia) Wu, 2012, "Correcting Estimation Bias in Dynamic Term Structure Models," Journal of Business and Economic Statistics, Vol. 30, No. 3, 454-467.

Blake, Andrew P, Garreth R. Rule, and Ole J. Rummel, 2015, "Inflation Targeting and Term Premia Estimates for Latin America," Latin American Economic Review, Vol. 24, No. $3,1-21$.

Carriero, Andrea, Sarah Mouabbi, and Elisabetta Vangelista, 2018, "U.K. Term Structure Decompositions at the Zero Lower Bound," Journal of Applied Econometrics, Vol. 33, 643-661.

Chernov, Mikhail and Philippe Mueller, 2012, "The Term Structure of Inflation Expectations," Journal of Financial Economics, Vol. 106, No. 2, 367-394.

Chiquiar, Daniel, Antonio E. Noriega, and Manuel Ramos-Francia, 2010, "A Time-Series Approach to Test a Change in Inflation Persistence: the Mexican Experience," Applied Economics, Vol. 42, 3067-3075.

Christensen, Jens H. E., 2008, "The Corporate Bond Credit Spread Puzzle," FRBSF Economic Letter, 2008-10 (March 14).

Christensen, Jens H. E., Francis X. Diebold, and Glenn D. Rudebusch, 2011, "The Affine Arbitrage-Free Class of Nelson-Siegel Term Structure Models," Journal of Econometrics, Vol. 164, No. 1, 4-20. 
Christensen, Jens H. E., Eric Fischer, and Patrick J. Shultz, 2021, "Bond Flows and Liquidity: Do Foreigners Matter?," Journal of International Money and Finance, Vol. 117-102397, 1-20.

Christensen, Jens H. E., Jose A. Lopez, and Glenn D. Rudebusch, 2010, "Inflation Expectations and Risk Premiums in an Arbitrage-Free Model of Nominal and Real Bond Yields," Journal of Money, Credit and Banking, Supplement to Vol. 42, No. 6, 143-178.

Christensen, Jens H. E., Jose A. Lopez, and Glenn D. Rudebusch, 2015, "A ProbabilityBased Stress Test of Federal Reserve Assets and Income," Journal of Monetary Economics, Vol. 73, 26-43.

Christensen, Jens H. E. and Glenn D. Rudebusch, 2019, “A New Normal for Interest Rates? Evidence from Inflation-Indexed Debt," Review of Economics and Statistics, Vol. 101, No. 5, 933-949.

Christensen, Jens H. E., Glenn D. Rudebusch, and Patrick J. Shultz, 2021, "Accounting for Low Long-Term Interest Rates: Evidence from Canada," Working Paper 2020-35, Federal Reserve Bank of San Francisco.

Dai, Qiang and Kenneth J. Singleton, 2000, "Specification Analysis of Affine Term Structure Models," Journal of Finance, Vol. 55, No. 5, 1943-1978.

D'Amico, Stefania, Don H. Kim, and Min Wei, 2018, "Tips from TIPS: The Informational Content of Treasury Inflation-Protected Security Prices," Journal of Financial and Quantitative Analysis, Vol. 53, No. 1, 243-268.

De Pooter, Michiel, Patrice Robitaille, Ian Walker, and Michael Zdinak, 2014, "Are LongTerm Inflation Expectations Well Anchored in Brazil, Chile, and Mexico?," International Journal of Central Banking, Vol. 10, No. 2, 337-400.

Duffee, Gregory R., 2002, "Term Premia and Interest Rate Forecasts in Affine Models," Journal of Finance, Vol. 57, No. 1, 405-443.

Espada, Josué Fernando Cortés, Manuel Ramos-Francia, and Alberto Torres García, 2008, "An Empirical Analysis of the Mexican Term Structure of Interest Rates," Working paper 2008-07, Bank of Mexico.

Fleckenstein, Mathias, Francis A. Longstaff, and Hanno Lustig, 2014, "The TIPS-Treasury Bond Puzzle," Journal of Finance, Vol. 69, No. 5, 2151-2197.

Grishchenko, Olesya V. and Jing-Zhi Huang, 2013, "Inflation Risk Premium: Evidence from the TIPS Market," Journal of Fixed Income, Vol. 22, No. 4, 5-30. 
Holston, Kathryn, Thomas Laubach, and John C. Williams, 2017, "Measuring the Natural Rate of Interest: International Trends and Determinants," Journal of International Economics, Vol. 108, 559-575.

Hördahl, Peter and Oreste Tristani, 2012, "Inflation Risk Premia in the Term Structure of Interest rates," Journal of the European Economic Association, Vol. 10, No. 3, 634-657.

Hördahl, Peter and Oreste Tristani, 2014, "Inflation Risk Premia in the Euro Area and the United States," International Journal of Central Banking, Vol. 10, No. 3, 1-47.

Houweling, Patrick, Albert Mentink, and Ton Vorst, 2005, "Comparing Possible Proxies of Corporate Bond Liquidity," Journal of Banking and Finance, Vol. 29, 1331-1358.

Hu, Grace Xing, Jun Pan, and Jiang Wang, 2013, "Noise as Information for Illiquidity," Journal of Finance, Vol. 68, No. 6, 2341-2382.

Joyce, Michael, Peter Lildholdt, and S. Sörensen, 2010, "Extracting Inflation Expectations and Inflation Risk Premia from the Term Structure: A Joint Model of the UK Nominal and Real Yield Curves," Journal of Banking and Finance, Vol. 34, 281-294.

Kim, Don H. and Athanasios Orphanides, 2012, "Term Structure Estimation with Survey Data on Interest Rate Forecasts," Journal of Financial and Quantitative Analysis, Vol. 47, No. 1, 241-272.

Kim, Don H. and Kenneth J. Singleton, 2012, "Term Structure Models and the Zero Bound: An Empirical Investigation of Japanese Yields," Journal of Econometrics, Vol. 170, No. $1,32-49$.

Nagel, Stefan, 2016, "The Liquidity Premium of Near-Money Assets," Quarterly Journal of Economics, Vol. 131, No. 4, 1927-1971.

Nelson, Charles R. and Andrew F. Siegel, 1987, "Parsimonious Modeling of Yield Curves," Journal of Business, Vol. 60, No. 4, 473-489.

Rudebusch, Glenn D. and Eric Swanson, 2012, "The Bond Premium in a DSGE Model with Long-Run Real and Nominal Risks," American Economic Journals: Macroeconomics, Vol. 4, No. 1, 105-143.

Sack, Brian and Robert Elsasser, 2004, "Treasury Inflation-Indexed Debt: A Review of the U.S. Experience," Federal Reserve Bank of New York Economic Policy Review, Vol. 10, No. 1, 47-63.

Solís, Pavel, 2020, "Monetary Policy in Mexico: The Effects of Actions and Statements on Asset Prices and Portfolio Flows," Manuscript, Johns Hopkins University. 


\title{
Online Appendix
}

\section{"Inflation Expectations and Risk Premia in Emerging Bond Markets: Evidence from Mexico"}

\author{
Remy Beauregard ${ }^{\dagger}$ \\ Jens H. E. Christensen \\ Eric Fischer* \\ Simon $\mathrm{Zhu}^{\S}$
}

The views in this paper are solely the responsibility of the authors and should not be interpreted as reflecting the views of the Federal Reserve Bank of San Francisco or the Federal Reserve System.

${ }^{\dagger}$ University of California at Davis; e-mail: rebeauregard@ucdavis.edu.

${ }^{\ddagger}$ Corresponding author: Federal Reserve Bank of San Francisco, 101 Market Street MS 1130, San Francisco, CA 94105, USA; phone: 1-415-974-3115; e-mail: jens.christensen@sf.frb.org.

*Federal Reserve Bank of New York; e-mail: eric.fischer@ny.frb.org.

${ }^{\S}$ University of Texas at Austin; e-mail: simonwzhu@gmail.com.

This version: November 8, 2021. 


\section{Contents}

A Analysis of Nominal and Real Bond-Specific Factors 2

B Inflation Forecast Survey Sensitivity Analysis $\quad 6$

C $G^{X^{N}, X^{R}}(7)$ Model Results without Survey Information $\quad 8$

D Bonos Liquidity Premium Comparison to CFS 9

D.1 Replication of CFS Bonos Liquidity Premium Regressions . . . . . . . . . . . 10

$\begin{array}{ll}\text { E Liquidity Premium Sensitivity to Factor Structure } & 13\end{array}$

E.1 Bonos Liquidity Premia . . . . . . . . . . . . . . . . . . . . 13

E.2 Udibonos Liquidity Premia . . . . . . . . . . . . . . . . . . 17

$\begin{array}{lll}\text { F Udibonos Liquidity Premium Regressions } & 19\end{array}$

G On-The-Run Liquidity Premia in the Bonos Market $\quad 21$

G.1 On-The-Run Bid-Ask Spreads in the Bonos Market . . . . . . . . . . . . . . . 23

H Comparison of Bonos Term Premia 23

I Determinants of Term Risk Premia $\quad 25$ 


\section{A Analysis of Nominal and Real Bond-Specific Factors}

Motivated by the evidence in Section 2 of the paper, the dynamic term structure model we use in the empirical analysis assumes that both nominal and real bond prices contain liquidity premia that investors demand to assume their liquidity risk. In this appendix, we aim to build further support for that assumption. In doing so, we follow D'Amico et al. (2018, henceforth DKW), who note that, in a world without any financial market frictions, nominal yields $y_{t}^{N}$ must be the sum of the matching real yield $y_{t}^{R}$, expected inflation $\pi_{t}^{e}$, and the inflation risk premium $\phi_{t}$ :

$$
y_{t}^{N}(\tau)=y_{t}^{R}(\tau)+\pi_{t}^{e}(\tau)+\phi_{t}(\tau)
$$

Furthermore, the frictionless real yield is the sum of the neutral or natural real rate $r_{t}^{*}$ and a real term premium:

$$
y_{t}^{R}(\tau)=r_{t}^{*}+T P_{t}^{R}(\tau)
$$

In turn, the frictionless BEI that would prevail in a world without any financial frictions is then given by

$$
B E I \equiv y_{t}^{N}(\tau)-y_{t}^{R}(\tau)=\pi_{t}^{e}(\tau)+\phi_{t}(\tau)
$$

Comparing equations (1) and (2) motivates DKW to regress BEI on the first three principal components (PC) of nominal yields, which normally explain more than 99 percent of the nominal yield variation. If there are no priced frictions or other deviations from the law of one price in the data, this could be expected to yield high $R^{2} \mathrm{~s}$, in particular if the frictionless real yields $y_{t}^{R}$ have stationary dynamics (this is a big if, as we will explain below).

As for the observed nominal and real yields, denoted $\bar{y}_{t}^{N}$ and $\bar{y}_{t}^{R}$, respectively, they may each contain unobserved liquidity premia, denoted $\eta_{t}^{N}$ and $\eta_{t}^{R}$, respectively. Hence, we have the following relationships to the frictionless yields discussed above:

$$
\begin{aligned}
& \bar{y}_{t}^{N}(\tau)=y_{t}^{N}(\tau)+\eta_{t}^{N}(\tau), \\
& \bar{y}_{t}^{R}(\tau)=y_{t}^{R}(\tau)+\eta_{t}^{R}(\tau) .
\end{aligned}
$$

This implies that the observed nominal yield can be written as

$$
\bar{y}_{t}^{N}(\tau)=r_{t}^{*}+T P_{t}^{R}(\tau)+\pi_{t}^{e}(\tau)+\phi_{t}(\tau)+\eta_{t}^{N}(\tau),
$$


while the observed BEI becomes

$$
\overline{B E I}_{t}(\tau) \equiv \bar{y}_{t}^{N}(\tau)-\bar{y}_{t}^{R}(\tau)=\pi_{t}^{e}(\tau)+\phi_{t}(\tau)+\eta_{t}^{N}(\tau)-\eta_{t}^{R}(\tau)
$$

Returning to DKW's proposed regression, it is now clear that, provided $\eta_{t}^{N}(\tau)-\eta_{t}^{R}(\tau) \approx 0$ and $r_{t}^{*}$ and $T P_{t}^{R}(\tau)$ are stationary, it will be the case that observed $\overline{B E I}$ regressed on the first three PCs of nominal yields should generate fairly large $R^{2}$ s. On the other hand, if either of these two assumptions are not met, we are likely to see fairly low $R^{2}$, which then suggests that either (a) the frictionless real yields contain some trending component; or (b) nominal and/or real yields contain some sizable persistent priced frictions or liquidity premia that prevent the condition $\eta_{t}^{N}(\tau)-\eta_{t}^{R}(\tau) \approx 0$ from being satisfied.

DKW study U.S. Treasury and TIPS data, where it is reasonable to assume that, indeed, $\eta_{t}^{N}(\tau) \approx 0$. Also, they implicitly assume that there are no trends in TIPS yields, although that may be a questionable assumption given that evidence provided in Laubach and Williams (2016) and Christensen and Rudebusch (2019), among many others, points to a long-term secular decline in the natural real rate in the United States. As a consequence, when they obtain really low $R^{2} \mathrm{~s}$ in their regressions, DKW conclude that TIPS yields contain a significant liquidity premium $\eta_{t}^{R}$.

For our Mexican data, we first estimate arbitrage-free Nelson-Siegel (AFNS) models from Christensen et al. (2011) for the Mexican bonos and udibonos prices separately. This gives us fitted nominal and real yield curves at all relevant maturities, which are then used to calculate the corresponding fitted BEI rates. We then regress those fitted BEI rates on the three filtered state variables from the AFNS model estimation based on our sample of Mexican bonos prices, which serve as our equivalent of the first three principal components of nominal yields in the analysis of DKW:

$$
\widehat{B E I}_{t}(\tau)=\alpha^{\tau}+\beta_{L}^{\tau} \widehat{L}_{t}+\beta_{S}^{\tau} \widehat{S}_{t}+\beta_{C}^{\tau} \widehat{C}_{t}+\varepsilon_{t}^{\tau}
$$

The results at four maturities from two to ten years are reported in Table 1. The level and slope factors in the AFNS model are highly statistically significant across all considered maturities and have very stable coefficients. As for the curvature factor, its loading is insignificant at shorter maturities, but highly statistically significant at medium- and long-term maturities. This is consistent with its hump-shaped loading structure across maturities.

Despite this very stable and significant pattern in the regression coefficients of the three 


\begin{tabular}{|c|c|c|c|c|}
\hline \multirow{2}{*}{ Coef. } & \multicolumn{4}{|c|}{ BEI } \\
\cline { 2 - 5 } & $\tau=2$ & $\tau=5$ & $\tau=7$ & $\tau=10$ \\
\hline$\alpha$ & 0.01 & 0.01 & 0.00 & 0.00 \\
& $(0.01)$ & $(0.00)$ & $(0.00)$ & $(0.00)$ \\
$\beta_{L}$ & $0.34^{* *}$ & $0.40^{* *}$ & $0.43^{* *}$ & $0.46^{* *}$ \\
& $(0.06)$ & $(0.06)$ & $(0.06)$ & $(0.06)$ \\
$\beta_{S}$ & $0.13^{* *}$ & $0.14^{* *}$ & $0.13^{* *}$ & $0.13^{* *}$ \\
& $(0.03)$ & $(0.02)$ & $(0.02)$ & $(0.02)$ \\
$\beta_{C}$ & 0.03 & $0.06^{* *}$ & $0.07^{* *}$ & $0.07^{* *}$ \\
& $(0.02)$ & $(0.02)$ & $(0.02)$ & $(0.02)$ \\
\hline$R^{2}$ & 0.40 & 0.52 & 0.58 & 0.66 \\
\hline
\end{tabular}

Table 1: Breakeven Inflation Regressions

The table reports the results of regressions with breakeven inflation as the dependent variable and the estimated level, slope, and curvature factors from an AFNS model of nominal bonos prices. Standard errors computed by the Newey-West estimator (with three lags) are reported in parentheses. Asterisks $*$ and $* *$ indicate significance at the 5 percent and 1 percent levels, respectively.

factors, the obtained $R^{2}$ values fall in the range from 0.40 to 0.66 and decline as the maturity shortens. DKW interpret this kind of pattern as evidence of the existence of liquidity premia in the underlying bond yields. In our case, we think a similar interpretation applies. First, in our Mexican data, the udibonos real yields do not appear to have a trend. Hence, when we get $R^{2}$ s ranging from 0.40 to 0.66 , it is most likely caused by $\eta_{t}^{N}(\tau)-\eta_{t}^{R}(\tau) \approx 0$ not being satisfied. Second, the decline in $R^{2}$ as maturity is shortened is consistent with a liquidity premium interpretation given that yields at shorter maturities in our data primarily reflect the prices of seasoned bonds that have been outstanding for many years. As a consequence, shorter-term BEI rates are likely to be more biased by liquidity premia than the ten-year sector where a majority of the bond issuance has taken place historically. To summarize, building on the findings of DKW for the large U.S. TIPS market, where they find sizable liquidity premia, our regression results imply the existence of large and time-varying liquidity premia in the much smaller market for udibonos.

To provide evidence of the existence of important liquidity premia in Mexican bonos (beyond that provided in Christensen et al. (2021) as discussed in the paper), we again follow DKW. For U.S. data, they document that TIPS BEI tends to be below the inflation forecasts reported in surveys of both consumers and professional forecasters. Furthermore, as demonstrated by DKW, this is due to the existence of large positive liquidity premia in TIPS yields in combination with small and negligible liquidity premia in Treasury yields.

To repeat this exercise in our setting, Figure 1 compares the ten-year fitted BEI considered earlier with the ten-year CPI inflation forecasts that can be constructed from the long-term 


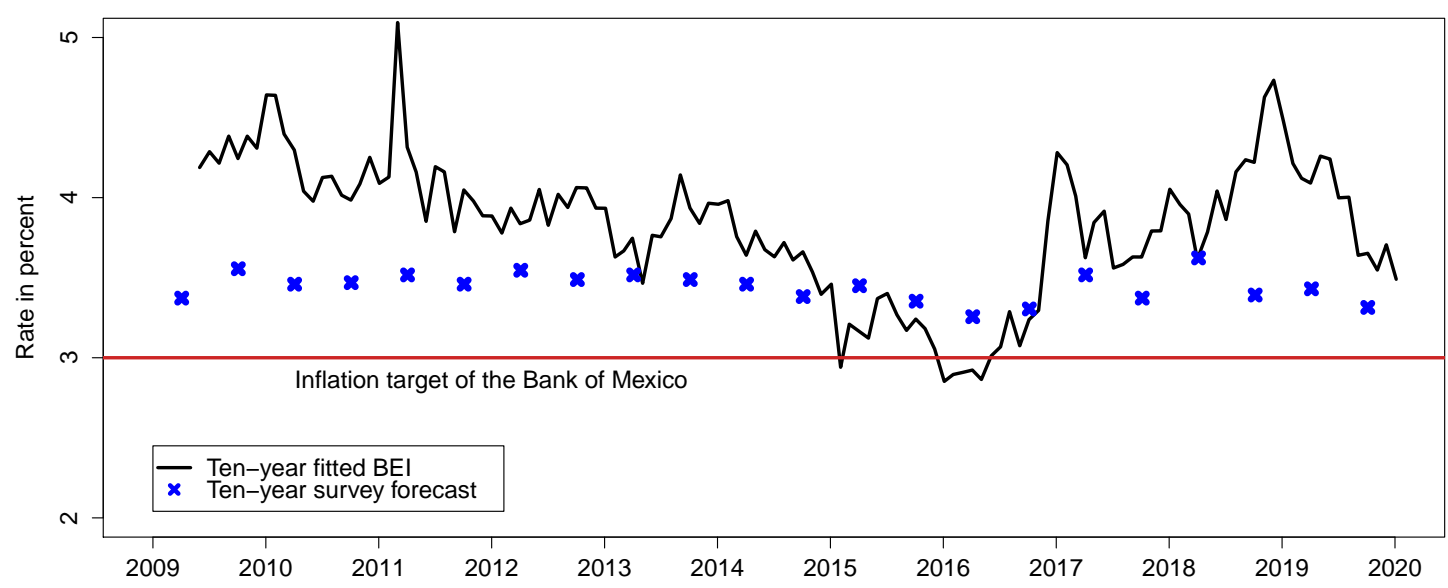

Figure 1: Survey Inflation Forecasts and Fitted BEI

Illustration of the ten-year fitted BEI obtained by fitting an AFNS model to Mexican bonos and udibonos prices separately. Also shown are the ten-year inflation forecasts from the semiannual Consensus Forecasts survey of professional forecasters tracking the Mexican economy.

economic forecasts reported semiannually in the Consensus Forecasts surveys of professional forecasters tracking the Mexican economy.

In the Mexican data, we see the opposite pattern of DKW whereby BEI tends to be above the survey forecasts of inflation. This leaves the possibility that there could be large liquidity premia in nominal bonos yields that more than offset the negative effects from the liquidity premia in the udibonos prices. Alternatively, this could be a sign that there are large positive and time-varying inflation risk premia in bonos prices.

As in DKW, we explore this further by correlating the difference between the ten-year fitted BEI and the ten-year survey inflation forecasts with measures of the priced frictions in the bonos market. It turns out that the difference is weakly positively correlated with the average bonos bid-ask spread in our sample $(17 \%)$ and with the mean absolute fitted errors of the bonos prices from the AFNS model estimation used in the construction of the fitted BEI $(19 \%){ }^{1}$ The small number of observations (21) prevents us from further substantiating this result. However, similar to DKW, we take this as weak evidence of the existence of liquidity premia in the bonos prices, even though we note that this variation could equally well reflect changes in inflation risk premia independent of the bonos and udibonos liquidity premia. ${ }^{2}$

\footnotetext{
${ }^{1}$ This is a noise measure of arbitrage capital frictions similar to the one developed in $\mathrm{Hu}$ et al. (2013).

${ }^{2}$ Hördahl and Tristani (2012) report a similar pattern for euro-area BEI rates and tie it to positive inflation risk premia.
} 
Finally, we stress that it is a key purpose of the empirical analysis in the paper to quantify the relative magnitudes of these three different types of risk premia in the pricing of bonos and udibonos and what they imply about bond investors' underlying inflation expectations.

\section{B Inflation Forecast Survey Sensitivity Analysis}

In this appendix, we examine the sensitivity of our estimation results to two key assumptions in the model estimation. In the first set of robustness exercises, we change the assumption about the standard deviation of the measurement errors for the model-implied inflation forecasts, while in the other set of exercises we vary the horizon and number of survey inflation forecasts used in the model estimation. To map the exercise to the analysis in the paper, we only show results for long-term inflation expectations covering a five-year period starting five years ahead, labeled 5yr5yr expected inflation. Moreover, we stress up front that the benchmark model implementation uses all available survey inflation forecasts in the model estimation.

Figure 2 shows the 5yr5yr model-implied expected inflation from changing the assumption made about the standard deviation of the measurement error of the survey inflation forecasts used in our benchmark model implementation. We vary this value from 0.0025 to 0.01 in 0.0025 increments, with 0.0075 being our benchmark as recommended by DKW. In addition, in a separate estimation, we leave it as a free parameter to be determined by the data, which yields a value of 0.0016 . We note that the model-implied 5yr5yr inflation expectations have little sensitivity to this choice unless the measurement error standard deviation is really low, in which case the model-implied long-term inflation expectations become almost as smooth as those reported in the surveys. Based on these observations we choose to proceed with our benchmark fixed value of 0.0075 for the standard deviation of the survey forecast measurement errors throughout the paper and in this analysis.

Next, we examine the sensitivity of the model-implied long-term inflation expectations to the specific survey inflation forecasts used in the model estimation. We assess this by studying output from five different model estimations. One is our benchmark estimation using all available inflation survey forecasts, while the four other results only use one of the inflation forecast survey series in the model estimation, namely monthly data on inflation forecasts for the following full calendar, semiannual data on five-year inflation forecasts, semiannual data on ten-year inflation forecasts, and semiannual data on 5yr5yr inflation forecasts, respectively. Figure 3 shows the 5yr5yr model-implied expected inflation from these five different 


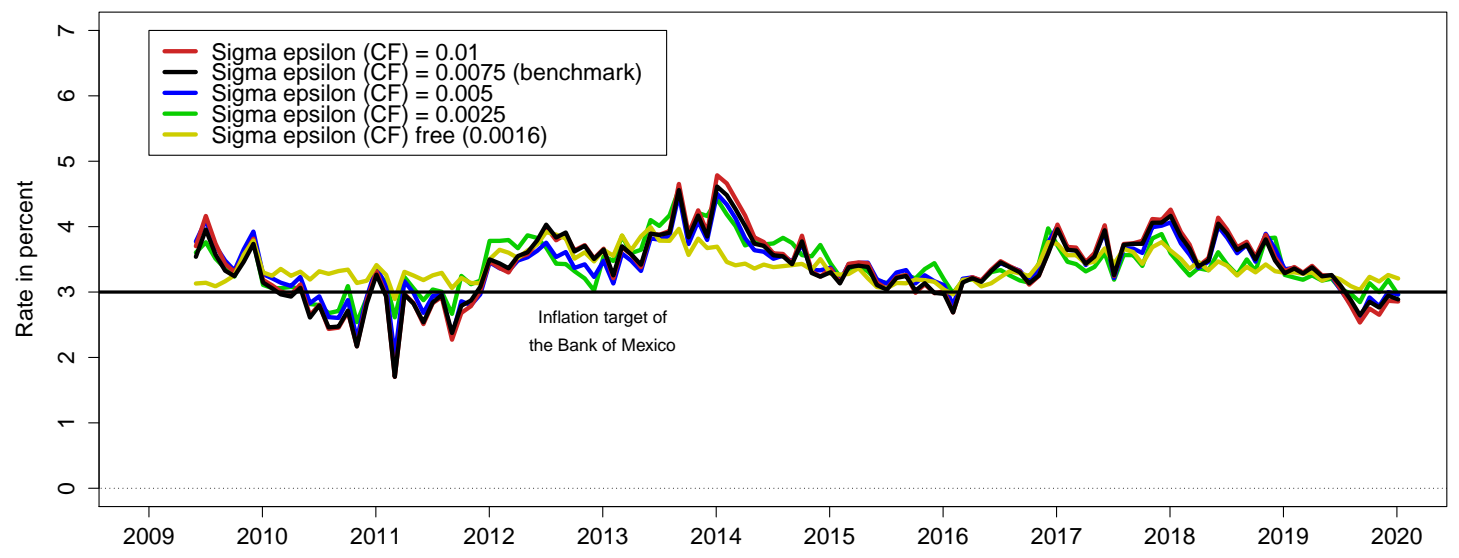

Figure 2: Sensitivity of 5yr5yr Model-Implied Expected Inflation to $\sigma_{\varepsilon}^{C F}$

Illustration of the 5yr5yr expected inflation implied by the $G^{X^{N}, X^{R}}(7)$ model estimated with five different assumptions about the standard deviation of the measurement error of the observed survey inflation forecasts: (1) fixed 0.01; (2) fixed 0.0075, which is our benchmark model implementation; (3) fixed 0.005 ; (4) fixed 0.0025 ; (5) leave $\sigma_{\varepsilon}^{C F}$ as a free parameter to be determined by the model estimation, which produces a value of 0.0016 . The shown data cover the period from May 31, 2009, to December 30, 2019.

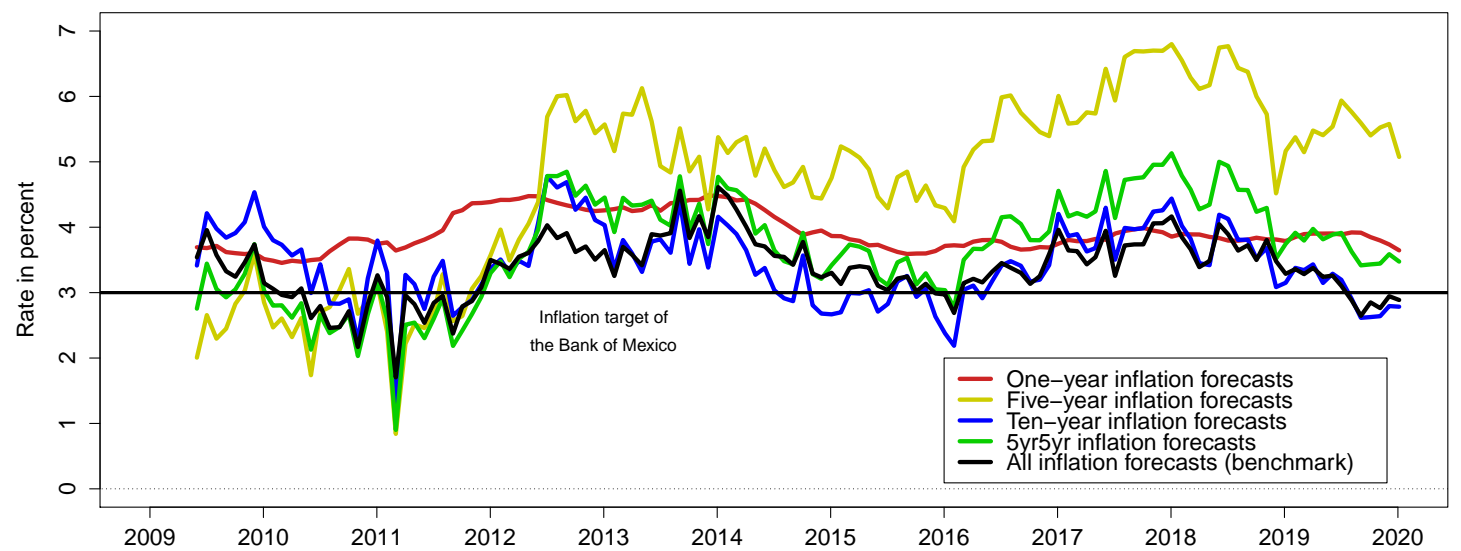

Figure 3: Sensitivity of 5yr5yr Model-Implied Expected Inflation to Survey Inflation Forecasts

Illustration of the 5yr5yr expected inflation implied by the $G^{X^{N}, X^{R}}(7)$ model estimated with four types of survey inflation forecasts: (1) the following calendar year; (2) the next five years; (3) five-year forecasts five years ahead; (4) the next ten years, which is our benchmark implementation. The shown data cover the period from May 31, 2009, to December 30, 2019. 
estimations. We note that using the monthly inflation forecasts for the coming calendar year produces very smooth and rather stable model-implied long-term inflation expectations, while using the semiannual five-year inflation forecasts gives rise to higher and very volatile model-implied inflation expectations, including long-term 5yr5yr inflation forecasts. In contrast, using semiannual ten-year or 5yr5yr inflation forecasts or all survey inflation forecasts as in our benchmark implementation produces very similar and more stable model-implied long-term inflation expectations. Overall, we consider our benchmark implementation using all available survey inflation forecasts to be representative given that its estimate consistently falls in the range of estimates produced by these four alternative model implementations.

Furthermore, unreported results show that the estimated state variables are essentially indistinguishable across all five model estimations. In addition, their estimated $\mathbb{Q}$-dynamics are also practically identical. Thus, the source of the differences in the model-implied inflation expectations can be traced back to differences in the estimated real-world $\mathbb{P}$-dynamics.

In summary, the provided evidence suggests that the model-implied inflation expectations are not overly sensitive to the assumption made about the distribution of the fitted errors of the inflation forecasts. In contrast, greater dispersion is observed depending on the specific inflation forecast horizon used. Given that we have no reason to put more weight on any particular forecast horizon we simply include all available inflation forecasts in our benchmark implementation.

\section{C $G^{X^{N}, X^{R}}(7)$ Model Results without Survey Information}

In this appendix, we assess the sensitivity of our estimation results to the exclusion of the survey inflation forecasts in the model estimation.

Figure 4 shows the decomposition of 5yr5yr BEI implied by the $G^{X^{N}, X^{R}}(7)$ model when estimated without any inflation expectations from the Consensus Forecasts surveys of professional forecasters. As established in Appendix B, with survey information included, the $G^{X^{N}, X^{R}}(7)$ model is able to provide a close fit to the survey inflation forecasts. In contrast, when we estimate the model without the survey inflation forecasts, the model-implied inflation expectations appear to be unreasonably volatile switching from almost 5 percent to below zero in less than one year and do the reverse a couple of years later. This supports our choice to focus on the $G^{X^{N}, X^{R}}(7)$ model estimated with the survey inflation forecasts in the paper. 


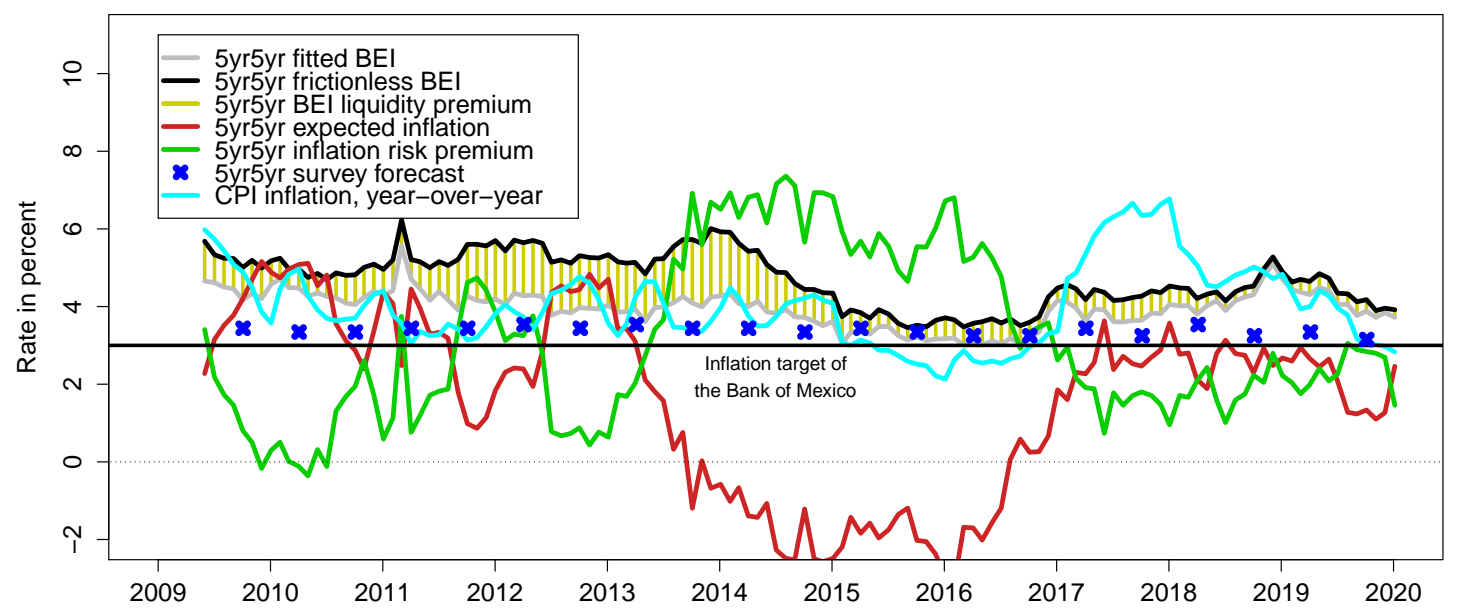

Figure 4: Decomposition of 5yr5yr BEI: No Survey Information

Illustration of the fitted 5yr5yr BEI obtained by fitting an AFNS model to Mexican bonos and udibonos prices separately and its decomposition based on the $G^{X^{N}, X^{R}}(7)$ model estimated with an unrestricted specification of $K^{\mathbb{P}}$ and a diagonal specification of $\Sigma$ and without any survey information into: (1) the estimated frictionless BEI, (2) expected inflation, and (3) the residual inflation risk premium. The difference between the fitted and frictionless 5yr5yr BEI is highlighted in yellow and represents the net liquidity premium of the observed 5yr5yr BEI. The shown data cover the period from May 31, 2009, to December 30, 2019.

\section{Bonos Liquidity Premium Comparison to CFS}

As a robustness check and to ensure that our results are consistent with those reported by Christensen et al. (2021, henceforth CFS), we estimate the liquidity-adjusted AFNS model, denoted the $G^{X^{N}}(4)$ model in the terminology of our paper, used by CFS for four different samples of Mexican bonos prices. The first sample is the original sample of 21 bonos prices covering the period from June 30, 2010, to December 30, 2017, considered by CFS. The second sample is a simple extension of the CFS sample with data extended back in time to January 31, 2007, and forward in time to December 31, 2019. The third sample represents an expansion of the second sample by including all new bonos issued since 2017, that is, a straightforward minimalist expansion of the CFS sample. In contrast, the fourth and final sample represents a comprehensive expansion of the second sample by including all available bonos since 2007 (accessed through Bloomberg as of January 2020), and this is the sample of bonos prices we analyze in the paper and henceforth refer to as the BCFZ sample.

The resulting average estimated bonos liquidity premium series are shown in Figure 5, including the estimate produced by the joint model of nominal and real bond prices examined 


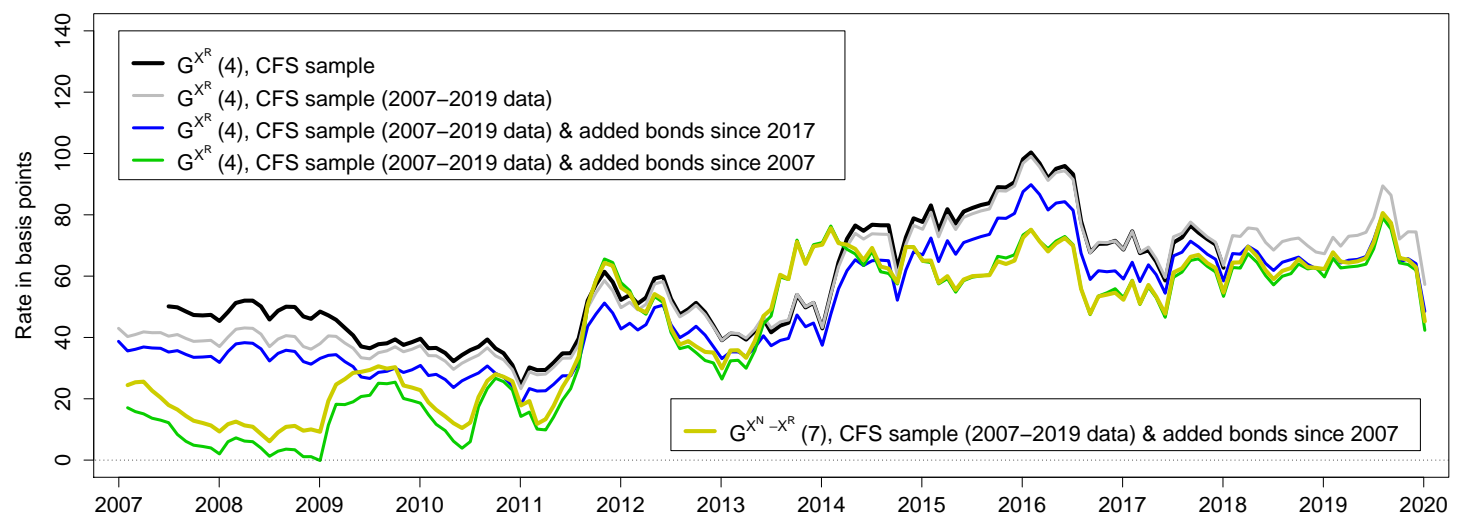

Figure 5: Average Estimated Liquidity Premium of Mexican Bonos

Illustration of the average estimated liquidity premium of Mexican bonos for each observation date implied by the $G^{X^{N}}$ (4) model considered in Christensen et al. (2021, henceforth CFS), each estimated with a diagonal specification of $K^{P}$ and $\Sigma$. The Mexican bonos liquidity premiums are measured as the estimated yield difference between the fitted yield to maturity of individual Mexican bonos and the corresponding frictionless yield to maturity with the liquidity risk factor turned off. Four different data samples are considered: (1) The original sample used in CFS with prices for 21 bonos covering the period from May 31, 2007 to December 30, 2017; (2) a simple extension of the CFS sample with data from January 31, 2007 to December 31, 2019; (3) an expansion of the data sample under (2) with additional bonos since 2017; (4) an expansion of the data sample under (2) with all available bonos since 2007 (accessed through Bloomberg as of January 2020).

in the paper and denoted the the $G^{X^{N}, X^{R}}(7)$ model. We note that the first three samples produce very similar results, while the fourth sample leads to a slightly different series. However, they are all highly positively correlated and qualitatively very similar, specifically the correlation between the estimates from the second and fourth sample is $88 \%$. Finally, the estimated produced by the $G^{X^{N}}(4)$ and $G^{X^{N}, X^{R}}(7)$ models using our BCFZ sample are barely distinguishable. Thus, the estimated bonos liquidity premia obtained with our $G^{X^{N}, X^{R}}(7)$ model are fully consistent with those reported by CFS once the changes in the sample of bonos used in the model estimation are accounted for.

\section{D.1 Replication of CFS Bonos Liquidity Premium Regressions}

In this appendix, we explore the determinants of the estimated liquidity premiums embedded in the bonos prices. Specifically, we repeat the regressions performed by CFS, who used a total of sixteen different variables to explain the variation in their average estimated bonos liquidity premium shown with a solid black line in Figure 5. Here, we therefore use the average bonos liquidity premium estimated with our $G^{X^{N}, X^{R}}(7)$ model using the BCFZ sample and 
shown with a solid yellow line in Figure 5 as the dependent variable and regress it on the expanded sample of the same sixteen variables considered by CFS.

Table 2 contains the results of the regressions and reported in a format identical to CFS. First, the adjusted $R^{2}$ is maintained close to the original $74 \%$ versus $81 \%$ on the expanded sample. Thus, the explanatory power is slightly increased for the expanded bonos sample we consider in this paper. Second and more importantly, the coefficient on the foreign share remains statistically significant in the core benchmark regression (1) as well as individually, while it loses its significance, but maintains its positive value once the one-month cetes rate is included in the regressions. Thus, we view the updated results to be consistent with the conclusions reached by CFS regarding the connection between our estimated bonos liquidity premium series and the foreign share held of those securities. Hence, a tight positive connection between these two variables remains in place based on our expanded sample. Furthermore, the negative sign on the one-month cetes rate, which is only statistically significant when we exclude the foreign share as an explanatory variable, contrasts with the positive sign found by Nagel (2016), as also noted by CFS. This suggests that the longer-term bonos in our sample are far from money-like in the sense discussed in Nagel (2016), and their liquidity premiums therefore have different dynamics with respect to the level of Mexican short-term interest rates. ${ }^{3}$ Finally, we note that the list of control variables remains relevant for our expanded sample given the high adjusted $R^{2}$ produced by the regression in the third column of the table.

To summarize, the regression results reveal that the increase in the share of foreign holdings of Mexican bonos is significantly positively correlated with the change in the bonos liquidity premiums, both on its own and after including our control variables. In terms of magnitudes, the results imply that a 1 percentage point increase in the foreign share raises the liquidity premium by about 0.01 percent or 1 basis point. Given that the foreign market share has increased by more than 40 percentage points between 2010 and 2017 as shown by CFS, our results suggest that the large increase in foreign holdings during our sample period has played a significant role for the upward trend in the liquidity premia in the Mexican bonos market since then and raised them by as much as 0.4 percent.

\footnotetext{
${ }^{3}$ Alternatively, it may be that the true relationship is similar to the one described in Nagel (2016), but we simply happen to consider a sample that is too short to detect the required persistent long-term positive connection between bonos liquidity premiums and the level of Mexican short-term interest rates.
} 


\begin{tabular}{|c|c|c|c|c|c|c|}
\hline \multirow{2}{*}{ Explanatory variables } & \multirow{2}{*}{$(1)$} & \multirow{2}{*}{$(2)$} & \multirow{2}{*}{$(3)$} & \multirow{2}{*}{$(4)$} & \multicolumn{2}{|c|}{ "Individual regressions } \\
\hline & & & & & $\widehat{\beta}$ & adj. $R^{2}$ \\
\hline Foreign share of bonos & $\begin{array}{l}0.89^{* *} \\
(0.23)\end{array}$ & & $\begin{array}{c}0.66 \\
(0.35)\end{array}$ & & $\begin{array}{l}1.14^{* *} \\
(0.08)\end{array}$ & 0.77 \\
\hline Peso/USD exchange rate & $\begin{array}{l}-3.24 \\
(2.32)\end{array}$ & $\begin{array}{l}-2.98 \\
(2.45)\end{array}$ & $\begin{array}{c}-1.67 \\
(2.21)\end{array}$ & $\begin{array}{l}-2.17 \\
(2.31)\end{array}$ & $\begin{array}{l}4.84^{* *} \\
(0.59)\end{array}$ & 0.48 \\
\hline EMBI & $\begin{array}{c}0.03 \\
(0.02)\end{array}$ & $\begin{array}{c}0.02 \\
(0.02)\end{array}$ & $\begin{array}{l}0.14^{* *} \\
(0.05)\end{array}$ & $\begin{array}{l}0.15^{* *} \\
(0.05)\end{array}$ & $\begin{array}{c}0.03 \\
(0.05)\end{array}$ & 0.02 \\
\hline WTI & $\begin{array}{l}-0.05 \\
(0.11)\end{array}$ & $\begin{array}{c}0.05 \\
(0.12)\end{array}$ & $\begin{array}{l}-0.02 \\
(0.10)\end{array}$ & $\begin{array}{l}-0.01 \\
(0.09)\end{array}$ & $\begin{array}{c}-0.37^{* *} \\
(0.13)\end{array}$ & 0.14 \\
\hline CPI Inflation & $\begin{array}{l}-2.36 \\
(1.26)\end{array}$ & $\begin{array}{c}-2.37^{*} \\
(1.16)\end{array}$ & $\begin{array}{l}-1.67 \\
(1.39)\end{array}$ & $\begin{array}{l}-0.40 \\
(1.40)\end{array}$ & $\begin{array}{l}-4.89 \\
(2.98)\end{array}$ & 0.05 \\
\hline Debt-to-GDP ratio & $\begin{array}{c}1.72 \\
(0.91)\end{array}$ & $\begin{array}{l}3.06^{* *} \\
(0.93)\end{array}$ & $\begin{array}{c}1.85 \\
(1.37)\end{array}$ & $\begin{array}{c}1.91 \\
(1.51)\end{array}$ & $\begin{array}{l}2.14^{* *} \\
(0.14)\end{array}$ & 0.71 \\
\hline Bonos bid-ask spread & $\begin{array}{c}1.06 \\
(1.42)\end{array}$ & $\begin{array}{l}-0.90 \\
(2.06)\end{array}$ & $\begin{array}{c}0.84 \\
(1.40)\end{array}$ & $\begin{array}{c}0.75 \\
(1.65)\end{array}$ & $\begin{array}{l}-3.72 \\
(4.88)\end{array}$ & 0.01 \\
\hline One-month cetes rate & $\begin{array}{c}1.66 \\
(1.73)\end{array}$ & $\begin{array}{c}1.97 \\
(1.60)\end{array}$ & $\begin{array}{c}2.33 \\
(2.48)\end{array}$ & $\begin{array}{c}0.69 \\
(2.50)\end{array}$ & $\begin{array}{l}-2.69 \\
(1.96)\end{array}$ & 0.04 \\
\hline Ten-year US Treasury yield & $\begin{array}{c}2.94 \\
(3.06)\end{array}$ & $\begin{array}{l}-1.27 \\
(2.95)\end{array}$ & $\begin{array}{c}3.66 \\
(2.84)\end{array}$ & $\begin{array}{l}1.96 \\
(2.77)\end{array}$ & $\begin{array}{c}-17.18^{* *} \\
(2.40)\end{array}$ & 0.44 \\
\hline Avg. bonos age & & & $\begin{array}{c}-3.56 \\
(5.63)\end{array}$ & $\begin{array}{c}0.69 \\
(5.35)\end{array}$ & $\begin{array}{l}9.57^{* *} \\
(0.79)\end{array}$ & 0.65 \\
\hline One-month bonos yield vol. & & & $\begin{array}{c}0.11 \\
(0.14)\end{array}$ & $\begin{array}{c}0.17 \\
(0.15)\end{array}$ & $\begin{array}{l}-0.13 \\
(0.19)\end{array}$ & 0.00 \\
\hline Bonos noise measure & & & $\begin{array}{l}-0.20 \\
(0.87)\end{array}$ & $\begin{array}{l}-0.47 \\
(0.94)\end{array}$ & $\begin{array}{c}0.34 \\
(1.26)\end{array}$ & -0.00 \\
\hline CDS rate & & & $\begin{array}{c}-0.14 \\
(0.09)\end{array}$ & $\begin{array}{l}-0.12 \\
(0.09)\end{array}$ & $\begin{array}{l}-0.03 \\
(0.05)\end{array}$ & -0.00 \\
\hline MSCI one-month return & & & $\begin{array}{c}0.07 \\
(0.15)\end{array}$ & $\begin{array}{l}-0.01 \\
(0.16)\end{array}$ & $\begin{array}{l}-0.04 \\
(0.33)\end{array}$ & -0.01 \\
\hline VIX & & & $\begin{array}{l}-0.03 \\
(0.38)\end{array}$ & $\begin{array}{c}-0.39 \\
(0.41)\end{array}$ & $\begin{array}{c}-1.23^{* *} \\
(0.22)\end{array}$ & 0.22 \\
\hline OTR premium & & & $\begin{array}{l}-0.37 \\
(0.27)\end{array}$ & $\begin{array}{c}-0.65^{* *} \\
(0.22)\end{array}$ & $\begin{array}{c}-1.12^{* *} \\
(0.23)\end{array}$ & 0.35 \\
\hline TED spread & & & $\begin{array}{c}-0.06 \\
(0.03)\end{array}$ & $\begin{array}{l}-0.02 \\
(0.03)\end{array}$ & $\begin{array}{c}-0.23^{* *} \\
(0.05)\end{array}$ & 0.23 \\
\hline Intercept & $\begin{array}{l}-36.34 \\
(31.76)\end{array}$ & $\begin{array}{l}-33.73 \\
(24.39)\end{array}$ & $\begin{array}{l}-60.19 \\
(42.42)\end{array}$ & $\begin{array}{l}-37.01 \\
(42.85)\end{array}$ & & \\
\hline Adjusted $R^{2}$ & 0.80 & 0.73 & 0.81 & 0.80 & & \\
\hline
\end{tabular}

Table 2: Regression Results for the Average Bonos Liquidity Premium

The table reports the results of regressions with the average estimated bonos liquidity premium as the dependent variable and 17 explanatory variables. Standard errors computed by the Newey-West estimator (with three lags) are reported in parentheses. Asterisks $*$ and ${ }^{* *}$ indicate significance at the 5 percent and 1 percent levels, respectively. 


\section{E Liquidity Premium Sensitivity to Factor Structure}

In this appendix, we examine how sensitive our estimated bonos and udibonos liquidity premium estimates are to the assumed factor structure of our $G^{X^{N}, X^{R}}(7)$ model.

\section{E.1 Bonos Liquidity Premia}

In this section, we assess the robustness of our estimated bonos liquidity premium series from our $G^{X^{N}, X^{R}}(7)$ model to the assumed structure of the nominal factors in the model.

Up front we note that the nominal factor structure in our $G^{X^{N}, X^{R}}(7)$ model is identical to the AFNS-L model used by CFS and referred to as the $G^{X^{N}}(4)$ model using our notation. As a consequence, we estimate this model using our sample of bonos prices. We also consider the simpler $G^{X^{N}}(3)$ model, which eliminates the curvature factor from the $G^{X^{N}}(4)$ model. Furthermore, we also consider the generalized version of the $G^{X^{N}}(4)$ model in which a second set of slope and curvature factors is included. This makes the frictionless part of the model identical to the arbitrage-free generalized Nelson-Siegel (AFGNS) model described in Christensen et al. (2009). Using our notation we refer to this model as the $G^{X^{N}}$ (6) model. Finally, we estimate the $G^{X^{N}, X^{R}}(7)$ model without and with survey information. We add that we implement all these models using both monthly data as in the paper and weekly data. This allows us to also assess the importance of the data frequency used in the model estimations.

The average estimated bonos liquidity premium series from these five model estimations are shown in Figure 6. The results reveal that the $G^{X^{N}}(3)$ model produces estimates, which are somewhat more volatile than those implied by the benchmark $G^{X^{N}}(4)$ model. On the other hand, the average estimated bonos liquidity premium series produced by the more flexible $G^{X^{N}}(6)$ model is highly positively correlated with the estimate from the $G^{X^{N}}(4)$ model. As a consequence, we consider the $G^{X^{N}}(4)$ model used by CFS to strike a reasonable balance between model fit, flexibility, and parsimony. For that reason, we choose to follow CFS and rely on the $G^{X^{N}}$ (4) model structure for the modeling of the Mexican bonos prices and this is built into our $G^{X^{N}, X^{R}}(7)$ model.

In addition, we note that all three models are very competitive in terms of their fit to the bonos prices. The $G^{X^{N}}(3)$ model produces a fit to the bonos prices measured as yield-tomaturity differences of 6.06 basis points for all bonos combined. The corresponding statistics for the $G^{X^{N}}(4)$ and $G^{X^{N}}(6)$ models are 4.14 basis points and 3.55 basis points, respectively, see Table 3 for details. Thus, along this dimension, we again see our choice to rely on the $G^{X^{N}}(4)$ model for our sample of bonos prices as striking a sensible balance between parsimony 


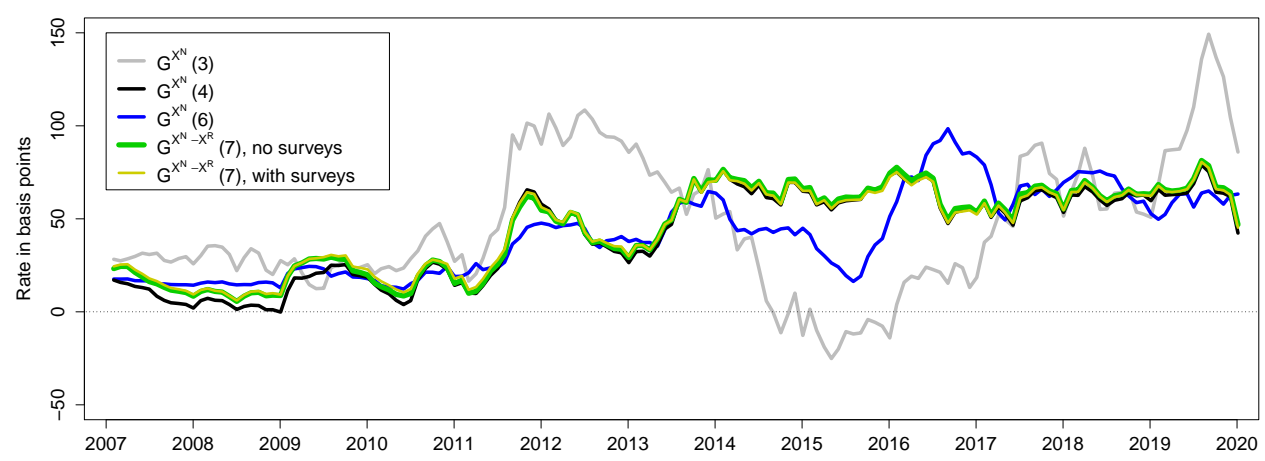

(a) Monthly

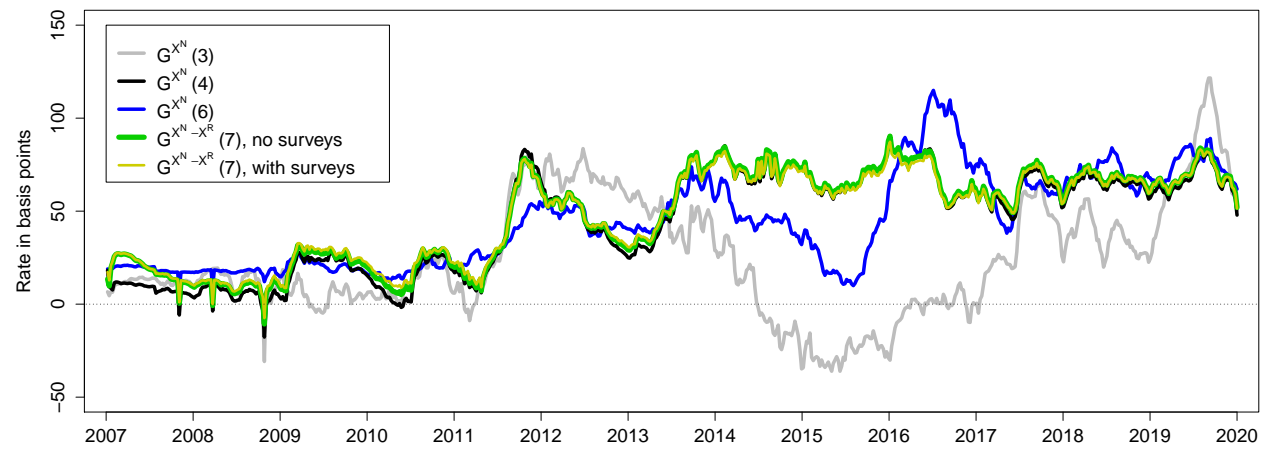

(b) Weekly

Figure 6: Factor Structure Sensitivity of Mexican Bonos Liquidity Premia

Illustration of the average estimated liquidity premium of Mexican bonos for each observation date implied by the $G^{X^{N}}(3), G^{X^{N}}(4)$, and $G^{X^{N}}(6)$ models described in the text and each estimated with a diagonal specification of $K^{\mathbb{P}}$ and $\Sigma$ as well as the $G^{X^{N}, X^{R}}(7)$ model without and with survey information. The Mexican bonos liquidity premiums are measured as the estimated yield difference between the fitted yield to maturity of individual Mexican bonos and the corresponding frictionless yield to maturity with the nominal liquidity risk factor $X_{t}^{N}$ turned off.

and fit.

Table 4 reports the estimated liquidity risk parameters, $\left(\beta^{N, i}, \delta^{N, i}\right)$, for each bonos in our sample. Given the similarity in the estimated average bonos liquidity premium series it is not surprising that these parameters are fairly similar to each other for each bonos across the different model estimations. 


\begin{tabular}{|c|c|c|c|c|c|c|c|c|}
\hline \multirow{2}{*}{ Bonos security } & \multicolumn{2}{|c|}{$G^{X^{N}}(3)$} & \multicolumn{2}{|c|}{$G^{X^{N}}(4)$} & \multicolumn{2}{|c|}{$G^{X^{N}}(6)$} & \multicolumn{2}{|c|}{$G^{X^{N}, X^{R}}(7)$} \\
\hline & Mean & RMSE & Mean & RMSE & Mean & RMSE & Mean & RMSE \\
\hline (1) $9 \% 12 / 20 / 2012^{\dagger}$ & 0.38 & 4.60 & -0.14 & 3.97 & 0.67 & 3.92 & 0.22 & 4.09 \\
\hline (2) $8 \% 12 / 7 / 2023^{+}$ & 0.71 & 5.46 & 0.75 & 4.97 & 0.61 & 3.85 & 0.91 & 5.12 \\
\hline (3) $8 \% 12 / 17 / 2015^{\dagger}$ & -0.50 & 6.83 & 0.46 & 4.22 & 0.19 & 3.28 & 0.32 & 4.16 \\
\hline (4) $10 \% 11 / 20 / 2036^{\times}$ & 1.15 & 4.08 & 1.03 & 3.61 & 0.93 & 2.99 & 0.74 & 3.52 \\
\hline (5) $7.5 \% 6 / 3 / 2027^{+}$ & -0.06 & 4.76 & 0.17 & 4.49 & 0.16 & 4.15 & 1.02 & 4.01 \\
\hline (6) $7.25 \% \quad 12 / 15 / 2016^{\dagger}$ & -1.14 & 6.69 & -0.09 & 3.73 & -0.07 & 3.60 & -0.53 & 4.11 \\
\hline (7) $7.5 \% 6 / 21 / 2012^{*}$ & -0.41 & 5.44 & 0.29 & 4.73 & -0.25 & 3.25 & 0.54 & 4.61 \\
\hline (8) $7.75 \% 12 / 14 / 2017^{\dagger}$ & -3.60 & 8.83 & 0.66 & 5.55 & 0.85 & 4.61 & 0.72 & 5.94 \\
\hline (9) $8.5 \% 5 / 31 / 2029^{+}$ & 0.48 & 3.54 & 0.95 & 3.36 & 0.66 & 2.70 & 0.93 & 3.34 \\
\hline (10) $8.5 \% 11 / 18 / 2038^{\times}$ & 1.38 & 4.44 & 0.57 & 3.26 & 1.15 & 3.53 & 0.96 & 3.41 \\
\hline (11) $8.5 \% 12 / 13 / 2018^{\dagger}$ & 1.33 & 5.20 & -0.34 & 4.09 & -0.01 & 3.58 & -0.42 & 4.07 \\
\hline (12) $6.25 \% 6 / 19 / 2014^{*}$ & 1.80 & 10.40 & 0.13 & 5.40 & -0.18 & 3.96 & -0.32 & 5.32 \\
\hline (13) $8 \% 6 / 11 / 2020^{\dagger}$ & 0.46 & 6.22 & 0.00 & 3.96 & -0.17 & 3.53 & -0.30 & 4.05 \\
\hline (14) $6 \% 6 / 18 / 2015^{*}$ & 6.25 & 10.88 & -0.76 & 4.88 & 0.32 & 4.41 & -0.42 & 4.83 \\
\hline (15) $6.5 \% 6 / 10 / 2021^{\dagger}$ & 1.79 & 5.92 & 0.51 & 3.52 & 0.44 & 3.13 & 0.33 & 3.43 \\
\hline (16) $6.25 \% 6 / 16 / 2016^{*}$ & -1.78 & 10.01 & 0.26 & 5.13 & 0.66 & 4.18 & 0.49 & 5.08 \\
\hline (17) $7.75 \% 5 / 29 / 2031^{+}$ & 0.41 & 3.38 & 0.68 & 3.28 & 0.65 & 2.68 & 0.81 & 3.41 \\
\hline (18) $6.5 \% 6 / 9 / 2022^{\dagger}$ & 2.34 & 6.29 & 0.38 & 3.12 & 0.63 & 3.00 & 0.30 & 3.08 \\
\hline (19) $7.75 \% 11 / 13 / 2042^{\times}$ & 0.54 & 5.13 & 0.50 & 3.19 & 0.65 & 2.98 & 0.70 & 3.25 \\
\hline (20) $5 \% 6 / 15 / 2017^{*}$ & -3.25 & 8.24 & 0.43 & 6.94 & -1.21 & 5.96 & 0.65 & 7.04 \\
\hline (21) $4.75 \% 6 / 14 / 2018^{*}$ & 3.96 & 7.66 & 0.64 & 5.55 & 0.76 & 4.13 & 0.55 & 5.50 \\
\hline (22) $7.75 \% 11 / 23 / 2034^{+}$ & 0.08 & 3.15 & 0.56 & 2.81 & 0.35 & 2.76 & 0.60 & 3.05 \\
\hline (23) $5 \% 12 / 11 / 2019^{*}$ & -1.21 & 5.65 & 0.10 & 3.26 & 0.04 & 2.64 & 0.14 & 3.41 \\
\hline (24) $5.75 \% 3 / 5 / 2026^{\dagger}$ & -1.65 & 5.50 & 0.24 & 3.05 & 0.14 & 2.63 & 0.43 & 2.99 \\
\hline (25) $8 \% 11 / 7 / 2047^{\times}$ & 1.29 & 2.90 & 0.66 & 2.54 & 0.60 & 1.90 & 0.52 & 2.85 \\
\hline (26) $7.25 \% 12 / 9 / 2021$ & 1.06 & 4.65 & 0.58 & 3.42 & 0.26 & 2.70 & 0.40 & 3.50 \\
\hline (27) $8 \% 9 / 5 / 2024^{*}$ & -0.38 & 2.48 & 0.06 & 1.88 & 0.03 & 2.20 & 0.31 & 1.90 \\
\hline (28) $6.75 \% 3 / 9 / 2023$ & 1.22 & 2.59 & 1.33 & 1.61 & 0.25 & 0.91 & 1.38 & 1.78 \\
\hline All bonos yields & 0.40 & 6.06 & 0.40 & 4.14 & 0.40 & 3.55 & 0.45 & 4.18 \\
\hline $\operatorname{Max} \mathcal{L}^{E K F}$ & \multicolumn{2}{|c|}{$12,843.69$} & \multicolumn{2}{|c|}{$13,454.42$} & \multicolumn{2}{|c|}{$13,708.99$} & \multicolumn{2}{|c|}{$19,749.05$} \\
\hline
\end{tabular}

Table 3: Pricing Errors of Bonos

This table reports the mean pricing errors (Mean) and the root mean-squared pricing errors (RMSE) of bonos in the $G^{X^{N}}(3), G^{X^{N}}(4)$, and $G^{X^{N}}(6)$ models, each estimated with a diagonal specification of $K^{\mathbb{P}}$ and $\Sigma$ using monthly data. Also reported are the corresponding statistics from the $G^{X^{N}, X^{R}}(7)$ model estimated as described in the paper. The errors are computed as the difference between the bonos market price expressed as yield to maturity and the corresponding model-implied yield. All errors are reported in basis points. 


\begin{tabular}{|c|c|c|c|c|c|c|c|c|c|c|c|c|c|c|c|c|}
\hline \multirow{2}{*}{ Bonos security } & \multicolumn{4}{|c|}{$G^{X^{N}}(3)$} & \multicolumn{4}{|c|}{$G^{X^{N}}(4)$} & \multicolumn{4}{|c|}{$G^{X^{N}}(6)$} & \multicolumn{4}{|c|}{$G^{X^{N}, X^{R}}(7)$} \\
\hline & $\beta^{N, \imath}$ & SE & $\delta^{N, \imath}$ & $\mathrm{SE}$ & $\beta^{N, \imath}$ & $\mathrm{SE}$ & $\delta^{N, 2}$ & $\mathrm{SE}$ & $\beta^{N, \imath}$ & $\mathrm{SE}$ & $\delta^{N, \imath}$ & $\mathrm{SE}$ & $\beta^{N, 2}$ & $\mathrm{SE}$ & $\delta^{N, \imath}$ & $\mathrm{SE}$ \\
\hline (1) $9 \% \quad 12 / 20 / 2012^{\dagger}$ & 0.99 & 0.24 & 9.07 & 8.01 & 0.67 & 0.10 & 0.34 & 0.07 & 0.16 & 0.12 & 9.27 & 8.87 & 0.64 & 0.15 & 10 & 7.65 \\
\hline (2) $8 \% 12 / 7 / 2023^{+}$ & 0.39 & 0.14 & 0.12 & 0.11 & 11.83 & 1.00 & 0.00 & 0.00 & 18.59 & 1.12 & 0.00 & 0.00 & 11.59 & 1.12 & 0.00 & 0.00 \\
\hline (3) $8 \% 12 / 17 / 2015^{\dagger}$ & 0.53 & 0.11 & 10 & 2.04 & 0.47 & 0.07 & 0.43 & 0.11 & 0.30 & 0.09 & 1.05 & 1.04 & 0.44 & 0.09 & 2.46 & 1.20 \\
\hline (4) $10 \% 11 / 20 / 2036^{\times}$ & 0.88 & 0.06 & 10 & 2.22 & 0.80 & 0.06 & 10 & 0.93 & 0.88 & 0.05 & 10 & 1.17 & 0.81 & 0.08 & 10 & 1.16 \\
\hline (5) $7.5 \% 6 / 3 / 2027^{+}$ & 0.46 & 0.04 & 1.08 & 2.09 & 0.47 & 0.27 & 0.08 & 0.08 & 0.79 & 0.37 & 0.07 & 0.06 & 0.45 & 0.33 & 0.09 & 0.12 \\
\hline (6) $7.25 \% 12 / 15 / 2016^{\dagger}$ & 8.06 & 2.11 & 0.01 & 0.00 & 0.47 & 0.09 & 0.20 & 0.08 & 0.34 & 0.10 & 0.25 & 0.14 & 0.48 & 0.17 & 0.17 & 0.11 \\
\hline (7) $7.5 \% 6 / 21 / 2012^{*}$ & 1.12 & 0.29 & 1.10 & 0.61 & 0.57 & 0.08 & 10 & 0.95 & 0.01 & 0.13 & 9.99 & 1.16 & 0.59 & 0.14 & 10 & 1.19 \\
\hline (8) $7.75 \% 12 / 14 / 2017^{\dagger}$ & 84.64 & 2.22 & 0.00 & 0.00 & 0.32 & 0.05 & 0.59 & 0.25 & 0.30 & 0.07 & 0.47 & 0.23 & 0.31 & 0.07 & 9.99 & 1.20 \\
\hline (9) $8.5 \% 5 / 31 / 2029^{+}$ & 0.56 & 0.05 & 10 & 2.26 & 0.42 & 0.04 & 10 & 1.06 & 0.56 & 0.06 & 10 & 1.20 & 0.41 & 0.06 & 10 & 1.21 \\
\hline (10) $8.5 \% 11 / 18 / 2038^{\times}$ & 1 & n.a. & 0.34 & 0.14 & 1 & n.a. & 0.23 & 0.08 & 1 & n.a. & 0.34 & 0.13 & 1 & n.a. & 0.24 & 0.12 \\
\hline (11) $8.5 \% \quad 12 / 13 / 2018^{\dagger}$ & 79.41 & 2.10 & 0.00 & 0.00 & 30.00 & 0.99 & 0.00 & 0.00 & 35.55 & 1.17 & 0.00 & 0.00 & 26.04 & 1.24 & 0.00 & 0.00 \\
\hline (12) $6.25 \% 6 / 19 / 2014^{*}$ & 57.35 & 2.18 & 0.00 & 0.00 & 0.56 & 0.08 & 4.18 & 0.71 & 0.30 & 0.11 & 9.98 & 1.18 & 0.54 & 0.11 & 9.91 & 1.24 \\
\hline (13) $8 \% 6 / 11 / 2020^{\dagger}$ & 0.34 & 0.06 & 10 & 2.10 & 0.24 & 0.04 & 10 & 1.08 & 0.33 & 0.06 & 10 & 1.13 & 0.24 & 0.06 & 10 & 1.26 \\
\hline (14) $6 \% 6 / 18 / 2015^{*}$ & 0.57 & 0.13 & 10 & 2.23 & 0.52 & 0.07 & 1.05 & 0.42 & 0.32 & 0.09 & 10 & 1.18 & 0.49 & 0.10 & 1.31 & 0.88 \\
\hline (15) $6.5 \% 6 / 10 / 2021^{\dagger}$ & 0.33 & 0.05 & 10 & 2.24 & 0.22 & 0.04 & 10 & 1.09 & 0.34 & 0.06 & 9.07 & 1.22 & 0.22 & 0.06 & 10 & 1.36 \\
\hline (16) $6.25 \% 6 / 16 / 2016^{*}$ & 0.49 & 0.10 & 2.34 & 1.93 & 0.42 & 0.06 & 2.75 & 1.06 & 0.30 & 0.08 & 5.49 & 1.30 & 0.40 & 0.09 & 3.11 & 1.24 \\
\hline (17) $7.75 \% 5 / 29 / 2031^{+}$ & 0.66 & 0.05 & 10 & 2.29 & 0.54 & 0.05 & 10 & 1.13 & 0.67 & 0.06 & 2.92 & 1.14 & 0.54 & 0.07 & 10 & 1.24 \\
\hline (18) $6.5 \% 6 / 9 / 2022^{\dagger}$ & 0.33 & 0.05 & 10 & 2.20 & 0.21 & 0.04 & 10 & 1.04 & 0.34 & 0.06 & 9.99 & 1.26 & 0.21 & 0.06 & 9.96 & 1.33 \\
\hline (19) $7.75 \% \quad 11 / 13 / 2042^{\times}$ & 1.14 & 0.10 & 0.67 & 0.35 & 1.20 & 0.10 & 0.36 & 0.11 & 1.16 & 0.08 & 0.49 & 0.16 & 1.22 & 0.15 & 0.38 & 0.22 \\
\hline (20) $5 \% 6 / 15 / 2017^{*}$ & 0.50 & 0.09 & 1.99 & 1.32 & 0.40 & 0.06 & 0.80 & 0.15 & 0.34 & 0.08 & 10 & 1.25 & 0.39 & 0.09 & 0.75 & 0.27 \\
\hline (21) $4.75 \% 6 / 14 / 2018^{*}$ & 0.82 & 0.39 & 0.25 & 0.19 & 0.37 & 0.05 & 2.23 & 0.82 & 0.39 & 0.08 & 2.21 & 0.74 & 0.36 & 0.08 & 2.25 & 1.13 \\
\hline (22) $7.75 \% 11 / 23 / 2034^{+}$ & 0.80 & 0.05 & 10 & 2.54 & 0.73 & 0.05 & 1.27 & 0.59 & 0.81 & 0.05 & 1.28 & 0.74 & 0.73 & 0.08 & 1.31 & 0.86 \\
\hline (23) $5 \% 12 / 11 / 2019^{*}$ & 97.80 & 2.43 & 0.00 & 0.00 & 0.30 & 0.05 & 2.65 & 1.09 & 0.37 & 0.07 & 3.41 & 1.56 & 0.29 & 0.07 & 2.87 & 1.33 \\
\hline (24) $5.75 \% 3 / 5 / 2026^{\dagger}$ & 0.42 & 0.05 & 10 & 2.80 & 14.59 & 1.27 & 0.00 & 0.00 & 0.47 & 0.11 & 0.65 & 0.47 & 11.88 & 1.58 & 0.00 & 0.00 \\
\hline (25) $8 \% 11 / 7 / 2047^{\times}$ & 1.33 & 0.08 & 10 & 4.80 & 1.42 & 0.10 & 9.89 & 1.51 & 1.35 & 0.07 & 10 & 3.02 & 1.46 & 0.13 & 10 & 2.27 \\
\hline (26) $7.25 \% \quad 12 / 9 / 2021$ & 0.32 & 0.06 & 10 & 5.41 & 0.23 & 0.05 & 10 & 2.09 & 0.36 & 0.08 & 9.99 & 4.20 & 0.23 & 0.08 & 10 & 3.08 \\
\hline (27) $8 \% 9 / 5 / 2024^{*}$ & 6.21 & 5.74 & 0.02 & 0.02 & 0.27 & 0.12 & 1.30 & 1.84 & 0.39 & 0.07 & 3.25 & 3.93 & 0.26 & 0.15 & 1.48 & 2.18 \\
\hline (28) $6.75 \% 3 / 9 / 2023$ & 23.54 & 6.34 & 0.01 & 0.00 & 0.26 & 0.18 & 1.91 & 2.25 & 0.36 & 0.20 & 9.99 & 4.43 & 0.25 & 0.44 & 2.46 & 2.61 \\
\hline
\end{tabular}

\section{Table 4: Estimated Liquidity Risk Parameters of Bonos}

This table reports the estimated liquidity risk parameters and associated standard deviations for each bonos in the $G^{X^{N}}(3), G^{X^{N}}(4)$, and $G^{X^{N}}(6)$ models, each estimated with a diagonal specification of $K^{\mathbb{P}}$ and $\Sigma$ using monthly data. Also reported are the corresponding statistics from the $G^{X^{N}, X^{R}}(7)$ model estimated as described in the paper. 


\section{E.2 Udibonos Liquidity Premia}

In this section, we assess the robustness of our estimated udibonos liquidity premium series from our $G^{X^{N}, X^{R}}(7)$ model to the assumed structure of the real factors in the model.

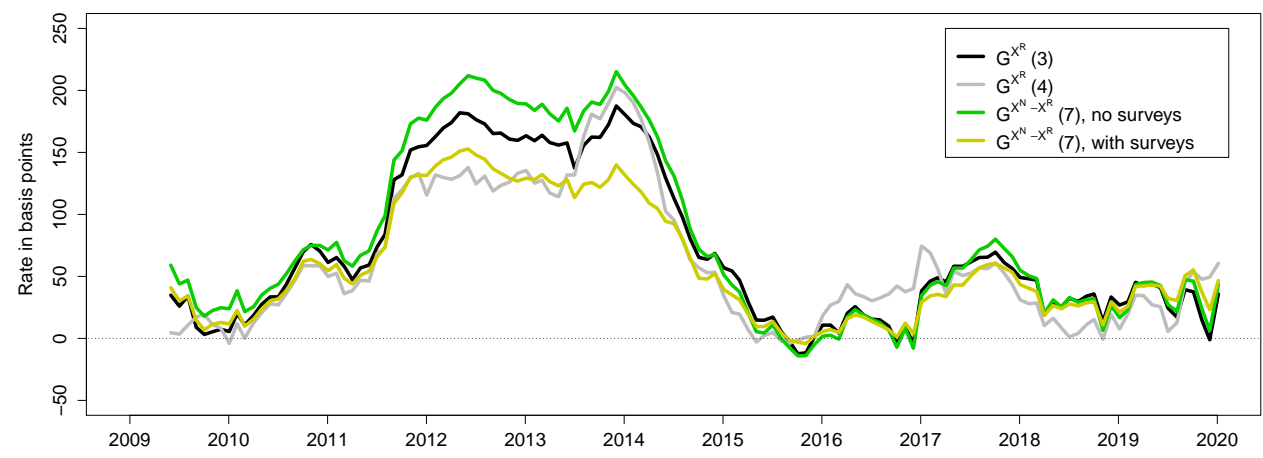

(a) Monthly

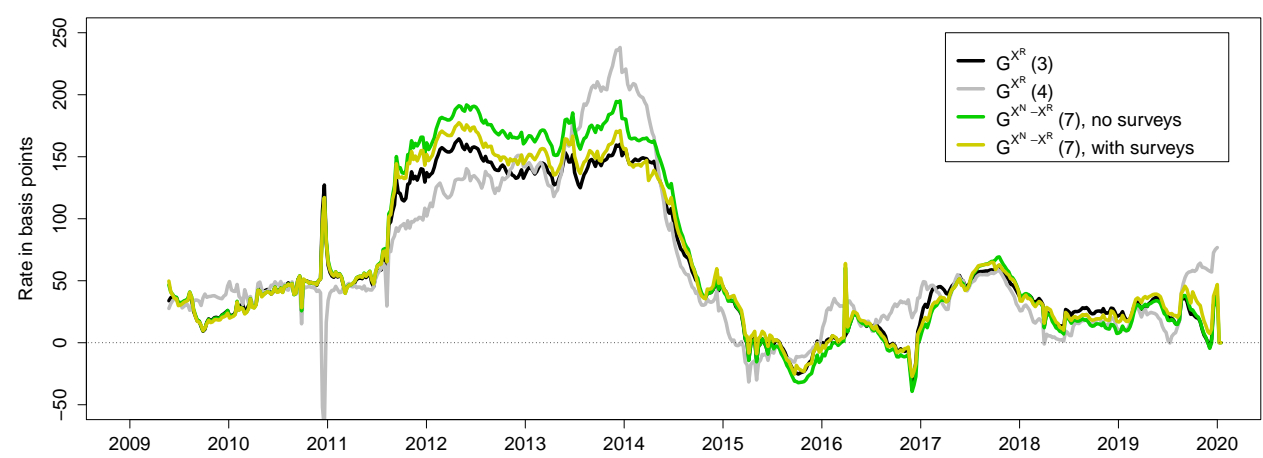

(b) Weekly

Figure 7: Factor Structure Sensitivity of Mexican Udibonos Liquidity Premia Illustration of the average estimated liquidity premium of Mexican udibonos for each observation date implied by the $G^{X^{R}}(3)$ and $G^{X^{R}}(4)$ models, each estimated with a diagonal specification of $K^{P}$ and $\Sigma$, as well as the $G^{X^{N}, X^{R}}(7)$ model without and with survey information. The Mexican udibonos liquidity premiums are measured as the estimated yield difference between the fitted yield to maturity of individual Mexican udibonos and the corresponding frictionless yield to maturity with the real liquidity risk factor $X_{t}^{R}$ turned off.

Thanks to the smaller number of available udibonos, we choose to use the $G^{X^{R}}(3)$ model as our benchmark for those bond prices. It has a level and slope factor structure for the frictionless real yields in addition to a liquidity risk factor to capture the bond-specific liquidity risk premiums embedded in the udibonos prices. Still, in this appendix, we explore the impact on our results from using the more flexible $G^{X^{R}}(4)$ model structure for the udibons prices similar to the one we use for the nominal bonos prices. As before, we compare the results to 


\begin{tabular}{l|cc|cc|cc}
\hline \hline \multirow{2}{*}{ Udibonos security } & \multicolumn{2}{|c|}{$G^{X^{R}}(3)$} & \multicolumn{2}{|c|}{$G^{X^{R}}(4)$} & \multicolumn{2}{c}{$G^{X^{N}, X^{R}}(7)$} \\
\cline { 2 - 7 } & Mean & RMSE & Mean & RMSE & Mean & RMSE \\
\hline (1) $5.5 \% 12 / 20 / 2012 \dagger$ & -6.56 & 12.12 & 0.99 & 4.86 & -4.21 & 10.14 \\
(2) $3.5 \% 12 / 19 / 2013 \dagger$ & -0.15 & 6.95 & 0.17 & 4.43 & 0.70 & 7.07 \\
(3) $4.5 \% 12 / 18 / 2014 \dagger$ & 0.16 & 7.99 & 0.23 & 4.90 & 2.02 & 8.55 \\
(4) $4.5 \% 12 / 4 / 2025^{+}$ & 0.09 & 8.56 & 0.08 & 6.26 & -0.26 & 8.85 \\
(5) $4.5 \% 11 / 22 / 2035^{\times}$ & 0.01 & 4.50 & 0.33 & 3.62 & -0.60 & 4.95 \\
(6) $5 \% 6 / 16 / 2016 \dagger$ & -1.77 & 8.72 & 0.61 & 5.35 & 2.73 & 8.89 \\
(7) $3.25 \% 12 / 23 / 2010$ & 6.74 & 14.69 & -0.99 & 3.39 & 4.44 & 9.79 \\
(8) $3.5 \% 12 / 14 / 2017 \dagger$ & -10.85 & 13.16 & -2.45 & 5.64 & -5.16 & 9.80 \\
(9) $3.25 \% 6 / 21 / 2012$ & -3.40 & 8.92 & 0.16 & 5.34 & 0.31 & 7.50 \\
(10) $4 \% 6 / 13 / 2019 \dagger$ & 1.43 & 7.60 & 2.41 & 6.27 & 3.07 & 7.78 \\
(11) $4 \% 11 / 15 / 2040^{\times}$ & 0.51 & 4.66 & 1.01 & 3.85 & 1.11 & 4.36 \\
(12) $2.5 \% 12 / 10 / 2020 \dagger$ & -0.04 & 7.78 & -0.68 & 6.57 & 1.41 & 8.98 \\
(13) $2 \% 6 / 9 / 2022 \dagger$ & 1.04 & 7.14 & 0.74 & 5.51 & 0.96 & 7.22 \\
(14) $4 \% 11 / 8 / 2046^{\times}$ & -0.06 & 3.53 & 0.13 & 2.39 & 0.14 & 3.51 \\
(15) $4 \% 11 / 30 / 2028 \dagger$ & 1.81 & 4.33 & 0.22 & 2.72 & 0.85 & 4.20 \\
(16) $4 \% 11 / 3 / 2050^{\times}$ & 0.41 & 1.85 & -0.20 & 0.76 & -0.12 & 1.50 \\
\hline All udibonos yields & -0.89 & 7.85 & 0.28 & 5.14 & 0.36 & 7.51 \\
Max $\mathcal{L}^{E K F}$ & $5,550.62$ & $5,680.91$ & $19,749.05$ \\
\hline \hline
\end{tabular}

Table 5: Pricing Errors of Udibonos

This table reports the mean pricing errors (Mean) and the root mean-squared pricing errors (RMSE) of udibonos in the $G^{X^{R}}(3)$ and $G^{X^{R}}(4)$ models, each estimated with a diagonal specification of $K^{\mathbb{P}}$ and $\Sigma$ using monthly data. Also reported are the corresponding statistics from the $G^{X^{N}, X^{R}}(7)$ model estimated as described in the paper. The errors are computed as the difference between the udibonos market price expressed as yield to maturity and the corresponding model-implied yield. All errors are reported in basis points.

those obtained from the $G^{X^{N}, X^{R}}(7)$ model estimated without and with survey information, and we again consider both monthly data as in the paper and higher frequency weekly data.

The average estimated udibonos liquidity premiums from these model estimations are shown in Figure 7, where we note a very high positive correlation between all the series. This conclusion is independent of the data frequency used. This suggests that our results would change little by adding more frictionless factors. Therefore, to keep our model empirically tractable, we prefer the $G^{X^{R}}(3)$ model for the udibonos data.

As shown in Table 5, the $G^{X^{R}}(3)$ model produces a fit to the udibonos prices measured as yield-to-maturity differences of 7.85 basis points for all bonos combined, while the corresponding statistic for the $G^{X^{R}}(4)$ model is 5.14 basis points.

Table 6 reports the estimated liquidity risk parameters, $\left(\beta^{R, j}, \delta^{R, j}\right)$, for each udibonos in our sample. Given the similarity in the estimated average udibonos liquidity premium series it is not surprising that these parameters are fairly similar to each other for each udibonos 


\begin{tabular}{l|cc|cc||cc|cc||cc|cc}
\hline \hline \multirow{2}{*}{ Udibonos security } & \multicolumn{4}{|c||}{$G^{X^{R}}(3)$} & \multicolumn{4}{c||}{$G^{X^{R}}(4)$} & \multicolumn{3}{c||}{$G^{X^{N}, X^{R}}(7)$} \\
\cline { 2 - 10 } & $\beta^{R, 3}$ & $\mathrm{SE}$ & $\delta^{R, \jmath}$ & $\mathrm{SE}$ & $\beta^{R, \jmath}$ & $\mathrm{SE}$ & $\delta^{R, 3}$ & $\mathrm{SE}$ & $\beta^{R, \jmath}$ & $\mathrm{SE}$ & $\delta^{R, \jmath}$ & $\mathrm{SE}$ \\
\hline$(1) 5.5 \% 12 / 20 / 2012 \dagger$ & 2.00 & 0.36 & 0.04 & 0.02 & 0.91 & 0.30 & 9.25 & 8.71 & 1.51 & 1.23 & 0.04 & 0.05 \\
$(2) 3.5 \% 12 / 19 / 2013 \dagger$ & 0.56 & 0.16 & 1.18 & 6.26 & 9.48 & 6.05 & 0.01 & 0.01 & 0.45 & 0.13 & 2.19 & 1.14 \\
$(3) 4.5 \% 12 / 18 / 2014 \dagger$ & 0.49 & 0.13 & 8.97 & 8.71 & 1.73 & 4.29 & 0.05 & 0.17 & 0.40 & 0.11 & 9.95 & 7.50 \\
$(4) 4.5 \% 12 / 4 / 2025^{+}$ & 0.45 & 0.06 & 9.98 & 8.71 & 0.51 & 0.06 & 9.66 & 8.70 & 0.40 & 0.06 & 9.97 & 7.49 \\
$(5) 4.5 \% 11 / 22 / 2035^{\times}$ & 1 & n.a. & 10.00 & 8.70 & 1 & n.a. & 9.77 & 8.69 & 1 & n.a. & 10 & 7.49 \\
$(6) 5 \% 6 / 16 / 2016 \dagger$ & 0.71 & 0.26 & 0.12 & 0.05 & 0.46 & 0.13 & 9.99 & 8.69 & 0.51 & 0.49 & 0.14 & 0.26 \\
$(7) 3.25 \% 12 / 23 / 2010$ & 1.19 & 3.48 & 0.44 & 2.35 & 0.00 & 0.49 & 10.00 & 8.68 & 3.24 & 1.28 & 0.11 & 0.07 \\
$(8) 3.5 \% 12 / 14 / 2017 \dagger$ & 1.25 & 0.18 & 0.06 & 0.02 & 31.64 & 7.90 & 0.00 & 0.00 & 2.11 & 1.14 & 0.02 & 0.02 \\
$(9) 3.25 \% 6 / 21 / 2012$ & 0.44 & 0.17 & 10.00 & 4.83 & 0.43 & 0.24 & 10.00 & 8.67 & 0.26 & 0.17 & 9.80 & 1.15 \\
$(10) 4 \% 6 / 13 / 2019 \dagger$ & 0.41 & 0.09 & 0.60 & 0.19 & 0.44 & 0.10 & 0.69 & 0.47 & 0.33 & 0.08 & 0.90 & 0.99 \\
$(11) 4 \% 11 / 15 / 2040^{\times}$ & 1.20 & 0.08 & 0.68 & 0.60 & 1.11 & 0.05 & 3.92 & 8.51 & 1.19 & 0.06 & 5.50 & 1.16 \\
$(12) 2.5 \% 12 / 10 / 2020 \dagger$ & 0.62 & 0.11 & 0.27 & 0.09 & 0.52 & 0.11 & 0.67 & 0.38 & 0.71 & 0.41 & 0.16 & 0.15 \\
$(13) 2 \% 6 / 9 / 2022 \dagger$ & 0.48 & 0.07 & 1.67 & 1.47 & 0.55 & 0.11 & 1.12 & 1.09 & 0.42 & 0.07 & 1.59 & 1.30 \\
$(14) 4 \% 11 / 8 / 2046^{\times}$ & 1.43 & 0.10 & 9.28 & 7.43 & 1.23 & 0.12 & 6.66 & 8.63 & 1.43 & 0.13 & 8.99 & 1.55 \\
$(15) 4 \% 11 / 30 / 2028 \dagger$ & 0.67 & 0.08 & 10.00 & 8.44 & 0.75 & 0.14 & 0.40 & 0.48 & 0.65 & 0.14 & 10.00 & 3.29 \\
$(16) 4 \% 11 / 3 / 2050^{\times}$ & 1.49 & 0.24 & 3.69 & 7.85 & 1.32 & 0.43 & 10.00 & 8.23 & 1.52 & 1.04 & 4.77 & 3.05 \\
\hline \hline
\end{tabular}

\section{Table 6: Estimated Liquidity Risk Parameters of Udibonos}

This table reports the estimated liquidity risk parameters and associated standard deviations for each udibonos in the $G^{X^{R}}(3)$ and $G^{X^{R}}(4)$ models, each estimated with a diagonal specification of $K^{\mathbb{P}}$ and $\Sigma$ using monthly data. Also reported are the corresponding results from the $G^{X^{N}, X^{R}}(7)$ model estimated as described in the paper.

across the different model estimations.

\section{F Udibonos Liquidity Premium Regressions}

Now, we repeat the regression exercise using the average estimated udibonos liquidity premium series as the dependent variable. Furthermore, a number of variables are replaced with the appropriate substitutes. The foreign share is now the foreign-held share of the udibonos market. The bid-ask is the average bid-ask spread of the udibonos in our sample, while the average age is the average age of the udibonos in the sample. Also, the one-month yield volatility is the one-month realized volatility of daily changes in the fitted ten-year udibonos yield. Finally, the noise measure is constructed from the fitted error of a standard AFNS model of our sample of daily udibonos prices.

Based on the regression results reported in Table 7, we make the following observations. First, the foreign-held share is a significant determinant of the liquidity premia of udibonos in our preferred regression (1), similar to what we find for bonos. However, now the effect is two to three times larger so that, for each percentage point increase in the foreign share, the udibonos liquidity premia increase between 2 and 3 basis points. Second, increases in both 


\begin{tabular}{|c|c|c|c|c|c|c|}
\hline \multirow{2}{*}{ Explanatory variables } & \multirow{2}{*}{$(1)$} & \multirow{2}{*}{$(2)$} & \multirow{2}{*}{$(3)$} & \multirow{2}{*}{ (4) } & \multicolumn{2}{|c|}{ "Individual regressions } \\
\hline & & & & & $\widehat{\beta}$ & adj. $R^{2}$ \\
\hline Foreign share of udibonos & $\begin{array}{l}2.41^{*} \\
(1.01)\end{array}$ & & $\begin{array}{c}1.49 \\
(1.11)\end{array}$ & & $\begin{array}{l}5.43^{* *} \\
(2.00)\end{array}$ & 0.16 \\
\hline Peso/USD exchange rate & $\begin{array}{c}0.11 \\
(3.14)\end{array}$ & $\begin{array}{l}-0.38 \\
(3.40)\end{array}$ & $\begin{array}{c}1.56 \\
(4.75)\end{array}$ & $\begin{array}{c}0.87 \\
(4.54)\end{array}$ & $\begin{array}{c}-8.43^{* *} \\
(1.89)\end{array}$ & 0.28 \\
\hline EMBI & $\begin{array}{l}0.13^{* *} \\
(0.04)\end{array}$ & $\begin{array}{l}0.14^{* *} \\
(0.04)\end{array}$ & $\begin{array}{c}0.17^{*} \\
(0.07)\end{array}$ & $\begin{array}{l}0.18^{*} \\
(0.07)\end{array}$ & $\begin{array}{c}-0.24^{*} \\
(0.12)\end{array}$ & 0.07 \\
\hline WTI & $\begin{array}{l}1.87^{* *} \\
(0.24)\end{array}$ & $\begin{array}{l}2.02^{* *} \\
(0.22)\end{array}$ & $\begin{array}{l}1.66^{* *} \\
(0.24)\end{array}$ & $\begin{array}{l}1.66^{* *} \\
(0.24)\end{array}$ & $\begin{array}{l}1.64^{* *} \\
(0.23)\end{array}$ & 0.56 \\
\hline CPI Inflation & $\begin{array}{c}10.59^{* *} \\
(2.61)\end{array}$ & $\begin{array}{c}12.25^{* *} \\
(2.20)\end{array}$ & $\begin{array}{c}12.72^{* *} \\
(2.72)\end{array}$ & $\begin{array}{c}13.72^{* *} \\
(2.55)\end{array}$ & $\begin{array}{l}2.95 \\
(5.53)\end{array}$ & -0.00 \\
\hline Debt-to-GDP ratio & $\begin{array}{l}-1.62 \\
(1.50)\end{array}$ & $\begin{array}{l}-0.77 \\
(1.47)\end{array}$ & $\begin{array}{l}-2.55 \\
(2.04)\end{array}$ & $\begin{array}{l}-2.48 \\
(1.98)\end{array}$ & $\begin{array}{c}-4.14^{* *} \\
(1.18)\end{array}$ & 0.26 \\
\hline Udibonos bid-ask spread & $\begin{array}{c}0.47 \\
(0.54)\end{array}$ & $\begin{array}{c}0.22 \\
(0.52)\end{array}$ & $\begin{array}{c}0.33 \\
(0.55)\end{array}$ & $\begin{array}{c}0.13 \\
(0.54)\end{array}$ & $\begin{array}{l}-1.15 \\
(2.62)\end{array}$ & -0.01 \\
\hline One-month cetes rate & $\begin{array}{c}5.82 \\
(3.14)\end{array}$ & $\begin{array}{l}2.11 \\
(2.84)\end{array}$ & $\begin{array}{c}3.85 \\
(4.09)\end{array}$ & $\begin{array}{l}1.73 \\
(3.99)\end{array}$ & $\begin{array}{l}-6.62^{*} \\
(3.26)\end{array}$ & 0.05 \\
\hline Ten-year US Treasury yield & $\begin{array}{c}-41.33^{* *} \\
(4.86)\end{array}$ & $\begin{array}{c}-47.99^{* *} \\
(3.67)\end{array}$ & $\begin{array}{c}-37.88^{* *} \\
(5.62)\end{array}$ & $\begin{array}{c}-40.28^{* *} \\
(5.25)\end{array}$ & $\begin{array}{l}-20.40 \\
(11.80)\end{array}$ & 0.06 \\
\hline Avg. udibonos age & & & $\begin{array}{l}-1.08 \\
(5.15)\end{array}$ & $\begin{array}{l}-0.51 \\
(5.13)\end{array}$ & $\begin{array}{c}-9.93^{*} \\
(4.79)\end{array}$ & 0.09 \\
\hline One-month udibonos yield vol. & & & $\begin{array}{l}-0.37 \\
(0.21)\end{array}$ & $\begin{array}{l}-0.35 \\
(0.20)\end{array}$ & $\begin{array}{c}0.51 \\
(0.55)\end{array}$ & 0.00 \\
\hline Udibonos noise measure & & & $\begin{array}{c}1.37 \\
(0.77)\end{array}$ & $\begin{array}{l}1.41 \\
(0.77)\end{array}$ & $\begin{array}{l}2.53^{*} \\
(1.24)\end{array}$ & 0.06 \\
\hline CDS rate & & & $\begin{array}{l}-0.01 \\
(0.14)\end{array}$ & $\begin{array}{l}0.01 \\
(0.14)\end{array}$ & $\begin{array}{c}-0.56^{* *} \\
(0.19)\end{array}$ & 0.12 \\
\hline MSCI one-month return & & & $\begin{array}{c}0.26 \\
(0.29)\end{array}$ & $\begin{array}{c}0.18 \\
(0.27)\end{array}$ & $\begin{array}{c}0.39 \\
(0.60)\end{array}$ & -0.01 \\
\hline VIX & & & $\begin{array}{l}-0.03 \\
(0.65)\end{array}$ & $\begin{array}{l}-0.29 \\
(0.58)\end{array}$ & $\begin{array}{c}0.02 \\
(1.12)\end{array}$ & -0.01 \\
\hline OTR premium & & & $\begin{array}{l}-1.25^{*} \\
(0.50)\end{array}$ & $\begin{array}{c}-1.48^{* *} \\
(0.48)\end{array}$ & $\begin{array}{c}-2.15^{* *} \\
(0.77)\end{array}$ & 0.09 \\
\hline TED spread & & & $\begin{array}{l}-0.11 \\
(0.21)\end{array}$ & $\begin{array}{l}-0.10 \\
(0.21)\end{array}$ & $\begin{array}{l}-0.50 \\
(0.65)\end{array}$ & 0.01 \\
\hline Intercept & $\begin{array}{l}-45.32 \\
(60.31)\end{array}$ & $\begin{array}{l}-41.16 \\
(60.22)\end{array}$ & $\begin{array}{l}-15.51 \\
(67.79)\end{array}$ & $\begin{array}{c}11.04 \\
(65.05)\end{array}$ & & \\
\hline Adjusted $R^{2}$ & 0.87 & 0.86 & 0.88 & 0.88 & & \\
\hline
\end{tabular}

Table 7: Regression Results for the Average Udibonos Liquidity Premium

The table reports the results of regressions with the average estimated udibonos liquidity premium as the dependent variable and 17 explanatory variables. Standard errors computed by the Newey-West estimator (with three lags) are reported in parentheses. Asterisks $*$ and ${ }^{* *}$ indicate significance at the 5 percent and 1 percent levels, respectively. 
the WTI oil price and CPI inflation are associated with increases in the udibonos liquidity premia. These results are unusual as they suggest that udibonos become less desirable in more inflationary environments, which is when they are most valuable for investors as a hedge against inflation risk. Third, increases in the debt-to-GDP ratio tend to lower udibonos liquidity premia, although not significantly so. Provided the extra debt is mainly issued in the bonos market, which is a reasonable assumption given the small size of the udibonos market, this finding could reflect the resulting change in the relative desirability of udibonos vis-á-vis bonos. Finally, we note that the ten-year U.S. Treasury yield has a statistically significant negative coefficient in all these regressions. Thus, higher U.S. yields tend to lower the liquidity premia in the udibonos market. In addition, we note that we also get satisfactorily high $R^{2} \mathrm{~s}$ in these regressions, with 0.87 produced by our preferred benchmark regression (1).

\section{G On-The-Run Liquidity Premia in the Bonos Market}

In this appendix, as a final robustness check of our estimated liquidity premia of bonos, we first examine the estimates we obtain for the most recently issued bonos, commonly referred to as the on-the-run securities. ${ }^{4}$ This is followed by an analysis of the bid-ask spreads of on-the-run bonos.

The average bonos liquidity premium studied so far is computed from the outstanding bonos at each point in time, meaning that its maturity varies with the composition of securities in the market. Some of its variation therefore reflects the fact that old and somewhat illiquid bonds mature and are replaced by new and more liquid securities. Although the average bonos liquidity premium is of great interest on its own, it may also be useful to examine their liquidity premia at fixed maturities. This is done in Figure 8, where we report the liquidity premium for the most recently issued 5-, 10-, 20-, and 30-year bonos in addition to the average estimated bonos liquidity premium examined previously. We first note that, in general, the most recently issued 5- and 10-year bonos have lower estimated liquidity premia than the average bonos, while the estimated liquidity premia of the most recently issued 20-year bonos are slightly above average. In contrast, the estimated liquidity premia of on-the-run 30-year bonos are markedly higher than the average liquidity premium. This is consistent with our finding that issuance of 30-year bonos is not optimal for the Mexican government from a cost-benefit perspective. Finally, we stress that we see the same relative pattern in estimated

\footnotetext{
${ }^{4}$ We do not include an analysis of on-the-run liquidity premia in the udibonos market due to their infrequent issuance.
} 


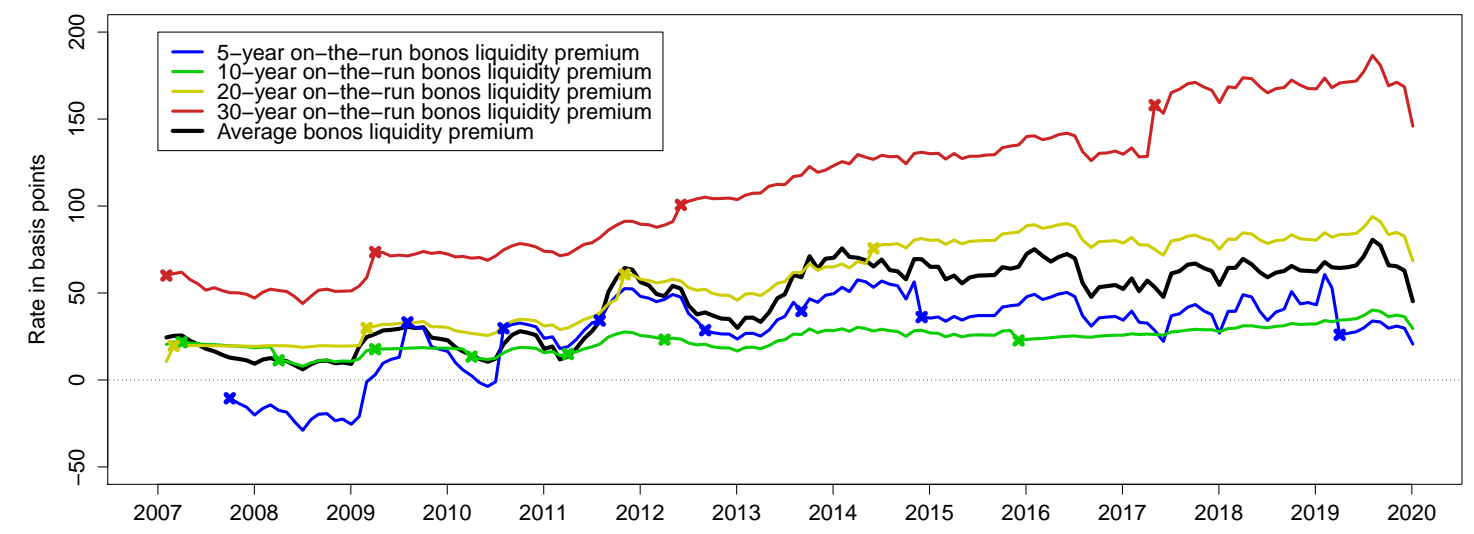

Figure 8: Estimated On-The-Run Liquidity Premia of Mexican Bonos

Illustration of the average estimated liquidity premium of Mexican bonos for each observation date implied by the $G^{X^{N}, X^{R}}(7)$ model implemented as described in the paper. The Mexican bonos liquidity premiums are measured as the estimated yield difference between the fitted yield to maturity of individual Mexican bonos and the corresponding frictionless yield to maturity with the nominal liquidity risk factor $X_{t}^{N}$ turned off. Cross $\times$ indicates the issuance of new bonos.

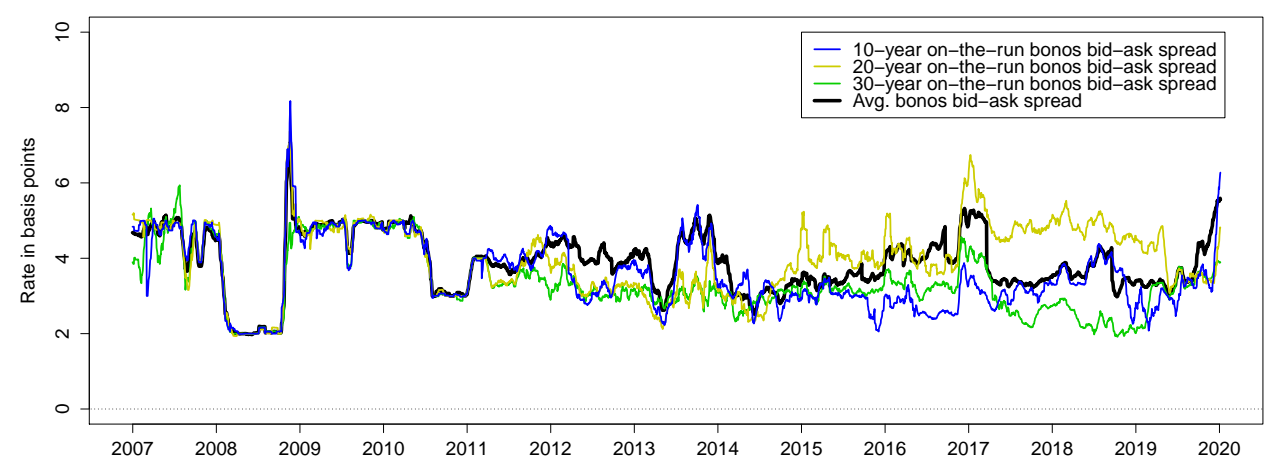

Figure 9: Bid-Ask Spreads of On-The-Run Mexican Bonos

on-the-run liquidity premia across the four types of bonos issued by the Mexican government as we do in our cost-benefit analysis in the paper, although, for consistency across bonos and udibonos in that exercise, we infer their liquidity premia using an alternative less direct approach than the one described here. 


\section{G.1 On-The-Run Bid-Ask Spreads in the Bonos Market}

Figure 9 reports the bid-ask spreads of the most recently issued (on-the-run) 10-, 20-, and 30-year Mexican bonos. The figure also shows the average bid-ask spread of the bonos in our sample at each point in time. The key point to take away is that the bid-ask spreads of the 10- and 30-year on-the-run bonos are very close to each other most of the time. Thus, the differences in their estimated liquidity premia documented in Figure 8 do not reflect their current trading conditions, but rather fears about future market conditions in states of the world where bonos investors might be forced to liquidate their positions prematurely during times of financial market stress. Under such circumstances investors in this market do not appear to be overly worried about their ability to trade 10-year bonos without depressing market prices. Clearly, they do not have the same confidence about 30-year bonos. As a consequence, to assume the perceived liquidity risk of these securities, investors demand quite sizable liquidity premia, which have trended higher during our sample period. CFS show that this upward trend is likely caused by the significant increase in foreign participation in the bonos market during this period.

\section{H Comparison of Bonos Term Premia}

In this appendix, as a final model validation, we examine the properties of the estimated nominal bonos term premia implied by our $G^{X^{N}, X^{R}}(7)$ model implemented as described in the paper.

We define the nominal term premia in the standard way as

$$
T P_{t}^{N}(\tau)=y_{t}^{N}(\tau)-\frac{1}{\tau} \int_{t}^{t+\tau} E_{t}^{\mathbb{P}}\left[r_{s}^{N}\right] d s
$$

where $y_{t}^{N}(\tau)$ refers to the liquidity-adjusted frictionless nominal zero-coupon yields, while $E_{t}^{\mathbb{P}}\left[r_{s}^{N}\right]$ represents the corresponding expected future nominal short rate, which is determined by the estimated model dynamics.

To validate the estimated bonos term premia from the $G^{X^{N}, X^{R}}(7)$ model, we compare them to a composite of existing standard bonos term premium estimates analyzed by AguilarArgaez et al. (2020). ${ }^{5}$ Specifically, using synthetic bonos zero-coupon yields, they implement the model approaches of Kim and Wright (2005) and Adrian et al. (2013) in addition to a

\footnotetext{
${ }^{5}$ Blake et al. (2015) report ten-year bonos term premium estimates that are qualitatively similar, but for a shorter 2006-2014 period.
} 


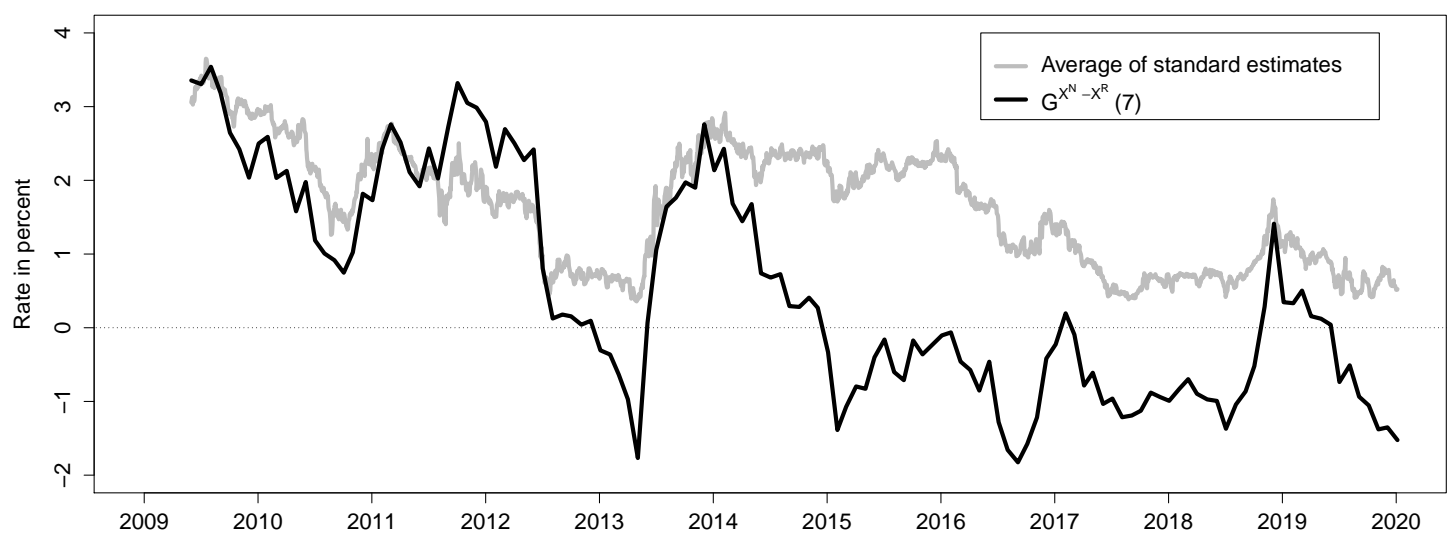

Figure 10: Comparison of Ten-Year Bonos Term Premia

Illustration of the ten-year bonos term premium implied by the $G^{X^{N}, X^{R}}(7)$ model. Also shown is the average of three standard estimates of the ten-year bonos term premium examined in Aguilar-Argaez et al. (2020).

third approach using interest rate swaps with floating payments tied to the 28-day TIIE rate. ${ }^{6}$ The average of the resulting three ten-year nominal bonos term premium estimates are shown with a solid grey line in Figure 10 and compared with the corresponding estimate from the $G^{X^{N}, X^{R}}(7)$ model shown with a solid black line.

This comparison makes clear that five pronounced events stand out in the data. First, Mexican term premia were at their sample highs in the spring of 2009 in the aftermath of the global financial crisis. Second, they trended lower during the 2009-2012 period in a persistent manner, likely as a consequence of U.S. unconventional monetary policies. Third, they spiked up sharply during the global taper tantrum in May 2013. Fourth, they spiked up temporarily around the 2016 U.S. presidential election. Finally, they rose sharply in the second half of 2018 as U.S.-Chinese trade disputes intensified. Overall, the term premium estimate from the $G^{X^{N}, X^{R}}(7)$ model appears to exhibit reasonable variation over time with sensible responses to well-known economic events the past decade.

\footnotetext{
${ }^{6}$ TIIE is short for tasa de interés interbancaria de equilibrio. These rates are calculated daily by the Bank of Mexico and represent the interest banks pay to borrow money in the Mexican interbank market at horizons of 28,91 , and 182 days.
} 


\section{Determinants of Term Risk Premia}

In this appendix, we proceed to perform a set of regression exercises using the $G^{X^{N}, X^{R}}(7)$ model-implied term premia as dependent variables with the goal of better understanding their determinants. Specifically, we perform one set of regressions using the 5yr5yr bonos term premium as the dependent variable and another set of regressions using the 5yr5yr udibonos term premium as the dependent variable. Furthermore, in the bonos term premium regressions, we use the same set of explanatory variables as in the bonos liquidity premium regressions reported in Table 2 in Appendix D.1, while in the udibonos term premium regressions we use the same set of explanatory variables as those used in the udibonos liquidity premium regressions in Table 7 in Appendix F.

The results from the 5yr5yr bonos term premium regressions are reported in Table 8. First, the foreign share is a very important determinant of the term premia of Mexican bonos yields, but now with a negative sign. This means that foreign bond fund outflows are associated with spikes in Mexican term premia. Second, both the peso-U.S. dollar exchange rate and the EMBI are positively correlated with the bonos term premia. Thus, a depreciation of the peso against the U.S. dollar tends to coincide with upticks in Mexican term premia. Upticks in the EMBI have similar effects. Third, increases in oil prices or Mexican CPI inflation also tend to push up Mexican bonos term premia. Fourth and unexpectedly, an increase in the Mexican debt-to-GDP ratio is associated with declines in the Mexican bonos term premium. Fifth, increases in bonos market frictions as captured by bonos bid-ask spreads tend to push up bonos term premia, while the one-month cetes rate has a negative coefficient. Hence, a tightening of monetary policy as reflected in higher cetes rates tends to flatten the bonos yield curve through a reduction of the bonos term premia. Lastly, U.S. Treasury securities represent an important substitute to Mexican bonos for foreign investors in this market. Therefore, it is not surprising that increases in U.S. Treasury yields tend to push up Mexican bonos term premia essentially one-for-one. ${ }^{7}$ In addition, we note that the expanded set of explanatory variables in regression (3) hardly affect the explanatory power as measured by the adjusted $R^{2}$. This provides further support for our choice of preferred benchmark variables included in regression (1) in the table.

The results for the regressions using the 5yr5yr udibonos term premium as the dependent variable are reported in Table 9 . We note that the results are qualitatively very similar to

\footnotetext{
${ }^{7}$ In the regressions, the bonos term premium is measured in basis points, while the ten-year U.S. Treasury yield is measured in percent. Thus, a coefficient of 100 on the U.S. Treasury yield implies a one-for-one relationship.
} 


\begin{tabular}{|c|c|c|c|c|c|c|}
\hline \multirow{2}{*}{ Explanatory variables } & \multirow{2}{*}{$(1)$} & \multirow{2}{*}{$(2)$} & \multirow[b]{2}{*}{$(3)$} & \multirow{2}{*}{$(4)$} & \multicolumn{2}{|c|}{ "Individual regressions } \\
\hline & & & & & $\widehat{\beta}$ & adj. $R^{2}$ \\
\hline Foreign Share of Bonos & $\begin{array}{l}-4.11^{*} \\
(1.65)\end{array}$ & & $\begin{array}{l}-4.49 \\
(2.39)\end{array}$ & & $\begin{array}{c}-8.83^{* *} \\
(0.94)\end{array}$ & 0.61 \\
\hline Peso/USD exchange rate & $\begin{array}{c}8.51 \\
(11.54)\end{array}$ & $\begin{array}{c}13.21 \\
(10.34)\end{array}$ & $\begin{array}{c}4.09 \\
(15.43)\end{array}$ & $\begin{array}{c}9.42 \\
(15.30)\end{array}$ & $\begin{array}{c}-34.39^{* *} \\
(5.88)\end{array}$ & 0.44 \\
\hline EMBI & $\begin{array}{l}1.17^{* *} \\
(0.22)\end{array}$ & $\begin{array}{l}1.11^{* *} \\
(0.23)\end{array}$ & $\begin{array}{c}0.83^{*} \\
(0.40)\end{array}$ & $\begin{array}{c}0.74 \\
(0.39)\end{array}$ & $\begin{array}{c}0.12 \\
(0.45)\end{array}$ & -0.01 \\
\hline WTI & $\begin{array}{l}3.23^{* *} \\
(0.86)\end{array}$ & $\begin{array}{l}1.95^{*} \\
(0.97)\end{array}$ & $\begin{array}{l}3.51^{* *} \\
(1.03)\end{array}$ & $\begin{array}{l}3.03^{* *} \\
(0.99)\end{array}$ & $\begin{array}{l}4.04^{* *} \\
(0.73)\end{array}$ & 0.31 \\
\hline CPI Inflation & $\begin{array}{c}6.83 \\
(7.85)\end{array}$ & $\begin{array}{l}-2.26 \\
(7.46)\end{array}$ & $\begin{array}{l}16.58 \\
(9.85)\end{array}$ & $\begin{array}{c}2.04 \\
(8.03)\end{array}$ & $\begin{array}{c}-2.59 \\
(26.53)\end{array}$ & -0.01 \\
\hline Debt-to-GDP ratio & $\begin{array}{l}-4.26 \\
(6.55)\end{array}$ & $\begin{array}{c}-16.91^{* *} \\
(4.55)\end{array}$ & $\begin{array}{l}-9.87 \\
(9.41)\end{array}$ & $\begin{array}{l}-15.62 \\
(8.55)\end{array}$ & $\begin{array}{c}-19.77^{* *} \\
(2.73)\end{array}$ & 0.56 \\
\hline Bonos bid-ask spread & $\begin{array}{c}20.90^{*} \\
(10.24)\end{array}$ & $\begin{array}{c}24.65^{*} \\
(9.45)\end{array}$ & $\begin{array}{c}24.71 \\
(14.30)\end{array}$ & $\begin{array}{c}18.33 \\
(12.01)\end{array}$ & $\begin{array}{l}81.00^{*} \\
(35.54)\end{array}$ & 0.11 \\
\hline One-month cetes rate & $\begin{array}{l}-13.45 \\
(10.87)\end{array}$ & $\begin{array}{c}-10.82 \\
(9.89)\end{array}$ & $\begin{array}{l}-29.96 \\
(15.35)\end{array}$ & $\begin{array}{l}-17.19 \\
(14.84)\end{array}$ & $\begin{array}{c}-32.54^{* *} \\
(10.15)\end{array}$ & 0.12 \\
\hline Ten-year US Treasury yield & $\begin{array}{l}90.77^{* *} \\
(17.80)\end{array}$ & $\begin{array}{c}120.54^{* *} \\
(19.33)\end{array}$ & $\begin{array}{l}79.35^{* *} \\
(21.27)\end{array}$ & $\begin{array}{l}91.78^{* *} \\
(22.79)\end{array}$ & $\begin{array}{c}161.42^{* *} \\
(28.89)\end{array}$ & 0.39 \\
\hline Avg. bonos age & & & $\begin{array}{c}53.04 \\
(32.25)\end{array}$ & $\begin{array}{c}30.34 \\
(34.61)\end{array}$ & $\begin{array}{c}-70.85^{* *} \\
(10.21)\end{array}$ & 0.55 \\
\hline One-month bonos yield vol. & & & $\begin{array}{l}-0.03 \\
(0.66)\end{array}$ & $\begin{array}{l}-0.37 \\
(0.73)\end{array}$ & $\begin{array}{c}1.85 \\
(1.91)\end{array}$ & 0.00 \\
\hline Bonos noise measure & & & $\begin{array}{c}1.91 \\
(3.70)\end{array}$ & $\begin{array}{l}2.33 \\
(3.97)\end{array}$ & $\begin{array}{c}28.81^{* *} \\
(6.94)\end{array}$ & 0.16 \\
\hline CDS rate & & & $\begin{array}{c}0.89 \\
(0.66)\end{array}$ & $\begin{array}{c}0.70 \\
(0.75)\end{array}$ & $\begin{array}{c}1.38 \\
(0.84)\end{array}$ & 0.06 \\
\hline MSCI one-month return & & & $\begin{array}{c}0.43 \\
(1.19)\end{array}$ & $\begin{array}{c}0.32 \\
(1.19)\end{array}$ & $\begin{array}{c}1.94 \\
(2.50)\end{array}$ & -0.00 \\
\hline VIX & & & $\begin{array}{c}1.39 \\
(2.44)\end{array}$ & $\begin{array}{l}2.16 \\
(2.60)\end{array}$ & $\begin{array}{c}15.90^{* *} \\
(2.61)\end{array}$ & 0.35 \\
\hline OTR premium & & & $\begin{array}{c}0.64 \\
(2.30)\end{array}$ & $\begin{array}{l}3.76^{*} \\
(1.71)\end{array}$ & $\begin{array}{c}14.55^{* *} \\
(1.62)\end{array}$ & 0.42 \\
\hline TED spread & & & $\begin{array}{l}-0.68 \\
(0.81)\end{array}$ & $\begin{array}{l}-0.48 \\
(0.86)\end{array}$ & $\begin{array}{l}-2.88 \\
(2.03)\end{array}$ & 0.04 \\
\hline Intercept & $\begin{array}{l}-610.40 \\
(318.03)\end{array}$ & $\begin{array}{l}-295.37 \\
(286.57)\end{array}$ & $\begin{array}{c}-523.18 \\
(412.84)\end{array}$ & $\begin{array}{l}-422.30 \\
(405.36)\end{array}$ & & \\
\hline Adjusted $R^{2}$ & 0.85 & 0.84 & 0.85 & 0.85 & & \\
\hline
\end{tabular}

Table 8: Regression Results for the 5yr5yr Bonos Term Premium

The table reports the results of regressions with the average estimated bonos term premium as the dependent variable and 17 explanatory variables. Standard errors computed by the Newey-West estimator (with three lags) are reported in parentheses. Asterisks $*$ and ${ }^{* *}$ indicate significance at the 5 percent and 1 percent levels, respectively. 


\begin{tabular}{|c|c|c|c|c|c|c|}
\hline \multirow{2}{*}{ Explanatory variables } & \multirow{2}{*}{ (1) } & \multirow{2}{*}{$(2)$} & \multirow{2}{*}{ (3) } & \multirow{2}{*}{ (4) } & \multicolumn{2}{|c|}{ Individual regressions } \\
\hline & & & & & $\widehat{\beta}$ & $\operatorname{adj} . R^{2}$ \\
\hline$\overline{\text { Foreign Share of Udibonos }}$ & $\begin{array}{l}-9.80^{*} \\
(4.10)\end{array}$ & & $\begin{array}{l}-7.53 \\
(5.12)\end{array}$ & & $\begin{array}{l}-3.40 \\
(5.65)\end{array}$ & 0.00 \\
\hline Peso/USD exchange rate & $\begin{array}{c}28.03^{* *} \\
(6.86)\end{array}$ & $\begin{array}{c}30.01^{* *} \\
(7.48)\end{array}$ & $\begin{array}{l}12.48 \\
(9.51)\end{array}$ & $\begin{array}{c}15.95 \\
(11.59)\end{array}$ & $\begin{array}{c}-19.35^{* *} \\
(4.61)\end{array}$ & 0.28 \\
\hline EMBI & $\begin{array}{l}0.91^{* *} \\
(0.15)\end{array}$ & $\begin{array}{l}0.88^{* *} \\
(0.16)\end{array}$ & $\begin{array}{l}0.65^{* *} \\
(0.24)\end{array}$ & $\begin{array}{l}0.59^{*} \\
(0.25)\end{array}$ & $\begin{array}{c}0.43 \\
(0.29)\end{array}$ & 0.03 \\
\hline WTI & $\begin{array}{l}2.36^{* *} \\
(0.57)\end{array}$ & $\begin{array}{l}1.77^{* *} \\
(0.64)\end{array}$ & $\begin{array}{l}2.74^{* *} \\
(0.63)\end{array}$ & $\begin{array}{l}2.75^{* *} \\
(0.64)\end{array}$ & $\begin{array}{l}1.91^{* *} \\
(0.57)\end{array}$ & 0.14 \\
\hline CPI Inflation & $\begin{array}{c}26.42^{* *} \\
(5.55)\end{array}$ & $\begin{array}{c}19.67^{* *} \\
(6.65)\end{array}$ & $\begin{array}{c}22.81^{* *} \\
(6.58)\end{array}$ & $\begin{array}{c}17.79^{* *} \\
(6.04)\end{array}$ & $\begin{array}{c}0.23 \\
(16.74)\end{array}$ & -0.01 \\
\hline Debt-to-GDP ratio & $\begin{array}{l}-7.92^{*} \\
(3.18)\end{array}$ & $\begin{array}{c}-11.40^{* *} \\
(3.37)\end{array}$ & $\begin{array}{l}-4.54 \\
(4.83)\end{array}$ & $\begin{array}{l}-4.92 \\
(4.81)\end{array}$ & $\begin{array}{c}-10.29^{* *} \\
(2.45)\end{array}$ & 0.31 \\
\hline Udibonos bid-ask spread & $\begin{array}{c}3.13 \\
(1.64)\end{array}$ & $\begin{array}{c}4.14 \\
(2.38)\end{array}$ & $\begin{array}{c}2.47 \\
(1.94)\end{array}$ & $\begin{array}{c}3.50 \\
(2.59)\end{array}$ & $\begin{array}{c}8.62 \\
(7.24)\end{array}$ & 0.01 \\
\hline One-month cetes rate & $\begin{array}{c}-59.30^{* *} \\
(9.40)\end{array}$ & $\begin{array}{c}-44.20^{* *} \\
(6.18)\end{array}$ & $\begin{array}{c}-48.80^{* *} \\
(15.39)\end{array}$ & $\begin{array}{c}-38.04^{* *} \\
(10.53)\end{array}$ & $\begin{array}{c}-28.51^{* *} \\
(6.27)\end{array}$ & 0.20 \\
\hline Ten-year US Treasury yield & $\begin{array}{l}79.40^{* *} \\
(14.17)\end{array}$ & $\begin{array}{c}106.47^{* *} \\
(15.36)\end{array}$ & $\begin{array}{c}62.17^{* *} \\
(12.94)\end{array}$ & $\begin{array}{l}74.34^{* *} \\
(15.56)\end{array}$ & $\begin{array}{c}106.87^{* *} \\
(23.34)\end{array}$ & 0.34 \\
\hline Avg. udibonos age & & & $\begin{array}{c}19.24 \\
(17.25)\end{array}$ & $\begin{array}{c}16.37 \\
(17.06)\end{array}$ & $\begin{array}{c}-48.45^{* *} \\
(9.05)\end{array}$ & 0.41 \\
\hline One-month udibonos yield vol. & & & $\begin{array}{l}-0.63 \\
(0.59)\end{array}$ & $\begin{array}{l}-0.73 \\
(0.65)\end{array}$ & $\begin{array}{c}1.76 \\
(0.92)\end{array}$ & 0.01 \\
\hline Udibonos noise measure & & & $\begin{array}{l}-0.08 \\
(2.28)\end{array}$ & $\begin{array}{l}-0.28 \\
(2.24)\end{array}$ & $\begin{array}{l}8.59^{* *} \\
(2.67)\end{array}$ & 0.14 \\
\hline CDS rate & & & $\begin{array}{c}0.71 \\
(0.37)\end{array}$ & $\begin{array}{c}0.61 \\
(0.44)\end{array}$ & $\begin{array}{l}1.35^{*} \\
(0.59)\end{array}$ & 0.13 \\
\hline MSCI one-month return & & & $\begin{array}{l}-0.34 \\
(0.72)\end{array}$ & $\begin{array}{c}0.08 \\
(0.85)\end{array}$ & $\begin{array}{c}0.83 \\
(1.80)\end{array}$ & -0.01 \\
\hline VIX & & & $\begin{array}{l}-1.87 \\
(1.22)\end{array}$ & $\begin{array}{l}-0.53 \\
(1.54)\end{array}$ & $\begin{array}{l}8.85^{* *} \\
(2.38)\end{array}$ & 0.22 \\
\hline OTR premium & & & $\begin{array}{l}4.24^{*} \\
(1.65)\end{array}$ & $\begin{array}{l}5.43^{* *} \\
(1.49)\end{array}$ & $\begin{array}{c}10.89^{* *} \\
(0.99)\end{array}$ & 0.48 \\
\hline TED spread & & & $\begin{array}{c}0.11 \\
(0.52)\end{array}$ & $\begin{array}{c}0.08 \\
(0.53)\end{array}$ & $\begin{array}{l}-1.16 \\
(1.27)\end{array}$ & 0.01 \\
\hline Intercept & $\begin{array}{c}-509.59^{*} \\
(204.58)\end{array}$ & $\begin{array}{l}-526.47^{*} \\
(206.73)\end{array}$ & $\begin{array}{l}-543.79^{*} \\
(222.73)\end{array}$ & $\begin{array}{c}-678.21^{* *} \\
(214.85)\end{array}$ & & \\
\hline Adjusted $R^{2}$ & 0.81 & 0.79 & 0.83 & 0.82 & & \\
\hline
\end{tabular}

Table 9: Regression Results for the 5yr5yr Udibonos Term Premium

The table reports the results of regressions with the average estimated udibonos term premium as the dependent variable and 17 explanatory variables. Standard errors computed by the Newey-West estimator (with three lags) are reported in parentheses. Asterisks * and ${ }^{* *}$ indicate significance at the 5 percent and 1 percent levels, respectively. 
those reported for the bonos term premium, which is reasonable in light of the high correlation of, and great similarity between, the two term premium series. In particular, it remains the case that a tightening of monetary policy as reflected in a higher one-month cetes rate flattens the udibonos real yield curve through a reduction in the real term premium. Furthermore, variation in U.S. Treasury yields affects both bonos and udibonos term premia essentially one-for-one. Finally, the foreign share also has a negative coefficient in these regressions. 


\section{References}

Adrian, Tobias, Richard K. Crump, and Emanuel Moench, 2013, "Pricing the Term Structure with Linear Regressions," Journal of Financial Economics, Vol. 110, 110-138.

Aguilar-Argaez, Ana, María Diego-Fernández, Rocío Elizondo, and Jessica Roldán-Peña, 2020, "Term Premium Dynamics and its Determinants: The Mexican Case," Bank of Mexico Working Papers No. 2020-18.

Blake, Andrew P, Garreth R. Rule, and Ole J. Rummel, 2015, "Inflation Targeting and Term Premia Estimates for Latin America," Latin American Economic Review, Vol. 24, No. $3,1-21$.

Christensen, Jens H. E., Francis X. Diebold, and Glenn D. Rudebusch, 2009, “An ArbitrageFree Generalized Nelson-Siegel Term Structure Model," Econometrics Journal, Vol. 12, No. 3, C33-C64.

Christensen, Jens H. E., Francis X. Diebold, and Glenn D. Rudebusch, 2011, "The Affine Arbitrage-Free Class of Nelson-Siegel Term Structure Models," Journal of Econometrics, Vol. 164, No. 1, 4-20.

Christensen, Jens H. E., Eric Fischer, and Patrick J. Shultz, 2021, "Bond Flows and Liquidity: Do Foreigners Matter?," Journal of International Money and Finance, Vol. 117-102397, 1-20.

Christensen, Jens H. E. and Glenn D. Rudebusch, 2019, “A New Normal for Interest Rates? Evidence from Inflation-Indexed Debt," forthcoming Review of Economics and Statistics.

D'Amico, Stefania, Don H. Kim, and Min Wei, 2018, "Tips from TIPS: The Informational Content of Treasury Inflation-Protected Security Prices," Journal of Financial and Quantitative Analysis, Vol. 53, No. 1, 243-268.

Hu, Grace Xing, Jun Pan, and Jiang Wang, 2013, "Noise as Information for Illiquidity," Journal of Finance, Vol. 68, No. 6, 2341-2382.

Kim, Don H. and Jonathan H. Wright, 2005, "An Arbitrage-Free Three-Factor Term Structure Model and the Recent Behavior of Long-Term Yields and Distant-Horizon Forward Rates," Working Paper Finance and Economics Discussion Series 2005-33, Board of Governors of the Federal Reserve System. 
Laubach, Thomas and John C. Williams, 2016, "Measuring the Natural Rate of Interest Redux," Business Economics, Vol. 51, No. 2, 57-67.

Nagel, Stefan, 2016, "The Liquidity Premium of Near-Money Assets," Quarterly Journal of Economics, Vol. 131, No. 4, 1927-1971.

Nelson, Charles R. and Andrew F. Siegel, 1987, "Parsimonious Modeling of Yield Curves," Journal of Business, Vol. 60, No. 4, 473-489. 